ISSN: 1688-9266
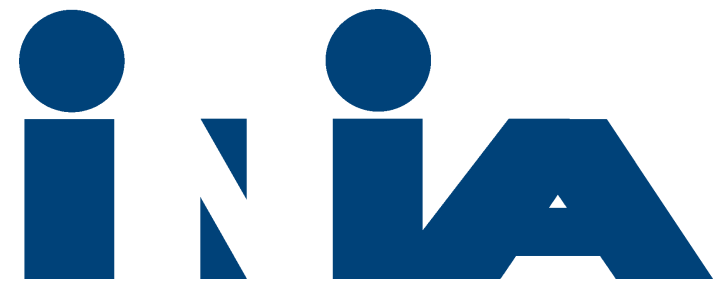

INSTITUTO NACIONAL DE INVESTIGACIÓN AGROPECUARIA

URUGUAY

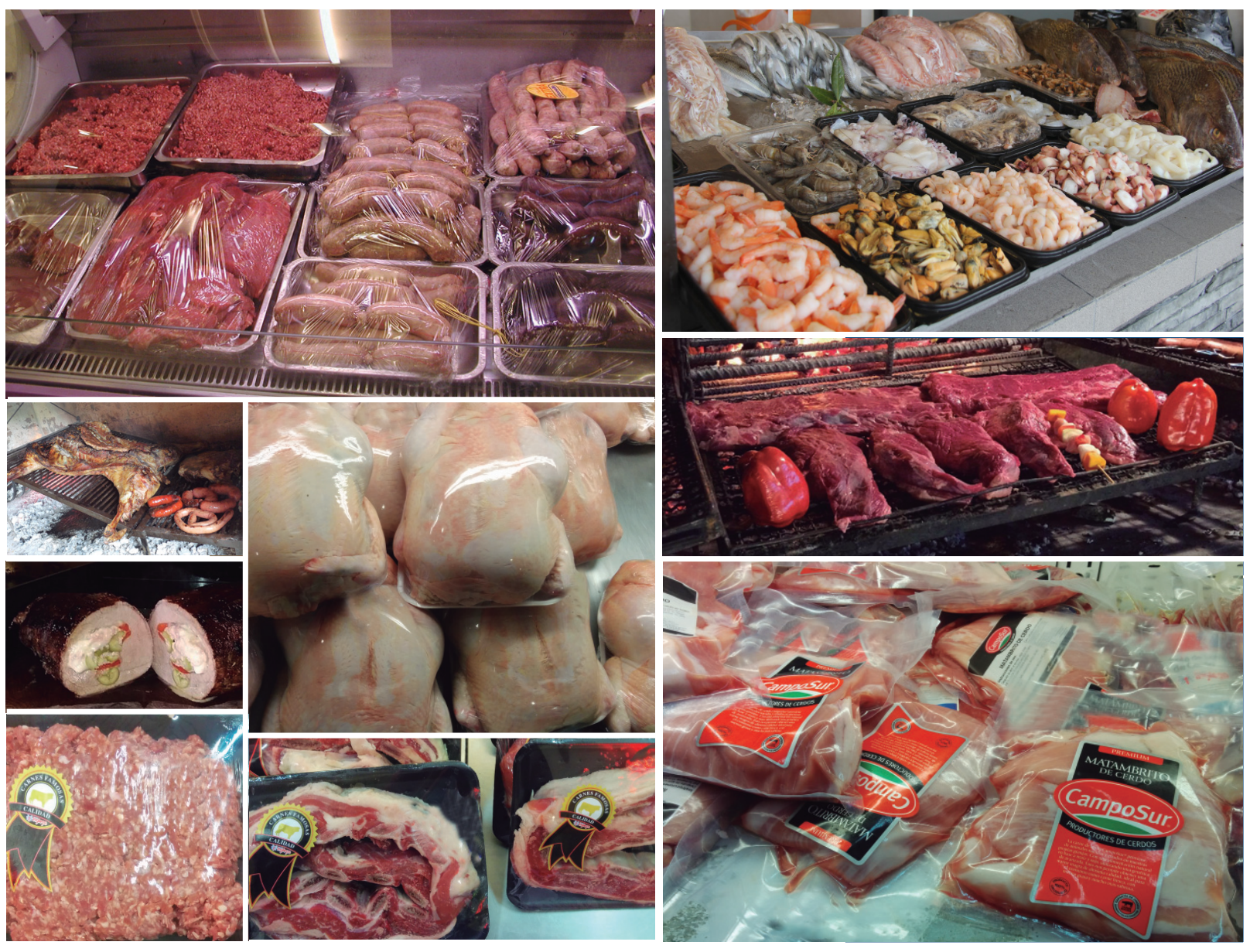

LOS CAMBIOS EN

LOS PATRONES DE

CONSUMO DE

CARNES EN EL

MERCADO INTERNO

Diciembre, 2014

SERIE TÉCNICA

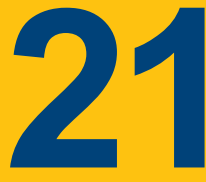

0 INIA 


\section{LOS CAMBIOS EN LOS PATRONES DE CONSUMO DE CARNES EN EL MERCADO INTERNO}

\section{Autores: Bruno Lanfranco Crespo ${ }^{1}$}

Catalina Rava Zefferino ${ }^{2}$ 
Título: LOS CAMBIOS EN LOS PATRONES DE CONSUMO DE CARNES EN EL MERCADO INTERNO

\section{Autores: Bruno Lanfranco Crespo \\ Catalina Rava Zefferino}

Serie Técnica $N^{\circ} 218$

(C) 2014, INIA

Los principales resultados de este trabajo fueron presentados en el Tercer Congreso Regional de Economía Agraria - XLII Reunión Anual de la Asociación Argentina de Economía Agraria - XVI Congreso de Economistas Agrarios de Chile. Asociación Argentina de Economía Agraria (AAEA)/ Sociedad Uruguaya de Economistas Agrícolas (SUEA)/Asociación Chilena de Economistas Agrarios. (AEA). 9 al 11 de noviembre de 2011. Hotel Dreams Valdivia. Valdivia, Chile. Parte de los mismos fueron también publicados en el Spanish Journal of Agricultural Research, Vol. 12(1), de diciembre de 2013.

Editado por la Unidad de Comunicación y Transferencia de Tecnología del INIA Andes 1365, Piso 12. Montevideo - Uruguay

http://www.inia.uy

Quedan reservados todos los derechos de la presente edición. Esta publicación no se podrá reproducir total o parcialmente sin expreso consentimiento del INIA. 


\section{I nstituto Nacional de I nvestigación Agropecuaria}

\section{Integración de la Junta Directiva}

Ing. Agr., MSc., PhD. Álvaro Roel - Presidente

D.M.T.V., PhD. J osé Luis Repetto - Vicepresidente

MINISTERIO DE GANADERÍA

AGRICULTURA Y PESCA

REPÚBLICA ORIENTAL DEL URUGUAY

D.M.V. Álvaro Bentancur

D.M.V., MSc. Pablo Zerbino
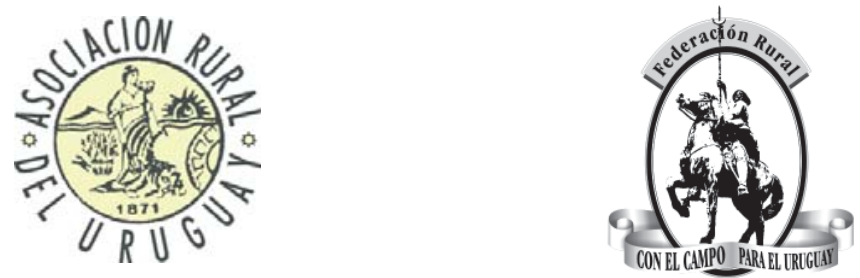

Ing. Agr. J oaquín Mangado

Ing. Agr. Pablo Gorriti
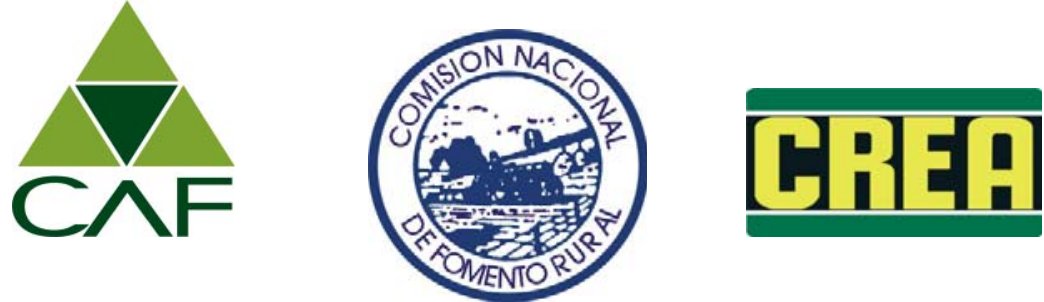



\section{CONTENIDO}

Página

1 ANTECEDENTES Y OBJETIVOS DEL ESTUDIO …......................................... 1

2 LA DEMANDA DE CARNES EN URUGUAY Y EN EL MUNDO …...........................

2.1 Los cambios en la producción y consumo mundial ........................................... 3

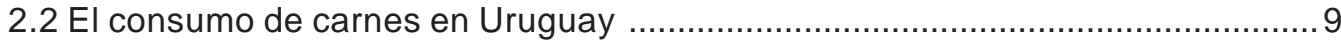

2.2.1 El consumo interno de carnes en la segunda mitad del siglo $X X$............. 9

2.2.2 Los cambios de las últimas dos décadas ......................................... 12

2.2.3 Consumo de pescado y frutos del mar .............................................. 17

2.3 Los factores determinantes del consumo ....................................................... 18

2.4 Análisis empírico de la demanda por carnes ................................................... 23

2.4.1 Estimaciones de demanda en la literatura internacional ......................... 23

2.4.2 Estimaciones de demanda en la literatura nacional ............................... 25

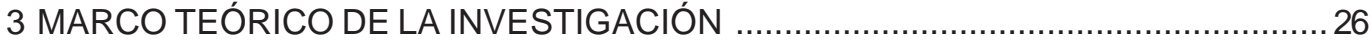

3.1 La demanda a nivel del consumidor: teoría vs. aplicación ................................ 26

3.1.1 Dificultades de la estimación empírica ................................................ 26

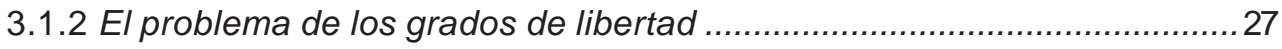

3.1.3 Formas funcionales en la estimación de demanda ................................ 29

3.2 Una posible respuesta: los sistemas incompletos de demanda ....................... 31

3.2.1 Propiedades de los sistemas incompletos de demanda ......................... 31

3.2.2 Integrabilidad en sistemas incompletos de demanda ............................. 31

3.2.3 Dualidad bajo la condición de cuasi integrabilidad................................ 32

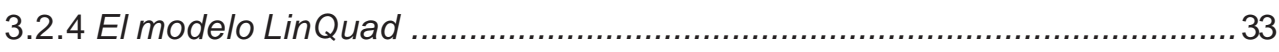

3.2.5 Sistemas de ecuaciones con variables dependientes limitadas ............... 35

3.2.6 Estimación en dos pasos de sistemas de ecuaciones censuradas ......... 37

3.2.7 Sistemas incompletos de demanda con datos censurados ..................... 39

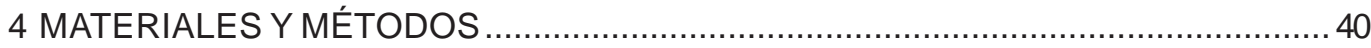

4.1 Construcción de la base de datos para el estudio ........................................... 40

4.1.1 Características de las encuestas de gastos e ingresos ......................... 40

4.1.2 Selección y descripción de las variables de interés................................ 42 
4.2 Métodos econométricos y técnicas de estimación .............................................4 47

4.2.1 Estimación de las ecuaciones de decisión ................................................ 47

4.2.2 Estimación del sistema de ecuaciones de regresión ..............................4 48

4.2.3 Cálculo de las elasticidades de demanda ............................................. 48

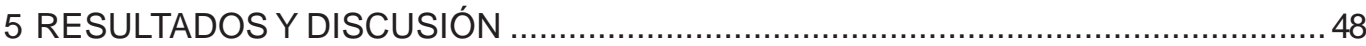

5.1 Características generales de los hogares .................................................. 48

5.2 Demanda de productos cárnicos: efectos sobre la decisión de consumo .........51

5.2.1 Frecuencia de consumo de productos cárnicos .................................... 51

5.2.2 Efectos sobre la probabilidad de consumo ............................................. 53

5.3 Demanda de Productos Cárnicos: Efectos sobre el Nivel de Consumo .............. 55

5.3.1 Efecto del ingreso del hogar sobre la demanda .....................................5 55

5.3.2 Efecto directo del precio sobre la demanda ........................................... 56

5.3.3 Efecto de los restantes precios sobre la demanda ................................5 57

5.3.4 Efecto de las características del hogar sobre la demanda .......................59

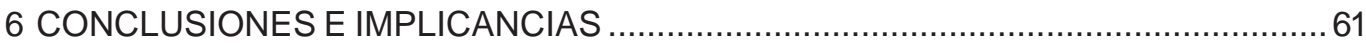

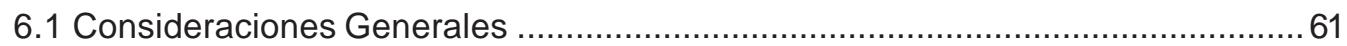

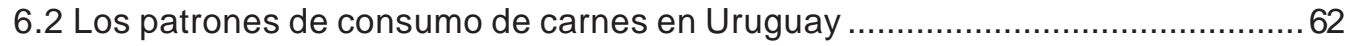

6.2.1 Los cambios de la demanda en el contexto nacional y global.................. 62

6.2.2 Principales conclusiones acerca de la demanda interna de carnes ......... 64

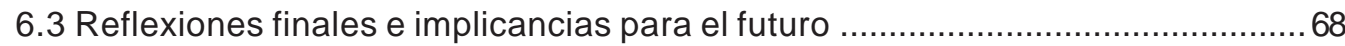

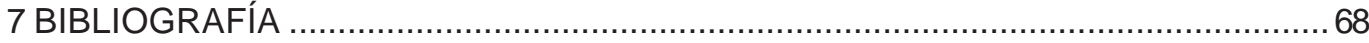




\section{ÍNDICE DE CUADROS}

Página

Cuadro 1. Indices de eficiencia de producción de carne referidos a animales individuales y población. 5

Cuadro 2. Contribución de los distintos tipos de carne en la producción mundial 1960-2010) 6

Cuadro 3. Producción mundial de carnes según región, años 1995 y 2007 ................... 8

Cuadro 4. Evolución del consumo per cápita de carnes en Uruguay, 2005-2011........ 15

Cuadro 5. Estimaciones de elasticidades de demanda de carnes

(trabajos internacionales seleccionados). 24

Cuadro 6. Elasticidades ingreso de productos cárnicos estimadas en base a cantidad y a gasto, 1994-95 26

Cuadro 7. Variables definidas para los productos de carne bovina. ...........................4 44

Cuadro 8. Variables definidas para los productos de otras carnes. ........................... 45

Cuadro 9. Variables definidas para fiambres, embutidos, chacinados y conservas. .. 46

Cuadro 10. Variable definida para comidas preparadas en base a carne.....................4 47

Cuadro 11. Distribución de hogares según nivel educativo del jefe de hogar (94-95 y 05-06).

Cuadro 12. Distribución de hogares según educación por sexo del jefe de hogar (94-95 y 05-06).

Cuadro 13. Tamaño promedio de hogar, total y según el sexo del jefe de hogar (94-95 y 05-06).

Cuadro 14. Hogares con menores de 18 y mayores de 64 según el sexo del jefe de hogar (94-95 y 05-06).

Cuadro 15. Hogares que consumieron alguna cantidad de los 13 productos cárnicos (94-95 y 05-06).

Cuadro 16. Cambio en la probabilidad de consumir 13 productos cárnicos según características socioeconómicas de los hogares (94-95 y 05-06)

Cuadro 17. Elasticidad ingreso de la demanda para 13 productos cárnicos (94-95 y 05-06).

Cuadro 18. Elasticidad precio directa de la demanda para 13 productos cárnicos (94-95 y 05-06).

Cuadro 19. Matriz de elasticidades, directas y cruzadas, de la demanda con respecto al precio, para 13 productos cárnicos (Período 1994-1995).

Cuadro 20. Matriz de elasticidades, directas y cruzadas, de la demanda con respecto al precio, para 13 productos cárnicos (Período 2005-2006).

Cuadro 21. Efecto de características del hogar en la demanda de productos cárnicos (94-95 y 05-06). 


\section{ÍNDICE DE FIGURAS}

Página

Figura 1. Producción mundial de carnes (1960-2010) y proyección para la década actual (2011-2020). 4

Figura 2. Evolución del consumo per cápita de carnes en Uruguay (1961-2010). 9

Figura 3. Evolución de los precios de distintas carnes en el mercado interno, (1997-2013). 13

Figura 4. Composición de la expedición de carne bovina en el mercado interno, (2007-2013). 16

Figura 5. Evolución del consumo interno de productos pesqueros en Montevideo, (1984-2007). 18

Figura 6. Precios mundiales para la carne bovina, porcina, ovina y aviar (1990-2013). ...... 21

Figura 7. Evolución del consumo per cápita de carnes en los Estados Unidos (1965-2013). 


\section{GLOSARIO DE SIGLAS Y ABREVIACIONES}

AIDS - Sistema Casi Ideal de Demanda (Almost Ideal Demand System).

ANC - Asociación Nacional de Carniceros.

CADA - Comisión de Administración del Abasto.

COMISEC - Comisión Sectorial para el MERCOSUR.

CIU - Cámara de Industrias del Uruguay.

EEB - Encefalopatía Espongiforme Bovina o «vaca loca».

EEUU - Estados Unidos de América.

EGIH95 - Encuesta de Gastos e Ingresos de los Hogares de 1994-1995.

ELES - Sistema Lineal de Costos Extendido (Extended Linear Expenditure System).

ENGIH05 - Encuesta Nacional de Gastos e Ingresos de los Hogares de 2005-2006.

FAO - Organización de las Naciones Unidas para la Agricultura y la Alimentación (Food and Agriculture Organization of the United Nations).

FFF - Formas Funcionales Flexibles (Flexible Functional Forms).

IFPRI - Instituto Internacional de Investigaciones sobre Políticas Alimentarias (International Food Policy Research Institute).

IICA - Instituto Interamericano de Cooperación para la Agricultura.

INAC - Instituto Nacional de Carnes.

INE - Instituto Nacional de Estadísticas.

INIA - Instituto Nacional de Investigación Agropecuaria.

IVA - Impuesto al Valor Agregado.

LAIAIDS - Aproximación Lineal al Sistema de Casi Ideal de Demanda (Linear Approximation to Almost Ideal Demand System).

LES - Sistema de Funciones Lineales de Costos (Linear Expenditure System).

LinQuad - Función de cuasi-gasto linear en ingreso y cuadrática en precios.

MERCOSUR - Mercado Común del Sur.

MGAP - Ministerio de Ganadería, Agricultura y Pesca.

MMV - Método de Máxima Verosimilitud (Maximum Likelihood).

NAFTA - Tratado de Libre Comercio de América del Norte (North America Free Trade Agreement) del que son signatarios Estados Unidos, México y Canadá.

PROCISUR - Programa Cooperativo para el Desarrollo Tecnológico del Cono Sur. 
OECD - Organización de Cooperación y Desarrollo Económico (Organization for Economic Cooperation and Development)

OPYPA - Oficina de Programación y Política Agropecuaria.

QES - Sistema de funciones cuadráticas de costos (Quadratic Expenditure Systems).

SUL - Secretariado Uruguayo de la Lana.

SUR - Regresiones al parecer no correlacionadas (Seemingly Unrelated Regressions)

UE - Unión Europea.

USDA - Departamento de Agricultura de los Estados Unidos (United States Department of Agriculture).

UTU - Universidad del Trabajo del Uruguay.

VAR - Vectores Auto Regresivos (autorregresivos). 


\section{AGRADECIMIENTOS}

Los autores desean expresar su agradecimiento a los diferentes revisores anónimos que participaron en las distintas instancias de evaluación del trabajo y sus resultados, tanto para el congreso regional de economía agrícola donde fueron presentados como de la revista científica donde fueron publicados. Gracias a las críticas y sugerencias recibidas en dichas instancias, la calidad del mismo pudo ser mejorada sustancialmente. Los errores $u$ omisiones que puedan subsistir en esta publicación son de entera responsabilidad de los autores. 



\section{LOS CAMBIOS EN LOS PATRONES DE CONSUMO DE CARNE EN EL MERCADO INTERNO}

\section{Resumen}

El objetivo fue estudiar el consumo de diferentes cortes y tipos de carnes por los hogares uruguayos en la última década del siglo XX y primera del siglo XXI. Se utilizaron las dos últimas encuestas de gastos e ingresos de hogares aplicando un procedimiento bietápico a un sistema incompleto de demanda con ecuaciones censuradas. El estudio involucró trece productos cárnicos: seis de carne bovina, uno de ovina, uno de porcina, uno de aviar, uno de pescados y mariscos y tres productos cárnicos genéricos. Se computaron elasticidades ingreso y precio con un intervalo de confianza $90 \%$. Los resultados verificaron una disminución en el consumo de todas las carnes, particularmente de la bovina, entre ambos períodos. No obstante, éstas continúan siendo un elemento preponderante en la dieta hogareña. La carne aviar mejoró sustancialmente su consumo relativo aunque los fiambres y embutidos consolidaron su preferencia. Entre las bovinas, se destacó la carne picada. El ingreso y tamaño de los hogares mostraron un efecto positivo sobre la probabilidad de consumo de casi todas las carnes, las que se comportaron siempre como bienes necesarios $(\eta<1)$ y normales $(\varepsilon<0)$. En general, todas se mostraron inelásticas frente al ingreso y reaccionaron en forma diferencial frente a cambios en su precio.

Palabras clave: demanda por carnes, probabilidad de consumo, elasticidad ingreso, elasticidad precio

\section{Summary}

The objective of this research was to study the consumption of different cuts and types of meat by Uruguayan households in the last decade of the XX century and the first decade of XXI century. It involved a two-step estimation of an incomplete system of censored demand equations using household data from the two last national household income and expenditure surveys. Thirteen meat products were included in the analysis: six beef products, four from other meats (sheep, pork, poultry, and fish), and three generic mixed-meat products. A complete set of shortterm income, own-price and cross-price elasticities were computed and reported with $90 \%$ confidence interval. The comparison between the two periods verified a decrease in the consumption of all meats, particularly beef. However, they continue being a dominant factor in household diets. Poultry meat substantially improved its relative consumption although cold cut meats and sausages consolidated as the most preferred among all meat products. The consumption of ground beef excelled among bovine cuts. Income level and household size showed a positive effect on the probability of spending on almost any meat. All meat items were necessary goods $(\eta<1)$ exhibiting income-inelastic responses. All of them behaved also as normal goods $(\varepsilon<0)$ although showing different responses to price changes.

Keywords: demand for meats, consumption probability, income elasticity, price elasticity

JEL: C31, C34, C51, D11, D12 



\section{LOS CAMBIOS EN LOS PATRONES DE DEMANDA DE CARNE EN EL MERCADO INTERNO}

\section{ANTECEDENTES Y OBJETIVOS DEL ESTUDIO}

En Uruguay existe una industria de procesamiento de carne especializada en la faena de bovinos y ovinos, siendo muy reducida en el caso de otras especies. Fabani (2011) resaltó este punto como un contraste con la conformación empresarial en otros países de la región donde se puede observar una plataforma más diversificada que incluye las aves, los cerdos y en ocasiones también proteína láctea.

Considerando las cuatro especies referidas, la faena de bovinos representa más del $80 \%$ del volumen total faenado en el país, cifra que Fabani (2011) señaló como relativamente estable en los últimos años. El crecimiento registrado en la producción de carne aviar y porcina es algo más reciente y se ha enfocado principalmente al mercado interno. Según apuntó Acosta (2011), esta especialización en rumiantes es muy poco común a nivel internacional, donde predomina la producción de carnes de monogástricos.

Por otro lado, en las últimas cuatro o cinco décadas se ha venido observando una fuerte reorientación de la industria frigorífica nacional hacia los mercados de exportación, particularmente en el caso de la carne bovina. La relación entre la exportación y el mercado interno, que en la década de los 60 se ubicaba en 70:30 a favor de la primera (Vázquez Platero y Picerno, 1994), se invirtió completamente en un proceso que alcanzó un mayor grado de profundización en los últimos veinte años.

De acuerdo a datos publicados por el Instituto Nacional de Carnes (INAC), Uruguay exporta alrededor de las dos terceras partes de una producción total anual de carne bovi- na que supera las 520 mil toneladas peso canal. No obstante dicha relación, el abasto interno ha sido el principal «mercado individual» durante los últimos años, solamente superado en algunos años por las exportaciones a los países del NAFTA ${ }^{1}$ considerados en su conjunto. El valor estratégico del mercado interno ha sido claramente apreciado por la industria frigorífica uruguaya. No en vano, los establecimientos habilitados a exportar atendieron el $82 \%$ del mercado interno en 2010 (Fabani, 2011).

En 2011, el consumo total de carnes en Uruguay promedió los 94,7 kg/hab. Casi las dos terceras partes de esa cifra correspondieron a carne bovina (64\%). El consumo per cápita de carne aviar superó el $20 \%$, en tanto que el de carne porcina llegó a $11 \%$ y el de ovina a un poco más de 4\% (INAC, 2012).

Los volúmenes de producción y exportación de carne ovina son sensiblemente inferiores a los de carne bovina, no obstante tienen una mayor orientación relativa hacia el mercado externo. Acosta (2011) ubicó el volumen de producción de esta carne en 21 mil toneladas en 2010 obtenidas a partir de un stock de 7,7 millones de cabezas. Un 95\% de este volumen fue destinado a la exportación y tan solo $5 \%$ al mercado interno.

Por otro lado, Uruguay produce anualmente alrededor de 20 mil toneladas peso canal de carne porcina, destinada en su totalidad al abastecimiento de alrededor del 50\% del mercado local (Errea, 2011a). Tras décadas de mantenerse en muy bajos niveles, el consumo interno de carne porcina ha mostrado algunos síntomas de crecimiento en el último quinquenio, abastecido por un aumento en la producción pero fundamentalmente por un aumento en las importaciones (Errea, 2012a). En ese sentido, Errea, Ruiz y Souto (2013) señalaron que la carne porcina tiene 
dos destinos posibles. La industria elaboradora de chacinados y otros productos manufacturados, históricamente demandante de más del $90 \%$ de la carne volcada al mercado interno y el consumo directo de carne (pulpas) responsable del restante $10 \%$.

La producción y consumo de carne aviar se han incrementado a nivel nacional, alcanzando casi 70 mil toneladas en 2010. El destino principal de la producción nacional es el consumo interno, el que acompaña el nivel de producción y que en el último quinquenio se ha ubicado en el entorno de 20 kg/hab/año (Errea, 2011b). En años recientes, las exportaciones han ido ganando lugar como destino de la producción. Históricamente, de proporción casi insignificante hasta la mitad de la década pasada han llegado a significar hasta un 15\% en 2012 (Errea, 2012b).

El complejo pesquero uruguayo comenzó y se consolidó en la década del setenta (Mazza, 1997). Si bien el consumo de pescado ha sido históricamente muy reducido entre los uruguayos, en la última década del siglo pasado se evidenció un aumento debido a factores tales como la crítica médica al consumo excesivo de carnes rojas y la aparición de las llamadas convenience foods a base de pescado (COMISEC, 1994b). Dicho aumento ha continuado en los años subsiguientes, estimándose que el consumo anual per cápita de pescado en la capital del país creció de 9,1 kg en 1997 a 12,6 kg en 2007 (López Ríos, 2007).

Vista la evolución y relevancia del consumo de carnes en el país, el objetivo de esta investigación fue evaluar los patrones de demanda de diferentes cortes y tipos de carnes por parte de los hogares uruguayos, durante la última década del siglo XX y la primera del siglo XXI. Para realizar este trabajo se utilizó la información proveniente de las dos últimas encuestas de gastos e ingresos de los hogares disponibles en el país. El análisis se llevó a cabo mediante un procedimiento bietápico aplicado a un sistema incompleto de demanda compuesto por ecuaciones censuradas.

El modelo bietápico aplicado interpreta la decisión de consumo en dos pasos o etapas. En el primer paso se procura identificar
Ios factores que determinan si un hogar consume o no un determinado alimento. En el segundo, se cuantifican los efectos sobre las cantidades demandadas, una vez tomada la decisión de consumo. Se asume que las variables que inciden sobre una y otra decisión no tienen por qué ser necesariamente las mismas.

El procedimiento utilizado permitió analizar el impacto que sobre la demanda de carnes tuvieron los precios pagados por los mismos, así como los efectos de diferentes características socioeconómicas de los hogares (localización, ingreso, tamaño y composición etaria) y de los jefes de hogar (edad, sexo y nivel educativo). Se consideraron trece productos cárnicos, seis de ellos de carne bovina, uno de carne ovina, uno de carne porcina, uno de carne aviar, uno de pescados y mariscos y tres de productos elaborados en base a distintas carnes (fiambres, chacinados y embutidos fríos y para cocinar y comidas prontas). En el caso particular de precios e ingresos, señalados por la teoría económica como los principales determinantes de la demanda a nivel de consumidores, se computó un juego completo de elasticidades.

Esta serie técnica consta de cinco capítulos, organizados de tal forma que no tienen por qué ser leídos en secuencia ni en su totalidad. El lector interesado simplemente en los resultados e implicancias prácticas del trabajo pero no en los aspectos metodológicos puede saltear parte o la totalidad del marco teórico y los métodos de análisis, para concentrarse en los capítulos correspondientes. Así, el presente capítulo incluye una breve introducción a la temática estudiada, resaltando las razones que impulsaron la realización del trabajo de investigación, a continuación del cual se exponen los objetivos planteados y se describe la organización de la publicación.

El segundo capítulo se pasa revista a los cambios más relevantes ocurridos en la producción y consumo de carnes a nivel mundial y en Uruguay a partir de la segunda mitad del siglo pasado. Se hace especial énfasis en los dos períodos de interés (última década del siglo XX y primera del siglo XXI), con el objetivo de facilitar la interpretación 
de los resultados encontrados en esta investigación. En la primera sección, se analizan las grandes tendencias que prevalecieron a nivel global en los patrones de consumo de carnes en el mundo, incluyendo los procesos de industrialización, distribución y marketing, la aparición de fenómenos como la seguridad alimentaria, la inocuidad y los cambios en las preferencias de los consumidores.

En la segunda sección, se discuten brevemente los factores principales que determinan el consumo. En la tercera sección del capítulo se repasa la información referente al abasto interno, poniendo énfasis en los dos períodos estudiados y en las perspectivas actuales de la demanda de carnes en el mercado local. En la última sección se presenta una breve revisión de los principales trabajos empíricos internacionales y locales que han estimado la demanda de carnes a través del cálculo de elasticidades precio e ingreso.

El capítulo 3 presenta el marco teórico propuesto para esta investigación. En la primera sección del capítulo se discuten los aspectos más relevantes de la teoría del consumidor. La atención principal está puesta en las condiciones y restricciones impuestas por la teoría a la construcción de modelos empíricos de demanda y las condiciones que estos deben cumplir para asegurar que los resultados obtenidos sean consistentes con los fundamentos de la teoría económica.

En la segunda sección, se presenta el enfoque metodológico utilizado en este trabajo. Para esto se discuten las propiedades de los sistemas incompletos de demanda (LaFrance y Haneman, 1989) que aseguran coherencia entre el campo de la teoría y el de la economía aplicada. Se analiza el comportamiento del consumidor bajo el concepto de la toma de decisión en dos etapas, es decir, primero se decide qué consumir y luego cuánto consumir. Se analizan las implicancias teóricas y prácticas del hecho de que no todos los consumidores consumen un determinado producto, para culminar con la discusión de los métodos de estimación que permiten resolver estos problemas (Shonkwiller y Yen, 1999).
El capítulo 4 refiere los materiales y métodos utilizados en el análisis. En la primera sección se presentan los principales aspectos de las dos últimas encuestas de ingresos y gastos de los hogares uruguayos. A partir de estas encuestas, que el Instituto Nacional de Estadísticas (INE) realiza a intervalos de 10 años, se colectaron los datos del estudio para los dos períodos considerados (1994-1995 y 2005-2006). En esta parte se detalla también el tratamiento de los datos y la construcción de las variables seleccionadas para el análisis. En la segunda sección de este capítulo, se describen los métodos econométricos y técnicas de estimación utilizadas en la investigación, las que toman como base con los fundamentos cuyos fundamentos teóricos fueron ampliamente discutidos en el capítulo anterior.

Los resultados empíricos de este trabajo se discuten en el capítulo 5. En la primera sección se presentan las estadísticas básicas que caracterizan a los hogares participantes del estudio. En la segunda sección se analizan los efectos sobre la decisión de consumo, en términos de la frecuencia y probabilidad de adquisición de los productos de interés. En la sección final se estudian los efectos sobre el nivel de consumo de dichos productos cárnicos. Se presentan las estimaciones de elasticidad ingreso y elasticidad precio, directa y cruzada. Finalmente se identifican los efectos que sobre la demanda mostraron las variables seleccionadas que caracterizaron a los hogares.

En el capítulo final de esta serie técnica se discuten las principales conclusiones e implicancias que surgen de la evidencia empírica obtenida. Se remarcan las fortalezas y debilidades del estudio y se hace una breve referencia de las necesidades de investigación para el futuro.

\section{LA DEMANDA DE CARNES EN URUGUAY Y EN EL MUNDO}

\subsection{Los cambios en la producción y consumo mundial}

Tal como indica el informe OECD-FAO (2012), la producción de carne se ha triplica- 
do a nivel mundial en el último medio siglo. Se prevé que continúe siendo uno de los productos con más rápido crecimiento, debido en gran medida a los mayores ingresos y la creciente «occidentalización» de la dieta de muchos países emergentes. El informe señala también que durante el mismo período, las existencias mundiales de bovinos, ovinos, porcinos y aves de corral han crecido en 57 $\%, 49 \%, 137 \%$ y 400\%, respectivamente.

En 1960, había 3 mil millones de habitantes en el planeta mientras que 50 años más tarde, hacia 2010, esa cifra alcanzaba los 7 mil millones ${ }^{2}$. De acuerdo a datos de $\mathrm{FAO}^{3}$, el consumo mundial por persona de todas las carnes (vacuna, ovina, aves y cerdo) se ubicaba en el entorno de $23 \mathrm{~kg}$ al año en 1960, en tanto que hacia 2010 se acercaba a los $42 \mathrm{~kg}$. Medido en moneda corriente, el ingreso per cápita en el mundo pasó de US\$ 460 por año en 1960 a poco más de US\$ 8.000 en 2005, último año con información disponible ${ }^{4}$. Teniendo en cuenta todo esto, no es de extrañar que el consumo mundial de carne pasara de algo más de 70 a casi 270 millones de toneladas (MT) en el mismo período.

La Figura 1 presenta la evolución de la producción y suministro ${ }^{5}$ mundial de carnes para el período 1960-2010, elaborada a partir de datos de la FAO y el USDA ${ }^{6}$, a la que se suman las proyecciones hasta el año 2020 de acuerdo al informe OECD-FAO (2012). Un importante aspecto a resaltar es que, más allá de su crecimiento, la producción de carnes ha venido experimentando cambios sustanciales durante esos mismos 50 años (1960-2010), si bien los mismos se profundizaron en los últimos 20 o 30. Dejando de lado el consumo de pescado ${ }^{7}$ que, como se

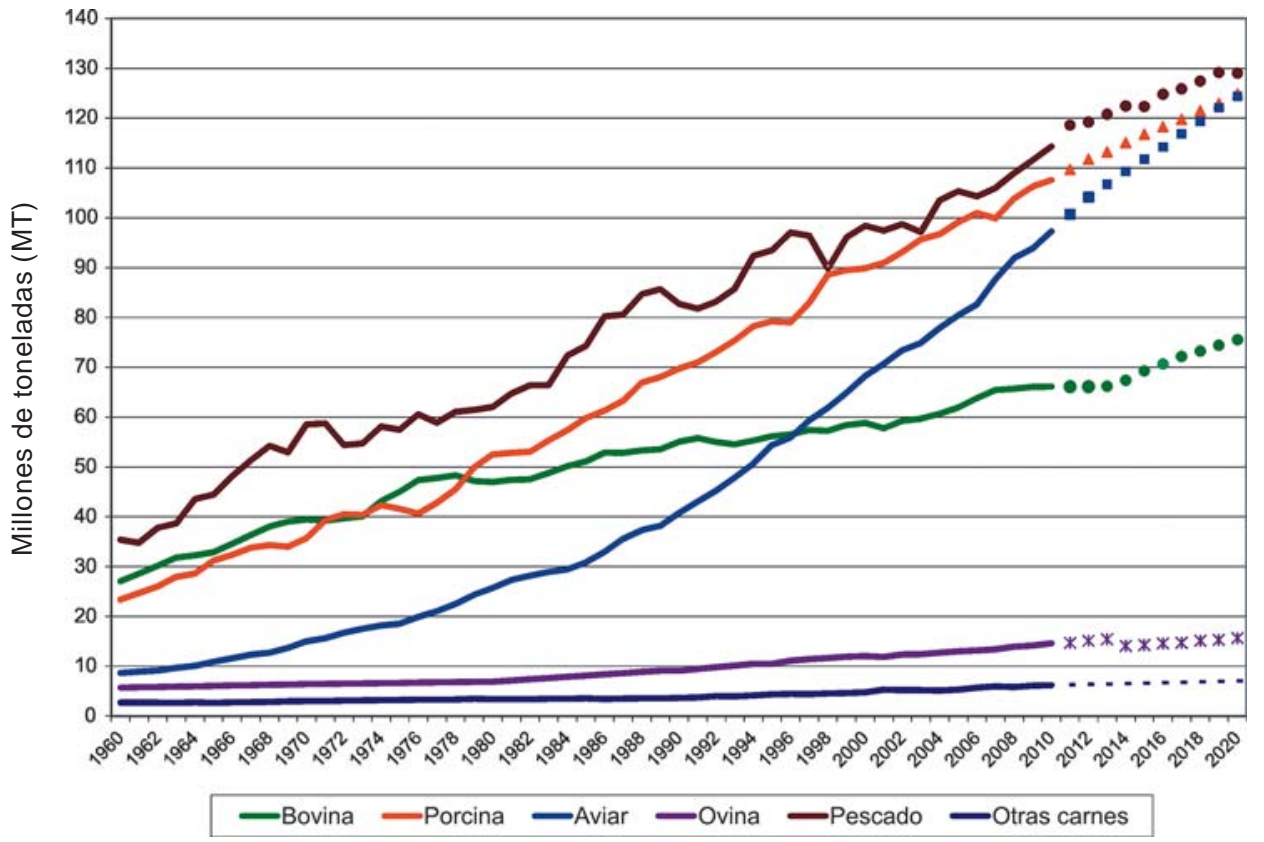

Figura 1. Producción mundial de carnes (1960-2010) y proyección para la década actual (2011-2020). Fuente: Período 1960-2010 elaborado en base USDA y FAO; proyección 2011-2020 de OECD-FAO (2012)

\footnotetext{
${ }^{2}$ http://www.geohive.com/earth/his history3.aspx

${ }^{3}$ http://faostat3.fao.org/

${ }^{4} \mathrm{http}: / /$ www.nationmaster.com/

${ }^{5} \mathrm{~A}$ los efectos del presente análisis se puede asumir la producción de carnes igual a su suministro y consumo. ${ }^{6}$ La Organización de las Naciones Unidas para la Agricultura (FAO) compila, procesa y almacena información estadística a través del sistema FAOSTAT desde 1961 (http://faostat.fao.org/). La otra fuente disponible actualmente es la del Foreign Agricultural Service del Departamento de Agricultura de los Estados Unidos (USDA). El sistema PSD Online (Production, Supply and Distribution) del USDA/FAS provee estadísticas globales datadas a partir de 1960 (http://www.fas.usda.gov/psdonline/).
} 
observa, ha ejercido por siempre un claro liderazgo desde que existen registros a nivel mundial, la carne bovina fue la de mayor consumo hasta finales de los 70 .

Aunque existen diferencias entre las respectivas estimaciones, ambas fuentes coinciden en que la carne porcina habría tomado la delantera frente a la bovina desde 1979, posición que ha mantenido hasta el presente. El consumo de carne bovina todavía se mantuvo por encima de la carne aviar hasta los últimos años del siglo XX. Aproximadamente entre 1997 y 1999 , pero claramente a partir del nuevo siglo, la carne de ave tomó el segundo lugar desplazando a la bovina al tercero. Por su parte, la carne ovina ha sido históricamente la de menor importancia relativa frente a las restantes, superando solamente a la producción y consumo de otras carnes menores. De acuerdo a las proyecciones, hacia 2020 la producción de carne aviar podría estar alcanzando la producción de carne de cerdo y posiblemente también a la de pescado.

Desde los inicios de la década de 1960 y partiendo de una producción algo superior a los $8 \mathrm{MT}$, la producción de carne aviar ha venido aumentando a tasas crecientes llegando prácticamente a las $100 \mathrm{MT}$ hacia 2010. En promedio, su crecimiento en dicho período fue equivalente al originado por una tasa promedio anual acumulativa de 5\%. La carne porcina pasó de poco más de $23 \mathrm{MT}$ en 1960 a casi 110 en 2010, mostrando el segundo nivel más alto de crecimiento, con una tasa anual acumulada de 3,1\%. Por su lado, el suministro de carne de pescado cre- ció a una tasa acumulativa anual de 2,4\%, de 35 a 114 MT.

Las carnes ovina y bovina, junto a las carnes menores, son las que menos crecieron durante las últimas cinco décadas, con tasas que oscilaron entre 1,7 y $1,9 \%$ acumulativo anual. Entre 1960 y 2010, la carne bovina pasó de 27 MT a 66 MT y la ovina de casi 6 a $15 \mathrm{MT}$, mientras que las carnes menores crecieron aproximadamente de 3 MT a 6 MT.

Puricelli (2011) ha señalado que la carne aviar es, por naturaleza, la que más rápido puede adaptarse a escenarios cambiantes de incremento de costos e impulsos en la demanda. Apunta que desde que nace un pollo hasta su faena transcurren de 2 a 3 meses. En términos de eficiencia de conversión, se necesitan casi $2 \mathrm{~kg}$ de alimento para producir $1 \mathrm{~kg}$ de carne. Para el caso de la producción porcina, se tardan alrededor de 6 meses y se necesitan alrededor de $3 \mathrm{~kg}$ de alimento para producir $1 \mathrm{~kg}$ de carne, en tanto que para el caso de la carne bovina, el período es de alrededor de 30 meses y el equivalente de $7 \mathrm{~kg}$ de alimento para producir $1 \mathrm{~kg}$ de carne. Ya Capurro (2000) había referido tasas de conversión similares. Indicó que tanto los vacunos como los ovinos precisan entre 7 y 8 kilos de grano para producir 1 kilo de carne, mientras que los porcinos requieren entre 4 y 5 kilos, las aves necesitan 3,5 kilos y los peces, menos de un kilo y medio.

En el Cuadro 1 se presentan índices de eficiencia de producción de carne para las especies domésticas más importantes bajo

Cuadro 1. Indices de eficiencia de producción de carne referidos a animales individuales y población.

\begin{tabular}{|l|c|c|c|c|}
\hline \multirow{2}{*}{ Producto } & \multicolumn{2}{|c|}{ Referida a animales individuales } & \multicolumn{2}{c|}{ Referida a la población total } \\
\cline { 2 - 5 } & Energía & Proteína & Energía & Proteína \\
\cline { 2 - 5 } & E prod.IE alim. & N prod./N alim. & E prod.IE alim. & N prod./N alim. \\
\hline Carne de bovino & $5,2-7,8$ & 8 & 3,2 & 8 \\
Carne de ovino & $11,0-14,6$ & 16,4 & $2,4-4,2$ & $6-14$ \\
Carne de cerdo & 35 & $25-32$ & $23-27$ & $17-22$ \\
Carne de pollo & 16 & 30 & 14,6 & $25-26$ \\
\hline
\end{tabular}

Fuente: Adaptado de Wadsworth (1997).

${ }^{7}$ Considerando conjuntamente captura (marina y de agua dulce) y producción acuícola. 
explotación comercial. El sistema de producción en sí puede influir en el indicador de eficiencia por lo que, en algunos casos, incluye un rango de eficiencia. Sin embargo, las diferencias más grandes se encuentran entre las diferentes especies. Por otro lado, la eficiencia de animales considerada solamente a nivel individual no toma en cuenta otros aspectos como la proporción en que los animales de una población contribuyen a la formación del producto final, por lo que dichos índices se presentan tanto para animales individuales como para la población total de la especie. Aquellas poblaciones que tienen una mayor proporción de sus miembros que contribuyen al producto final exhiben mayores índices de conversión de alimento a carne.

Se puede observar que los monogástricos (cerdos y aves) muestran mejores índices de eficiencia que los rumiantes (bovinos y ovinos) al expresarlos en términos biológicos. Esto tiene directa relación con los costos de producción. Sin embargo, no quiere decir que solo las actividades y especies con mejores índices de eficiencia tengan lugar en los sistemas de producción. Como afirma Wadsworth (1997), «el mundo real en el cual opera la agricultura es mucho más complejo».

Estas relaciones de eficiencia podrían explicar en buena parte el crecimiento diferencial que ha tenido el consumo de las carnes de aves y cerdos frente a las de bovinos y ovinos. Es lógico inferir que esa mayor eficiencia biológica en la producción de aves y cerdos favoreció el desarrollo de trayecto- rias tecnológicas diferenciadas, permitiendo un rápido despegue de estas producciones. En el caso de estas especies, los procesos de «tipo industrial» pudieron extenderse con mayor facilidad al sector primario, posiblemente ligados a los menores costos y a mayores posibilidades de coordinación entre los eslabones de la cadena.

En el Cuadro 2 se aprecia la contribución de cada tipo de carne en la producción mundial durante el período referido (1960-2010). En tanto que en 1960 la carne aviar representaba algo más del $8 \%$ del total, su nivel de producción se multiplicó por 11 en los siguientes 50 años. A su vez, su contribución relativa se multiplicó por 3 , alcanzando el $24 \%$. Este cambio relativo se hizo fundamentalmente a expensas de la carne vacuna. Aunque la producción de esta última más que se duplicó durante el mismo período, su participación cayó 10 puntos porcentuales, de $26,3 \%$ a $16,3 \%$.

La expansión diferencial observada en la producción y consumo de algunas carnes de especies no rumiantes, como porcina y aviar se profundizó aun más en las últimas tres décadas, de la mano de modificaciones verificadas en el estilo de vida y en los hábitos de consumo de las nuevas sociedades. En un informe publicado originalmente en 1999 por el Instituto Internacional de Investigaciones sobre Políticas Alimentarias (IFPRI), Delgado y otros (2001) sostenían que el incremento de la población, la urbanización y los ingresos en los países en desarrollo eran

Cuadro 2. Contribución de los distintos tipos de carne en la producción mundial (1960-2010).

\begin{tabular}{|c|c|c|c|c|c|c|c|c|c|c|c|c|}
\hline \multirow[t]{2}{*}{ Carne } & \multicolumn{2}{|c|}{1960} & \multicolumn{2}{|c|}{1970} & \multicolumn{2}{|c|}{1980} & \multicolumn{2}{|c|}{1990} & \multicolumn{2}{|c|}{2000} & \multicolumn{2}{|c|}{2010} \\
\hline & $\mathbf{M} \mathbf{T}^{(\mathrm{a})}$ & $\%$ & MT & $\%$ & MT & $\%$ & MT & $\%$ & IT & $\%$ & MT & $\%$ \\
\hline & 27,0 & 26,3 & & 25,0 & & & & & & 17,7 & 1 & 16,3 \\
\hline Porcina & 23,4 & 22,8 & 35,7 & 22,6 & 52,5 & 26,6 & 69,7 & 26 , & 89,9 & 27,1 & 107,6 & 26,5 \\
\hline Aviar & & & 15 & & 2 & 13,0 & 40,8 & 15,6 & 8,2 & 20,5 & 7,3 & 24,0 \\
\hline Ovin & & & & & & & & & $1<, U$ & & 14,6 & 3,6 \\
\hline Otras & & & & & & $1, I$ & & & 4,0 & & 6,2 & 1,5 \\
\hline Pescado & 35,4 & 34,4 & 58,5 & 37,0 & 62,0 & 31,4 & 82,7 & 31,7 & 98,4 & 29,6 & 114,3 & 28,2 \\
\hline Total & 102,8 & 100 & 158,1 & 100 & 197,5 & 100 & 261,0 & 100 & 332,1 & 100 & 406,0 & 100 \\
\hline
\end{tabular}

Nota: (a) - Millones de toneladas métricas; (b) - Incluye carne caprina, equina y otras especies.

Fuente: Elaborado en base a datos de FAO y USDA. 
los principales responsables del aumento en la demanda de alimentos de origen animal.

Otro informe publicado sobre la situación del mercado mundial de carnes hace ya una década (Gemines Consultores, 2003) señalaba que el desarrollo de economías de escala a nivel global derivó en una creciente concentración de la distribución de alimentos, lo que a su vez desató cambios a nivel de los canales de comercialización y de distribución hacia los puntos de venta. Según este informe, estos aspectos modificaron la dinámica del mercado mundial de la carne vacuna afectando, entre otras cosas, el consumo per cápita de este producto.

El referido informe resaltaba los importantes cambios estructurales sucedidos en el mercado de la carne en la década previa al cambio de siglo. Según el mismo, las crisis financieras experimentadas por varios países productores a partir de 1997 y sus efectos en los tipos de cambio, el aumento de la productividad en algunos países, las políticas comerciales a través de los programas de subsidios a las exportaciones y la ayuda interna, los cambios en los gustos del consumidor y el creciente énfasis en temas relativos a la inocuidad de los alimentos y a la seguridad alimentaria, han sido algunos de los ejemplos clave de estas transformaciones (Gemines Consultores, 2003).

La aparición de problemas sanitarios en distintas especies domésticas destinadas a la producción de carne en varias regiones del globo también ha determinado fuertes cambios en la demanda de carnes. En Europa, la actividad pecuaria se vio sensiblemente afectada por problemas sanitarios que afectaron particularmente al rubro bovino, como la encefalopatía espongiforme bovina (EEB) o «vaca loca». Lo mismo sucedió con la aparición de focos de fiebre aftosa en Europa y países exportadores de América del Sur, como Argentina, Brasil y Uruguay (Gemines Consultores, 2003). En particular, la crisis de la «vaca loca» desatada en 1996 en Inglaterra, afectó profundamente al resto de los mercados de carne bovina, obligando a un replanteo de los sistemas productivos por parte de los países productores.

Mohan (2002) argumentó que la crisis sanitaria tuvo consecuencias insospechadas, ya que fue la primera vez que se produjo una reacción por parte de los consumidores, con enormes efectos sobre el mercado mundial. En la Unión Europea (UE), donde se experimentó el principal impacto de la crisis sanitaria sobre los consumidores, se originó una fuerte psicosis que restringió la demanda por varios años. Recién hacia finales de la década comenzó a notarse una cierta recuperación de la confianza por parte del consumidor.

Todos estos sucesos que afectaron al mercado mundial promovieron la necesidad de búsqueda de nuevas alternativas para el negocio de la carne. Los principales países productores y exportadores comenzaron a orientarse hacia procesos de mejora de calidad, diferenciación y certificación de productos, requisitos fundamentales para el reposicionamiento competitivo y aún para el acceso a los mercados más desarrollados. Mientras tanto, los países importadores impusieron nuevos requerimientos y barreras a los productos extranjeros, amparados en cuestiones relativas a la protección de la salud humana, animal y del medio ambiente (Mohan, 2002).

Por su parte, el último informe sobre la situación de la ganadería mundial publicado por FAO (2009) expresaba que desde 1982, año en que se publicó el reporte anterior, «el sector pecuario se ha desarrollado y cambiado rápidamente en respuesta a los cambios de la economía mundial, al incremento de los ingresos en numerosos países en desarrollo y a la modificación de las expectativas sociales».

Algunos de los causales que impulsaron estos importantes incrementos en los consumos de carnes fueron el dinamismo de los países en desarrollo, altamente poblados, con incrementos en el nivel de ingreso, aumentos de la urbanización y sus consecuentes cambios en las dietas, pasando de consumir alimentos básicos a base de cereales, a consumir proteínas animales (Puricelli, 2011). En 1999, los países en desarrollo aportaron 3 MT adicionales a la producción mundial, o sea más del $80 \%$ del aumento total. Hacia fines de la primera década del siglo $X X I$, estos países, entre los que destacan China y Brasil, contribuían con el $61 \%$ de la 
producción mundial de carnes y más del 52\% de la producción mundial de carne vacuna.

Los países en desarrollo han respondido a la creciente demanda de productos pecuarios incrementando rápidamente la producción. Los insumos baratos, los cambios tecnológicos, la mejora en la eficiencia de escala, el manejo del riesgo sanitario y la garantía en la seguridad alimentaria de los últimos decenios han resultado en una mayor producción, tanto por un incremento en el número de animales como por el incremento logrado en la productividad.

Según el informe de FAO (2009), en el período de 1995 a 2007, la producción mundial de carne porcina se incrementó más de 31 MT en los países en desarrollo y apenas 3,4 MT en los países desarrollados. En el caso de la carne aviar, el incremento de producción en los países en desarrollo fue de casi 23 MT respecto a los 9,2 MT registradas por los países desarrollados. Por su parte, en 12 años, la producción mundial de carne bovina en los países en desarrollo se incrementó más de 9 millones de toneladas, reduciéndose la misma en los países desarrollados (Cuadro 3).

Entre 1961 y 2007, el mayor incremento en la producción de carne tuvo lugar en Asia, seguido por América Latina y El Caribe, sostenidos por la expansión de los sectores de la carne vacuna y carne aviar en Brasil y Argentina. Las tendencias del incremento de la producción, son similares a las del consumo. Entre 1980 y 2007 China multiplicó su producción de carne por más de seis, generando hoy en día el 31\% de la producción mundial. En Brasil la producción de carne se multiplicó casi por cuatro, y actualmente representa el 7\% de la producción mundial (FAO, 2009).

A modo de conclusión, «el rápido incremento de los ingresos y la veloz urbanización de los últimos tres decenios, junto con el subyacente crecimiento de la población, están haciendo que aumente la demanda de carne y otros productos animales en numerosos países en desarrollo. Los factores del lado de la oferta, como la globalización de las cadenas de suministro de alimentos para animales, el patrimonio genético y otras tecnologías están transformando aún más la estructura del sector» (FAO, 2009).

Las proyecciones de OECD-FAO (2014) para la década que transcurre y hasta 2022 prevén que la producción de todas las carnes crezca a un ritmo moderado de 1,6\% anual, limitada por los altos costos de insumos y la competencia en la demanda por tierra y agua de las producciones alternativas. La carne aviar, principal motor del rápido ritmo de crecimiento de la producción mundial de carne en la década pasada, aparece como la gran responsable también de la desaceleración observada en la década en curso. Aunque seguiría creciendo a una ma-

Cuadro 3. Producción mundial de carnes según región, años 1995 y 2007.

\begin{tabular}{|l|r|r|r|r|r|r|r|r|}
\hline \multirow{2}{*}{ País/Región } & \multicolumn{2}{c|}{ Porcina } & \multicolumn{2}{c|}{ Aviar } & \multicolumn{2}{c|}{ Bovina } & \multicolumn{3}{c|}{ Ovina } \\
\cline { 2 - 10 } & \multicolumn{1}{|c|}{ Miles } & \multicolumn{1}{c|}{ Tons } & \multicolumn{1}{c|}{ Miles } & \multicolumn{1}{c|}{ Tons } & Miles & \multicolumn{1}{c|}{ Tons } & \multicolumn{1}{c|}{ Miles } & Tons \\
\cline { 2 - 9 } & $\mathbf{1 9 9 5}$ & $\mathbf{2 0 0 7}$ & $\mathbf{1 9 9 5}$ & $\mathbf{2 0 0 7}$ & $\mathbf{1 9 9 5}$ & $\mathbf{2 0 0 7}$ & 1995 & 2007 \\
\hline Total Mundial & 80.123 & 115.454 & 54.602 & 86.772 & 54.191 & 61.881 & 10.436 & 14.038 \\
Países Desarrollados & 35.990 & 39.457 & 27.746 & 36.956 & 30.774 & 29.398 & 3.498 & 3.233 \\
Países en Desarrollo & 44.133 & 75.996 & 26.855 & 49.817 & 23.417 & 32.483 & 6.938 & 10.805 \\
Asia & 38.302 & 68.870 & 13.625 & 25.146 & 6.459 & 10.873 & 3.497 & 6.747 \\
América Latina y Caribe & 5.044 & 6.149 & 8.894 & 17.249 & 12.595 & 15.773 & 439 & 456 \\
Brasil & 2.800 & 3.130 & 4.154 & 8.907 & 5.710 & 7.900 & 125 & 120 \\
Argentina & 211 & 230 & 817 & 1.204 & 2.688 & 2.830 & 88 & 62 \\
Uruguay & 22 & 19 & 41 & 46 & 338 & 570 & 52 & 32 \\
\hline
\end{tabular}

Fuente: adaptado de FAO (2009). 
yor velocidad que las demás, la tasa de crecimiento acumulativa anual se ubicaría en $1,9 \%$. Este valor resulta bastante inferior al $3,7 \%$ registrado en los anteriores 10 años y marca incluso un ajuste a la baja de las estimaciones iniciales para el mismo período. Según esta misma fuente, la producción de pescado aumentaría a una tasa de 1,6\%, seguida de cerca por la bovina y la porcina, con tasas anuales de $1,5 \%$ y $1,4 \%$, respectivamente. Finalmente, la carne ovina crecería a una tasa de 1,3\% acumulativa anual hasta 2022.

\subsection{El consumo de carnes en Uruguay}

\subsubsection{El consumo interno de carnes en la segunda mitad del siglo $X X$}

Los patrones de consumo de carnes en Uruguay han presentado desde siempre un comportamiento casi único en el mundo, siendo comparables solamente con los de Argentina. El consumo anual per cápita de carne vacuna ha mostrado un predominio absoluto frente al de otras carnes a través de los años. Si bien ha mostrado una trayectoria descendente y con fluctuaciones a través de los años, su consumo continúa siendo muy elevado y superior al de todas las demás juntas (Figura 2).

Datos publicados por Bauzá (1952) sugieren que el consumo promedio de carnes en la ciudad de Montevideo durante la década de 1940 podía estimarse en alrededor de 92 kilos por cabeza y por año. De esta cifra, unos 80 kilos correspondían a carne bovina (88\%), siendo el restante $12 \%$ referido a unos 6 kilos a carne ovina y 5 kilos a carne porcina. Hacia 1960, los datos estadísticos compilados por FAO indican que el consumo de estas tres carnes en Uruguay superaba los 100 kg/ persona/año, de los cuales 76 kilos correspondían a carne bovina. La misma fuente atribuye un consumo muy superior a la carne ovina $(22 \mathrm{~kg})$ frente a la de cerdo $(7 \mathrm{~kg})$, explicado seguramente por el alto consumo ovino en el interior del país.

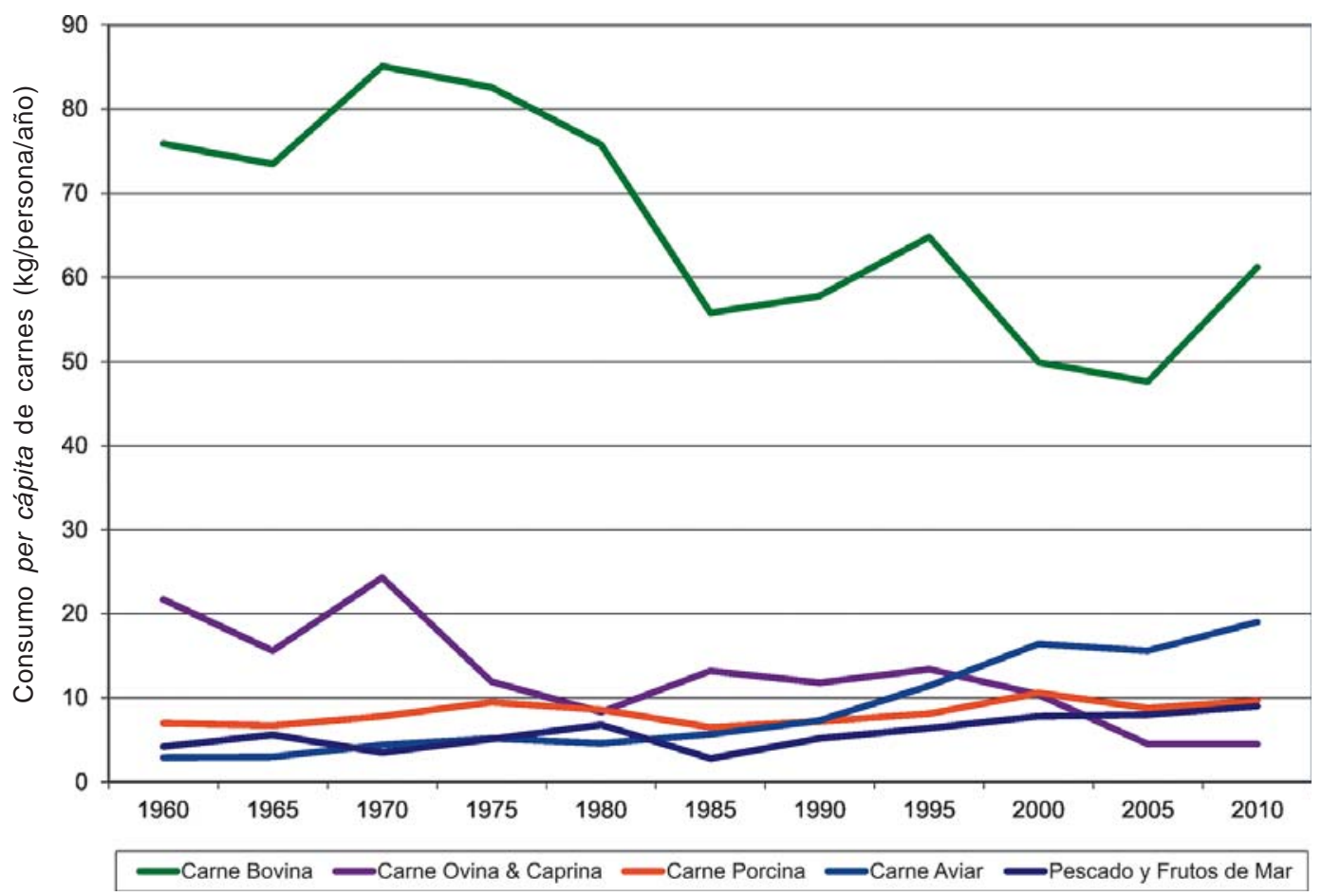

Figura 2. Evolución del consumo per cápita de carnes en Uruguay (1961-2010).

Fuente: Elaborado sobre la base de datos de FAO e INAC. 
Bauzá (1952) señaló que el abasto ${ }^{8}$ absorbía algo más de $15 \%$ de la faena vacuna nacional en 1915 y que, apenas 30 años después, en 1945, se cuadruplicó, llegando a casi $61 \%$. El pico máximo de participación del abasto en la producción nacional se observó en la década de los 60, cuando llegó a concentrar $69 \%$, siendo que a partir de entonces, dicha proporción fue disminuyendo sucesivamente a $63 \%$ en los 70 y a $56 \%$ en la década siguiente (Vázquez Platero y Picerno, 1994). De acuerdo a los estudios de la COMISEC (1994a), esa pérdida relativa de participación en el mercado interno $(0,2 \%$ por año en un período de 30 años) se explicó por una leve caída del consumo, con fluctuaciones no muy marcadas, complementado por fuertes oscilaciones de los volúmenes exportados, los cuales evolucionaron en forma casi paralela a los niveles de producción.

Antes de 1978, los frigoríficos exportadores estaban impedidos de intervenir en el mercado interno. Ambas actividades, abasto y exportación, se desarrollaban y controlaban por separado: la primera por la Comisión de Administración del Abasto (CADA) y la segunda por el INAC ${ }^{9}$. El estado operaba plantas, fijaba los precios al consumidor y al productor por vía administrativa, imponía detracciones a las exportaciones y vedas al consumo y mantenía stocks de carne bovina para regular la oferta y amortiguar las variaciones estacionales en los precios.

Todo esto tuvo consecuencias muy importantes sobre los patrones de consumo de carnes en la población. En agosto de 1978 comenzó un importante proceso orientado a la desregulación del sector. En particular referencia a las carnes, se suprimió el Frigorífico Nacional y se dio libertad para la instalación de nuevas plantas de faena. Se estableció la libertad de abasto en todo el territorio nacional, derogándose las prohibiciones y cuotas de faena. Consecuentemente, se liberalizó del precio del ganado y eliminó la fijación del precio de la carne y subproductos en todas sus etapas (Vázquez Platero y Picerno, 1994; COMISEC, 1994a; Rohner, 2010; Irigoyen, 1997).

Uno de los escasos mecanismos de intervención directa del Estado que persistió por algún tiempo en el mercado de carne bovina fue el stock regulador ${ }^{10}$. Para el invierno de 1985, INAC formó un stock de 8.500 toneladas que debieron ser exportadas al no ser absorbidas por el abasto. Por el contrario, en 1986, se almacenaron 6.500 toneladas que fueron colocadas en su totalidad en el mercado capitalino y sus alrededores.

En favor del mantenimiento e incluso ampliación de estos volúmenes se planteaba la necesidad de atender el desabastecimiento de carne en la plaza local debido a la reducción de la oferta de ganados prontos para faena en el período de post-zafra, entre los meses de julio y noviembre ${ }^{11}$. Frente a una demanda uniforme a través del año, el almacenamiento de carne procuraba mantener el equilibrio del poder adquisitivo de los consumidores mediante la regulación de los picos estacionales de alta y baja en la oferta y en los precios.

Pagés (1986) destacó los efectos negativos que la constitución de stocks reguladores tuvo sobre las posibilidades de desarrollo de rubros alternativos, como las carnes de ave, pescado y cerdo, en el mercado local. En ese sentido, sugirió que estas carnes hubieran podido llenar los vacíos dejados por la escasa oferta de carne bovina en la post-zafra. La supresión definitiva de este instrumento ocurrió hacia 1994, junto a la liberalización completa de la exportación de ganado en pie y la eliminación de las detracciones a las exportaciones de carne y ganado en pie. Estas medidas no solamente no

\footnotetext{
${ }^{8}$ Término con el que refiere comúnmente al mercado interno.

${ }^{9}$ Decreto 601/967 del 8 de setiembre de 1967.

${ }^{10} \mathrm{La}$ formación de stocks reguladores se basó en la normativa prevista en el artículo 3 del Decreto-Ley 15.605 de creación del INAC. El inciso A, numeral 9, facultaba a INAC «la adopción de las previsiones necesarias para asegurar la satisfacción de las necesidades del consumo en períodos de baja oferta, como así también cuando fuere necesario para mantener el abasto, realizar faenas utilizando la o las plantas que mejores condiciones le ofreciese».

${ }_{11}$ «Reducir el stock: Una política equivocada» Editorial del 14 de diciembre de 1986 de la publicación Carne de la Asociación Nacional de Carniceros (ANC).
} 
tuvieron efectos negativos serios sobre el consumo interno de carne bovina sino que, además, comenzó a abrir espacios al consumo de otras carnes.

Hacia los últimos años de la década de los 80 y primeros de los 90 , el consumo interno aparente de carne bovina se estabilizó en el entorno de las 200 mil toneladas en gancho. Las exportaciones, limitadas por entonces al circuito aftósico promediaban las 140 mil toneladas de peso canal. En el caso de la capital del país, el abasto de Montevideo era realizado por frigoríficos exportadores sin habilitaciones y por mataderos, mientras que el formato minorista de venta de carnes predominante era la carnicería. Al abasto de destinaban básicamente medias reses con hueso, un producto homogéneo y sin marca (Vázquez Platero y Picerno, 1994).

Los importantes cambios registrados por entonces tanto a nivel interno como externo, explican en buena medida la pérdida de importancia relativa del abasto. Coincidiendo con el proceso de apertura en el sector ganadero que terminó de liberalizar el mercado de haciendas, en mayo de 1993, Uruguay obtuvo su reconocimiento como de país libre de aftosa con vacunación. En junio de 1994, el país dejó de vacunar contra la fiebre aftosa y un año más tarde, en julio de 1995, accedió a la condición de país libre de aftosa sin vacunación. Esto le abrió las puertas a nuevos destinos en el mercado internacional y la posibilidad de exportar una mayor variedad de productos.

En la década del 90, la demanda interna se redujo a cerca del $45 \%$ de una faena total estimada entre 700 y 900 mil cabezas anuales y un valor de US\$200 millones (Vernazza y César, 2002). Durante el mismo período, el consumo interno de carne bovina osciló entre 140 y 220 mil toneladas peso canal, significando un valor anual promedio en el entorno de US\$280 millones (Ordeix, 2001). Vernazza y Costas (2002) constataron una disminución de $12 \%$ en el consumo de carne vacuna entre 1985 y 2001. Tomando los últimos 10 años de ese período (1992-2001), Vernazza (2003) ubicó dicho porcentaje en 14\%.
Alentado por una mejora en el poder de compra de los consumidores locales, el consumo de carne bovina per cápita ascendía a $60 \mathrm{~kg}$ anuales, siendo abastecido totalmente por producción nacional. Simultáneamente, comenzó a manifestarse una tendencia creciente del consumo de carne de ave, impulsado entre otros factores por su menor precio relativo, mientras que el consumo de carne ovina y porcina permanecían constantes (CIU, 1999).

Según el INE (1996) durante el período transcurrido entre la encuesta realizada entre setiembre de 1982 y agosto de 1983 hasta la realizada entre junio de 1994 y mayo de 1995, el gasto en carnes se redujo $18 \%$ como resultado de una disminución de $34 \%$ en carne vacuna y ovina compensado por un crecimiento del consumo de aves (87\%) y pescados y mariscos (110\%). Según Vernazza y Costas (2002), entre 1985 y 2001, el consumo de carnes porcina y aviar experimentaron incrementos de $44 \%$ y $232 \%$, respectivamente.

Por el lado de los ovinos, el consumo de carne de esta especie venía sufriendo una importante caída en el mercado interno. De un promedio de poco más de 20 kilos por habitante y por año, registrado entre 1960 y 1970, el consumo doméstico se redujo a menos de 12 kilos en 1975, valor que no se volvería a superar en adelante. A impulsos de altos precios de la lana en el mercado internacional, el stock ovino pasó de $15 \mathrm{mi}$ llones de cabezas en dicho año a casi 24 millones en 1986.

La perspectiva de alta disponibilidad de carne ovina enfrentada a una demanda externa débil y un consumo local doméstico muy bajo, impulsó, en la década de 1980, una campaña conjunta de largo aliento por parte de INAC y el Secretariado Uruguayo de la Lana (SUL) para promover el consumo de carne ovina. Esta campaña se integró con estímulos económicos (exoneración del IVA durante la post-zafra vacuna) y la promoción de su consumo. Incluso se llegó a proponer la inclusión de carne ovina en los stocks reguladores vigentes en ese entonces, como 
forma de incrementar la oferta de esta carne durante la post-zafra vacuna ${ }^{12}$.

Con el objetivo de actuar sobre los factores de mayor influencia en la conducta del consumidor, aparte del precio (Cazet, 1986), la promoción incluyó: a) realización de demostraciones prácticas del nuevo sistema de cortes a los carniceros de Montevideo y Canelones; b) campaña publicitaria de televisión y radio; c) distribución de material ilustrativo a los consumidores sobre presentación y preparación de la carne ovina; y d) provisión al comercio minorista de material impreso para su exposición en el punto de venta.

Esta no fue la única experiencia de promoción de consumo de carne ovina en Uruguay. La primera estuvo a cargo del Frigorífico Nacional en 1950, cuando promovió los cortes australianos en un intento de llegar al consumidor con un producto más adecuado ${ }^{13}$. Además de protagonizar las campañas de 1987 y 1994, las cuales se limitaron a Montevideo y Canelones, INAC y SUL lanzaron en 2007 el proyecto «Churrasco Ovino» primeramente en los departamentos de Paysandú, Rivera y Cerro Largo. Todos estos esfuerzos carecieron de largo aliento y tuvieron un éxito muy reducido, no logrando cambiar sustancialmente la demanda de esta carne en el mercado local.

\subsubsection{Los cambios de las últimas dos décadas}

Durante los años 90, algunos de los cambios en los hábitos de compra ocurridos en el mundo en las décadas anteriores comenzaron a observarse también en Uruguay. La participación de los supermercados se incrementó fuertemente en casi todos los géneros alimentarios. Si bien alcanzó también a los consumidores de carne, más de la mitad de las compras de este producto aun se orientaban a las carnicerías (INE, 1996).

De acuerdo a un estudio de la Cámara de Industrias del Uruguay (CIU, 1999), la aten- ción personalizada de la carnicería y la venta rápida de carne envasada en las góndolas, fue la combinación perfecta para incrementar las ventas de los productos cárnicos en las grandes superficies. Las ventas de carne desosada y envasada al vacío cobraron gran participación, implementándose el uso de marcas para diferenciar el producto y aumentar su valor ante el consumidor final.

A la fuerte caída registrada en el consumo local de carne bovina durante la segunda mitad de la década del 90, de más de $62 \mathrm{~kg}$ en 1995 a menos de $55 \mathrm{~kg}$ en 1999, siguió un importante repunte en los dos años siguientes. El cierre temporario de los mercados internacionales tras el rebrote de aftosa puso a disposición de los consumidores uruguayos toda una variedad de cortes de exportación normalmente no disponibles para el mercado interno y a precios reducidos (Lanfranco, 2003a).

Esta experiencia tuvo un marcado impacto sobre el comportamiento del consumo. Los frigoríficos comenzaron a percibir una evolución firme del consumo interno hacia las carnes de mayor calidad, color y terneza. La demanda de carne adquirió una mayor sofisticación; el consumidor aprendió y tuvo mayores posibilidades de elegir. El tipo de animal faenado para abasto también cambió, producto de las nuevas exigencias de calidad vigentes en el mercado interno. El carnicero comenzó a exigir medias reses livianas, con buen color y sin mucha grasa. Para ello se requirieron animales más jóvenes y más livianos. Aumentó la demanda por novillos entre 2 y 4 dientes, con una «media» en el entorno de los 100-120 kilos, y de vaquillonas con «medias» de entre 80 y 90 kilos, habiéndose relegado a la vaca a un segundo plano (Lanfranco, 2003b).

Otro cambio de gran relevancia fue el aumentó del consumo de cortes sin hueso, que en Montevideo y Canelones alcanzaron el $46 \%$ de las ventas, así como una preferencia marcada hacia la demanda de cortes pequeños (Lanfranco, 2003b). En opinión de

\footnotetext{
${ }^{12}$ Asociación Nacional de Carniceros (ANC). Carne, diciembre de 1986. Págs. 17-18.

${ }^{13}$ «Uruguay busca nuevos mercados: Abriendo puertas al churrasco ovino.» Acontecer Ovino Caprino, Vol. VIII N³8: pág. 68.
} 
varios operadores de la cadena cárnica, «en pocos años los únicos cortes que se venderán con hueso serán el asado y las costillas» y «salvo el caso de la colita, la 'unidad' de venta es cada vez más chica». Por otro lado, los cortes al vacío comenzaron a ganar espacio aunque a una velocidad bastante menor a la deseada por la industria, debido al desconocimiento o a la falta de costumbre de los consumidores acerca de esta forma de presentación.

En términos de volumen, la percepción se orientaba hacia una demanda interna estable y sin mucho espacio para aumentar un consumo per cápita ya de por sí muy alto. Varios observadores de la industria señalaron que tan pronto Uruguay comenzara a recuperar mercados valiosos, el precio de la carne normalmente se vería empujado al alza, con la consiguiente caída del consumo interno.

Sin embargo, ya antes que esto se pudiera concretar, la agudización de la crisis económica en 2002 y 2003 trajo aparejado un fenómeno de reversión en el mercado interno. Cuando el tema «calidad» había adquirido gran relevancia para el consumidor local y el mercado estaba evolucionando hacia la carne desosada y a la preparación de cortes más exigentes, las crecientes dificul- tades económicas obligaron a los consumidores a volver a poner el factor precio por encima de la calidad.

La Figura 3 ilustra la evolución de los precios al consumo de productos cárnicos en el mercado interno desde enero de 1997 hasta abril de 2013, tomando como base 100 el mes de diciembre de 1996. Hasta mayo de 2002 inclusive, la categoría pescados y mariscos fue la que acumuló el mayor incremento relativo $(50,2 \%)$. El índice de precios para carne bovina y ovina se incrementó $31,4 \%$, seguido del de carne de cerdo con 19,5\% y la de carne aviar con tan solo 3,9\%.

La devaluación del peso uruguayo de mediados de 2002 encareció los precios internos en el país y provocó una dramática caída en la demanda interna. Entre mayo y octubre de 2002, la cotización del dólar aumentó $58 \%$, en términos corrientes. El índice de precios al consumo de las carnes bovina y ovina se incrementó un $50 \%$, aunque mostrando grandes variaciones según los cortes.

Los mayores incrementos de precio se verificaron con los cortes de menor valor relativo como la aguja (55\%), la falda (75\%) y la picada común (62\%). Para cortes de mayor valor como la nalga y cuadril (43\%), el

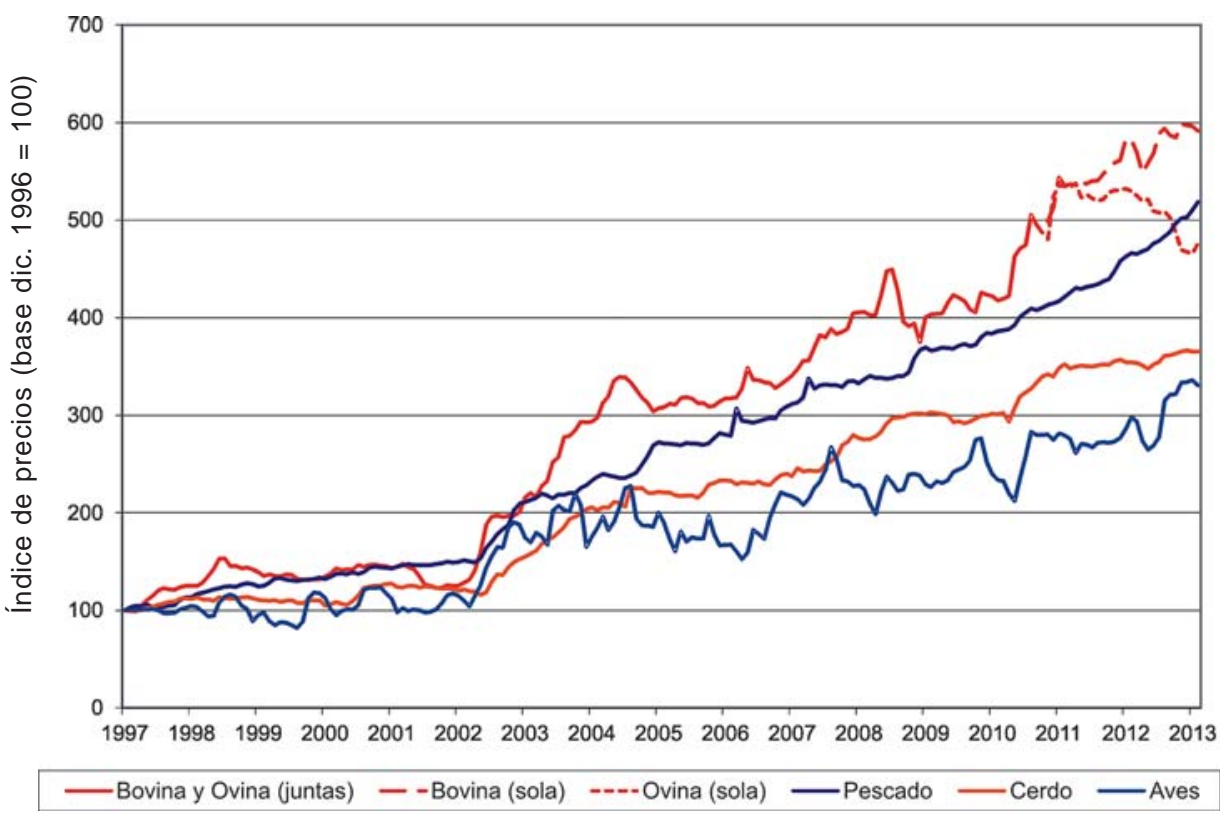

Figura 3. Evolución de los precios de distintas carnes en el mercado interno (1997-2013). Fuente: Elaborado sobre la base de datos del INE. 
peceto (46\%) y la carne picada especial (47\%), el incremento fue de menor magnitud. Por su parte, el precio de la carne de pescado creció $19 \%$ y la de cerdo $14 \%$. Si bien la aviar fue la de mayor encarecimiento relativo durante esos meses (59\%), se trató del producto cárnico cuyo precio sufrió el menor incremento relativo desde 1997.

Los estudios publicados por la Oficina de Programación y Política Agropecuaria (OPYPA) del Ministerio de Ganadería, Agricultura y Pesca (MGAP) sobre la evolución del consumo interno mostraron que en 2003 se produjo una de las mayores caídas en el consumo interno de carne bovina. A partir de los valores de elasticidad precio e ingreso estimados por Sáder (2000) para el período 1990-1999, dicha caída fue estimada entre $13,2 \%$ y $13,6 \%$ con respecto al año anterior. Con un volumen de 152 mil toneladas peso canal de carne bovina destinada al abasto, el consumo per cápita cayó a un mínimo histórico de 45,1 kg (Ilundain, Lema y Peyrou, 2002; 2003).

En esta coyuntura, las carnicerías no pudieron trasladar todo el aumento de la carne en gancho (que se ajustó 100\% al incremento del dólar) al precio al consumo. Esta brecha se acentuó a partir del segundo semestre de 2003, como respuesta al incremento de la demanda agregada por parte de la industria frigorífica, lo cual se tradujo en un incremento del precio del ganado y de la carne en gancho de carnicería, que a su vez se transfirió parcialmente al consumo (Ilundain, Lema y Peyrou, 2003).

A partir de 2003 , los precios de las distintas carnes evolucionaron en forma claramente diferente. El índice referido a carne vacuna y ovina fue el de mayor incremento relativo. Este mayor encarecimiento relativo de la carne bovina tuvo relación con la importante competencia ejercida por la exportación, cuya actividad se reinició en el segundo semestre de ese año con la consiguiente disminución de la importancia relativa del abasto en la faena nacional. Hasta diciembre de 2010, este índice incluía también a la carne ovina si bien queda claro que el mayor peso estaba en la bovina. Desde enero de 2011, el índice comenzó a publicarse por separado. Desde entonces se observó que el índice de precios de la carne ovina mostró un comportamiento descendente en tanto que la bovina continuó creciendo.

Basado en un estudio de preferencias y actitudes de los consumidores de Montevideo y Ciudad de la Costa, Vernazza (2003) comunicó que el $74 \%$ de los responsables de compras del hogar encuestados reconoció haber disminuido su adquisición de carne vacuna, lo cual parece confirmar la información discutida precedentemente. Por su parte, Costas y Herrera (2007) señalaron que, las caídas más significativas en los volúmenes comercializados en Montevideo ocurrieron en los volúmenes de carne sin hueso. El descenso más importante ocurrió en 2003 respecto al 2002, siendo en la carne sin hueso de $37,2 \%$ y de $16 \%$ para la carne con hueso.

Lanfranco, Reyes y Risso (2004) enfatizaron que aún en un contexto de suba de precios como el verificado en 2003 , la falta de oferta de algunos productos en virtud de su destino casi exclusivo a la exportación, la crisis económica vivida en el país con la consecuente caída en los salarios y aumento de los índices de desempleo, el Uruguay no quedó ajeno a los cambios sustanciales procesados en el mercado mundial de la carne y advertidos en el país ya desde la segunda mitad de la década anterior. Aspectos tales como la modificación en los hábitos de los consumidores y una mayor preocupación por una alimentación saludable, si bien pudo verse frenado su desarrollo en los primeros años del nuevo milenio, no desaparecieron. El avance de los supermercados como formato de venta, la aparición de cortes de exportación en el mercado local, la presentación de los productos en góndolas, el empacado de productos en bandejas, la comercialización de cortes al vacío, el incremento en la venta de comidas preparadas en base a carnes, fueron todas características que se incorporaron definitivamente al mercado local.

Sin desmedro de la enorme significación del mercado internacional para la industria cárnica bovina y pese a que la participación relativa del abasto ha venido disminuyendo durante las últimas cuatro décadas, el consumo anual por parte de la población uru- 
guaya comenzó a recomponerse con firmeza a partir de 2004. Con excepción de la carne ovina, tanto la porcina como la aviar crecieron aunque a un ritmo menor. Entre 2005 y 2011, el consumo per cápita de carne bovina creció $27,3 \%$, mientras que los consumos de carne de ave y de cerdo crecieron $25 \%$ y $19,3 \%$, respectivamente. Esto se observa a partir de los datos de INAC sobre consumo per cápita presentados en el Cuadro 4. A nivel global, el consumo carne creció a un 4,4\% acumulativo anual durante el período considerado.

En 2005, el consumo de carne bovina representó $62,2 \%$ de un total 76,5 kilos consumidos anualmente. La carne aviar se ubicó en el segundo lugar con $20,4 \%$ del consumo total de carnes; el consumo de carne porcina explicó $11,5 \%$ del consumo total y el de ovina 5,9\%. En 2011, el consumo total de carnes alcanzó $94,7 \mathrm{~kg} / \mathrm{hab}$, donde el $64 \%$ correspondió a la carne bovina, 20,6\% a carne aviar, $11,1 \%$ a carne porcina y $4,3 \%$ a carne ovina.

A partir de los datos anteriores, es fácil advertir la importancia que tiene este rubro de alimentación en la economía de los hogares uruguayos. Si bien el consumo de carnes está influenciado por los hábitos, costumbres y preferencias de los consumidores, el poder adquisitivo de la población y el precio son los factores que más inciden a la hora de efectuar la acción de compra. Según Caputti (2011) el aumento verificado en el último quinquenio se explicaría por un aumento similar del salario real, confirmando la relación entre el poder adquisitivo y el consumo de carne.

Específicamente con respecto a la carne bovina, a partir de 2008 el mercado interno se consolidó como principal destino de las carnes producidas en el país, en donde se volcó una cifra que oscila entre 170 y 190 mil toneladas peso canal sin afectar las colocaciones en el exterior (INAC, 2012). Hoy en día, un $80 \%$ del abastecimiento del mercado doméstico proviene de empresas que también exportan, siendo el restante $20 \%$ de empresas que solo atienden el mercado interno (Caputti, 2011).

Analizando las preferencias de los consumidores de los cortes cárnicos vacunos, del 2005 a esta parte, Costas (2011) observó un aumento de demanda hacia cortes con mayor rendimiento, y por lo tanto, de mayor valor. Mientras en 2005, la carne picada y la nalga sin hueso ocupaban el tercer y quinto lugar del ranking de los cortes más demandados por los consumidores de Montevideo, en 2010 se posicionan como los dos principales cortes adquiridos por los consumidores uruguayos. Según este autor, el asado de tira pasó del segundo al cuarto lugar del ranking de preferencias, en el mismo período.

Como se aprecia en la Figura 4 los cortes con hueso aun muestran una importante preponderancia en el mercado interno frente a los sin hueso. No obstante, los primeros han mostrado una lenta pero constante disminución en años recientes. Mientras que en 2007 y 2008 la proporción era de alrededor de 73:25, la misma cayó a 60:40 en 2013.

INAC (2012) analizó las variaciones acumuladas en los precios corrientes de los cortes de carne bovina, entre diciembre de 2010 y diciembre de 2011 . El estudio constató que los cortes del delantero se incrementaron $19,1 \%$, mientras que los cortes del trasero se incrementaron sólo 10,1\% en el período estudiado. Dentro de los cortes del delantero, la falda se incrementó $23,9 \%$, la aguja $19,8 \%$, la paleta con hueso

Cuadro 4. Evolución del consumo per cápita de carnes en Uruguay, 2005-2011.

\begin{tabular}{|l|c|r|r|r|r|r|r|}
\hline Kg/hab/año & $\mathbf{2 0 0 5} 200 \mathbf{6}$ & $\mathbf{2 0 0 7}$ & $\mathbf{2 0 0 8}$ & $\mathbf{2 0 0}$ & $\mathbf{9}$ & $\mathbf{2 0 1 0}$ & $\mathbf{2 0 1 1}$ \\
\hline Carne Bovina & 47,6 & 51,2 & 51,0 & 54,7 & 58,2 & 61,2 & 60,6 \\
Carne Ovina & 4,5 & 6,2 & 6,2 & 5,7 & 5,8 & 4,5 & 4,1 \\
Carne Porcina & 8,8 & 9,0 & 9,6 & 8,6 & 8,6 & 9,7 & 10,5 \\
Carne Aviar & 15,6 & 17,7 & 14,7 & 17,0 & 19,0 & 19,0 & 19,5 \\
\hline Totales & $\mathbf{7 6 , 5}$ & $\mathbf{8 4 , 1}$ & $\mathbf{8 1 , 5}$ & $\mathbf{8 6 , 0}$ & $\mathbf{9 1 , 6}$ & $\mathbf{9 4 , 4}$ & $\mathbf{9 4 , 7}$ \\
\hline
\end{tabular}

Fuente: INAC (2012). 


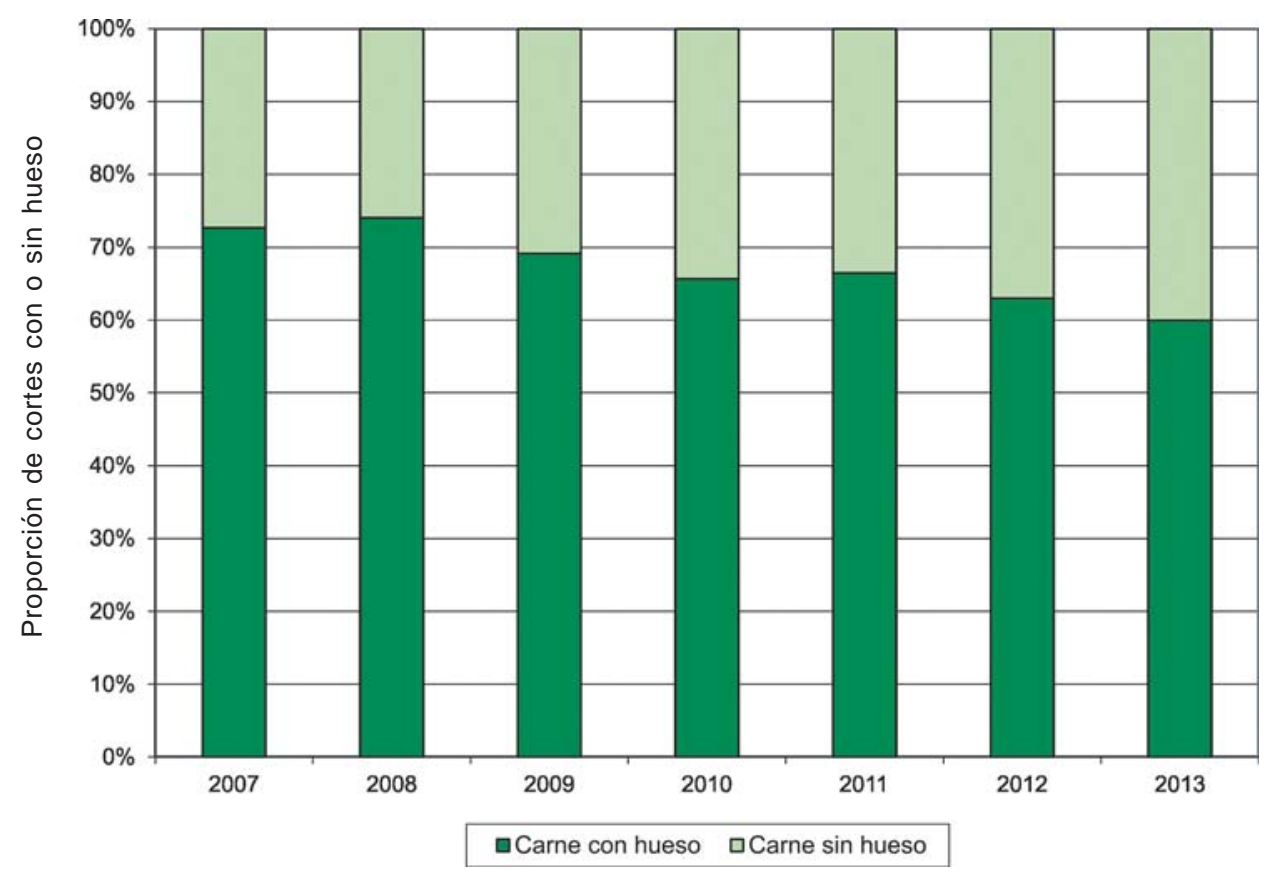

Gráfica 4. Composición de la expedición de carne bovina en el mercado interno, (2007-2013). Fuente: Elaborado sobre la base de datos del INAC.

$17,7 \%$ y el asado $17,2 \%$. A pesar de este incremento en los precios, principalmente en la carne bovina, en los últimos años se registra un acortamiento de la brecha de consumo de carnes entre la zona de mayor poder adquisitivo y la más baja, en el año 2005 esa diferencia ascendía a $22 \mathrm{~kg} / \mathrm{hab} / \mathrm{año}$, mientras que en 2010 se redujo a 16 kg/hab/ año (INAC, 2012).

Un cambio a destacar especialmente de estos últimos años es el ocurrido con el consumo de carne porcina. Tradicionalmente consumida a través de embutidos y chacinados, el consumo de carne fresca fue casi marginal hasta mediados de la primera década de este siglo. En ese sentido, Echenique y Capra (2006) destacaron que tras la caída del consumo cárnico global derivada de la crisis de 2001 se observó un crecimiento diferencial según especie, donde la tasa de recuperación del consumo de la carne de cerdo superó claramente a la observada en la carne vacuna. El consumo de carne de cerdo no solo logró recuperarse en relación a lo registrado en 2000 sino que en 2005 lo superó un $10 \%$.

Errea, Ruíz y Souto (2013) explicaron que casi la totalidad de la producción nacional se destina al mercado interno con dos posibles destinos: el consumo directo de carne (pulpas) y la industria elaboradora de productos porcinos (chacinados y otros). Históricamente, este último destino constituyó más del $90 \%$ de la carne volcada al mercado interno. Con un consumo total de $9 \mathrm{~kg} / \mathrm{hab} /$ año el consumo anual de carne fresca se ubicó históricamente en el orden del medio kilogramo por persona. Para el período 20002007, INAC estimó ese valor en menos de un kilo anual en Montevideo.

En los últimos años (2006-2012) tanto la carne de cerdo como los productos de chacinería se abarataron en términos absolutos de manera significativa. Este abaratamiento también fue relativo frente a las demás carnes, particularmente la vacuna. Como señalaron Errea, Ruíz y Souto (2013), esta última incrementó su precio en moneda constante un $12 \%$ en el caso de la nalga y un $8 \%$ en el caso de la aguja, mientras que las costillas de cerdo bajaron $9 \%$, todo durante el mismo período. La evolución de la carne aviar fue muy similar a la de la carne porcina, con una caída de $6 \%$ en el período analizado.

Estos autores señalaron el importante crecimiento de la demanda de carne fresca, 
abastecida tanto por la materia prima nacional como importada. Este nuevo comportamiento de la demanda vendría de la mano de una mejor calidad en la oferta y de precios competitivos con la carne vacuna. Advirtieron que en los últimos años se acentuó la venta de cortes de carne porcina de origen importado, fundamentalmente en supermercados pero también en carnicerías y pequeños almacenes. No obstante, el incremento de la importación no se ha producido en desmedro de la oferta de producción doméstica, la cual no cubre más de la mitad de la demanda actual. En base a todos estos elementos, Errea, Ruíz y Souto (2013) estimaron el consumo actual de carne fresca entre 4 y 4,5 kg/hab/año.

\subsubsection{Consumo de pescado y frutos del mar}

Finalmente, son escasas las referencias al consumo de pescado y frutos del mar en el mercado doméstico y los existentes se enfocan básicamente a Montevideo (Mazza, 2007; López Ríos, 2007). Según se explica en estos trabajos, la comercialización de los productos pesqueros en este departamento se fue desarrollando a lo largo de los años, en forma lenta, y sin una organización demasiado planificada. Cita como antecedente el intento de organización del sector pesquero por parte del estado, a través del ex-Servicio Oceanográfico y de Pesca (SOYP), que con la creación del terminal pesquero de 1972, por la Industria Lobera y Pesquera del Estado (ILPE), incorporó una flotilla de puestos móviles a efectos de llevar a cabo un programa de distribución y venta de pescado, mariscos y otros.

A pesar de que el programa perdió continuidad a lo largo del tiempo muchos de los puestos que hoy se instalan en las ferias vecinales son ex concesionarios de SOYP. ILPE. A mediados de los 90, los principales acopiadores de productos pesqueros cambiaron sus cámaras alquiladas o propias por plantas pesqueras, con habilitaciones para el mercado interno y, en algunos casos, también para la exportación (Mazza, 2007).

Este mismo autor comparó los niveles de consumo de productos pesqueros de los montevideanos de su estudio realizado en
2006 con los de la Dirección Nacional de Recursos Acuáticos (RENARA) para 1984 y 1986 y de INFOPESCA para 1996. Sobre la base de peso vivo o pescado entero, verificó un incremento de algo más de $12 \%$ en el consumo per cápita en 2006 respecto a los valores de 1984 y de casi $50 \%$ respecto a 1986.

Para el año 2006, Mazza (2007) estimó un consumo total de 14.195 toneladas, cifra equivalente a un consumo medio anual de 10,47 kilos por habitante, con variaciones desde un mínimo de 4,5 kilos en los barrios de menor poder adquisitivo hasta un máximo que superó los 17 kilos en las zonas de mayores ingresos. A su vez, López Ríos (2007) estimó el consumo para 2007 en 12,6 kilos por habitante, lo cual representa un incremento de $35 \%$ respecto a 1984 y $80 \%$ respecto a 1986 .

La Figura 5 muestra la evolución en el consumo de pescado entre 1984 y 2007 en base a los datos anteriores, donde se aprecia el crecimiento del consumo de estos productos por parte de la población de Montevideo. Si bien los capitalinos consumen más pescado que el promedio de los uruguayos, el consumo de diez kilos y medio al año es bajo comparado al consumo de otras carnes. Mazza (2007) calculó el valor de este consumo anual en algo menos de 30 millones de dólares, con un precio promedio al público de US\$2 por kilo base pescado entero. Según este autor, el importante incremento en el consumo de productos ictícolas en los últimos dos años se debió a la creciente oferta de productos frescos y congelados, a la aparición de platos preparados de origen nacional e importado y a la inclusión de la carne de pescado en las dieta de los uruguayos por recomendación de los doctores en medicina, que han realzado las propiedades de esta carne en materia de salud.

Actualmente, la proporción de consumo entre productos industrializados y frescos es aproximadamente 53:47, con una tendencia creciente en el consumo de pescado industrializado. Mazza (2007) señaló que en 2006 se vendieron en Montevideo 2.700 toneladas (base pescado entero) de productos congelados nacionales, por un valor de US\$ 5,4 millones. No obstante, dicho aumento no 


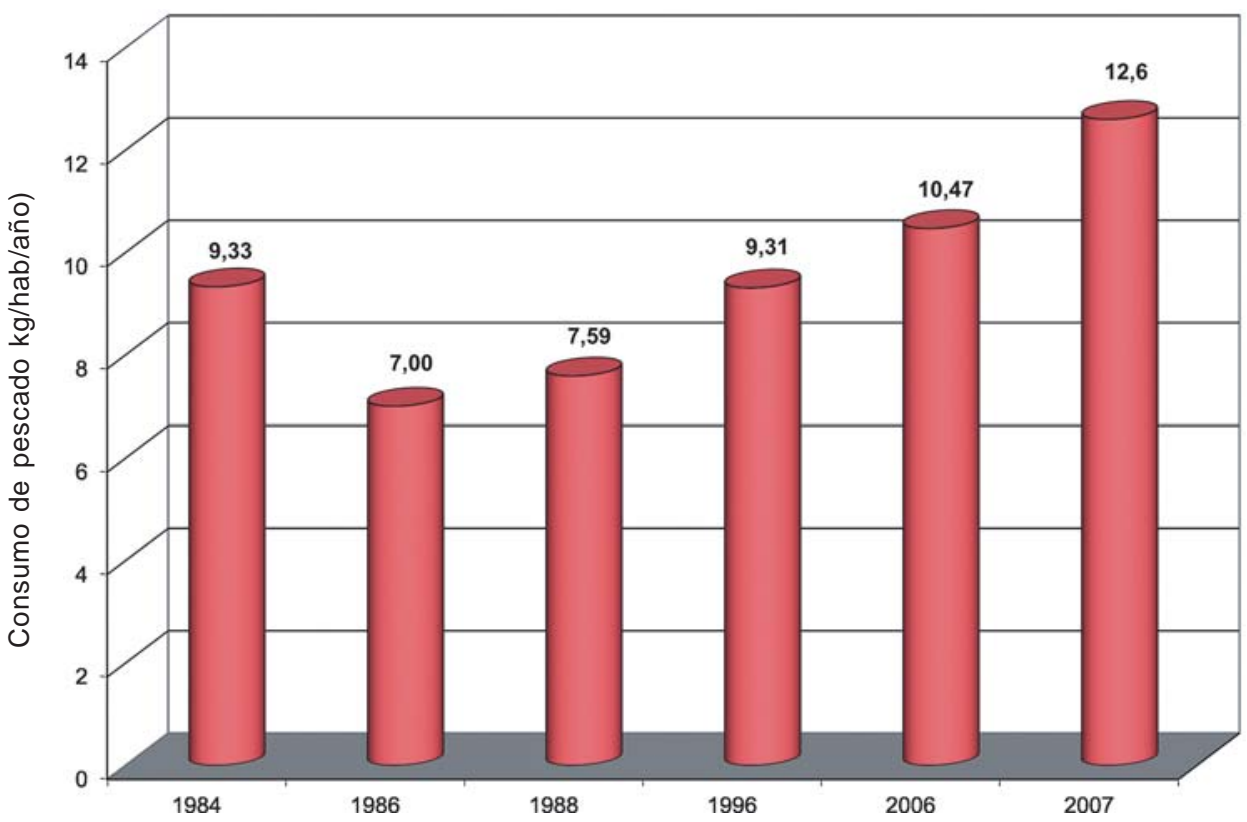

Figura 5. Evolución del consumo interno de productos pesqueros en Montevideo, (1984-2007). Fuente: Elaborado sobre la base de datos de Mazza (2007) y López Ríos (2007).

parece haber afectado el volumen de consumo de pescado fresco. A su vez, el $34 \%$ del pescado consumido en Montevideo es importado en forma de conservas, en su mayor parte de los países de la región. En 2006, el valor de estos productos importados fue de poco más de US\$12 millones.

La merluza (Merluccius hubbsi) ha sido, desde el comienzo del desarrollo pesquero en el país, la especie de mayor consumo. En el mercado interno, es consumida en un $90 \%$ en forma de filetes frescos sin piel y poca espina. La corvina (Micropogonias furnieri) ocupa el segundo lugar dentro del gusto de los consumidores de Montevideo. Se comercializa mayoritariamente entera, preparada en cortes para el horno o, eventualmente, el feriante prepara dos lomos de cada corvina. La pescadilla (Cynosciun guatucupa) ocupa el tercer lugar en importancia dentro del mercado local. Se comercializa en forma de filetes frescos y congelados, sin piel y poca espina. El lenguado (Paralichtys spp) es consumido por un público con buen poder adquisitivo. No tiene mucha relevancia en ferias, pescaderías y puestos costeros debido a su alto precio pero sí en supermercados, donde se vende en fresco, entero o en filetes, o congelado, donde también se presenta en forma de empanado. Los restaurantes también lo compran en buen volumen ya que en su mayoría lo adquieren de las valijas, a un precio menor.

Otras especies comercializadas en el mercado interno, aunque en porcentajes poco significativos, son los túnidos y el pez espada. Las especies más comunes son el bonito (Sarda sarda), la albacora (Thunnus alalunga), la aleta amarilla (Thunnus albacares), el ojo grande (Thunnus obesus) y el pez espada (Xiphias gladius). Algunas de estas especies pueden ser encontradas en ferias capitalinas y supermercados pero en volúmenes muy pequeños y en la modalidad de rodajas.

\subsection{Los factores determinantes del consumo}

La teoría económica postula varios factores que afectan el consumo de bienes y servicios. A nivel individual, los precios y el ingreso disponible, conjuntamente con sus preferencias y gustos particulares, determinan el consumo de cada persona. Cuando la restricción presupuestal impuesta por el nivel de ingresos del individuo o de la familia es severa, el precio de los productos es el fac- 
tor preponderante al tomar decisiones de consumo. En cambio, cuando esta es menos limitante, otros factores como los culturales, sicológicos o de cualquier otra índole, adquieren cada vez mayor peso (Lanfranco, 2003a).

En lo que en la jerga económica se conoce como ley de Engel, el gasto en alimentos representa un porcentaje mayor del gasto total en los hogares más pobres que en los hogares con ingresos más altos. A medida que mejoran los ingresos en una sociedad, la gente incrementa el gasto en alimentos aunque en forma decreciente. Este gasto representa una fracción cada vez menor del ingreso familiar. La elasticidad ingreso, término con el que se define a la respuesta en la demanda frente a cambios en los ingresos, está en relación directa con el nivel inicial de dichos ingresos y el nivel inicial de consumo del producto en cuestión. Partiendo de niveles bajos de ingresos y de consumo, cualquier aumento en el nivel de ingresos origina una reacción muy rápida sobre la demanda de un bien. A medida que el nivel de consumo es mayor, la respuesta a subsecuentes cambios en el ingreso va disminuyendo.

Este fenómeno ha sido largamente verificado en la práctica. En promedio, el incremento del consumo per cápita de productos pecuarios ha sido sustancialmente menor en los países desarrollados que en las regiones en desarrollo. No obstante, el nivel de consumo en dichas regiones sigue siendo considerablemente inferior al del mundo desarrollado, por más que en algunos países en rápido desarrollo esta brecha se está reduciendo (FAO, 2009). Las proyecciones a futuro se realizan sobre un escenario en que el aumento de los ingresos generará una demanda adicional de productos pecuarios mucho mayor en los países de ingresos bajos que en los de ingresos medios y altos.

La demanda de alimentos es particularmente alta en países con ingreso bajo pero creciente, ya que una mayor proporción del ingreso adicional es dirigido a mejorar las dietas. Esto explicaría que los países en desarrollo hayan sido entonces los impulsores de su crecimiento en la última década, «debido principalmente a los importantes incrementos en sus ingresos, que se trasladarían al gasto en mejores alimentos» (Puricelli, 2011). Esto sucede no solamente cuando se comparan niveles de ingresos de la población entre diferentes países (en desarrollo frente a desarrollados, por ejemplo) sino también entre segmentos de población dentro de un mismo país, incluso de los más desarrollados, como es el caso de los distintos patrones de consumo verificados entre diferentes grupos étnicos en los Estados Unidos (EE.UU.) (Lanfranco, 1999).

Según FAO (2009), la demanda creciente de proteínas de origen animal a expensas de los alimentos de origen vegetal en diversos países en desarrollo ha estado motivada por el crecimiento económico, el aumento de los ingresos per cápita y la urbanización. Desde comienzos de la década de 1960, el consumo per cápita de carne en los países en desarrollo se multiplicó por más de tres. Por ejemplo, el consumo per cápita de carne en China se ha cuadruplicado desde 1980, en tanto que en Brasil se multiplicó casi por dos (FAO, 2009).

En los países desarrollados, donde la demanda se encuentra muy saturada, la desaceleración del crecimiento de los ingresos y la población, el envejecimiento y la recurrencia de crisis alimentarias (E. coli y salmonella, gripe aviar, fiebre porcina, vaca loca) se han combinado para reducir la demanda de carnes en estos mercados. Se espera que el crecimiento en la demanda en los próximos años continúe liderado por las economías más grandes de Asia, América Latina y los países exportadores de petróleo (OECD-FAO, 2012).

Otra particularidad de la elasticidad ingreso es que su magnitud no es la misma para todos los productos. Los Ilamados bienes necesarios, entre los que se incluyen genéricamente los alimentos, exhiben una respuesta menos que proporcional a los cambios en el ingreso. A modo de ejemplo, ante un aumento de $10 \%$ en los ingresos, se espera que el incremento en el consumo de un bien necesario sea inferior a $10 \%$ y viceversa. Lo contrario sucede con los llamados bienes de lujo, donde la respuesta a un de- 
terminado cambio es más que proporcional ${ }^{14}$. Aunque tomados en forma genérica los alimentos constituyen bienes necesarios, algunos son más necesarios que otros pudiendo incluso existir productos alimenticios específicos que pueden catalogarse como de lujo, en función de su respuesta al cambio en los ingresos.

Esto tiene que ver con la calidad del producto, su disponibilidad o escasez, lo cual juega un importante papel en su precio, otro factor esencial en la determinación de la demanda. La elasticidad precio directa mide la respuesta en la demanda de un bien por efecto de un cambio en su precio. En términos generales, a medida que el precio de un producto aumenta, su demanda tiende a disminuir en mayor o menor proporción. Lo opuesto ocurre en caso de una caída en el precio, la que deriva en un aumento de la demanda ${ }^{15}$. La dirección del cambio en la demanda respecto al precio está dada por el signo de la elasticidad directa; la proporción en que ello ocurre se expresa a través la magnitud.

La proteína de origen animal es más cara que la de origen vegetal y dentro de la primera, la proveniente de rumiantes lo es más que la de monogástricos. Puricelli (2011) remarcó que el mayor incremento del consumo de la carne aviar y porcina se dio principalmente en los países en desarrollo, siendo menor en los desarrollados. Do todas formas, el consumo de la carne bovina también se incrementó de manera importante en los primeros.

Al ser la de mayor precio comparado al resto de las carnes analizadas, la bovina, habría exhibido una dinámica particular, con claras diferencias entre los mercados en desarrollo y desarrollados.

Otro elemento importante a considerar cuando se analiza la evolución del consumo de un determinado producto es la posibilidad que sea sustituido por productos alternativos. En el corto plazo, esto puede no ser muy relevante. Los mismos factores apuntados anteriormente (aspectos culturales, gus- tos y preferencias, disponibilidad del nuevo producto) pueden hacer difícil una sustitución inmediata pero en lapsos mayores puede ser muy importante.

Con referencia a las carnes, ha sido notoria la competencia sufrida por la bovina a manos de otras carnes a través de las últimas décadas. En el caso de las carnes rojas los principales competidores son la carne de cerdo, la carne de pollo y, compitiendo con estos cada vez más firme, la carne de pescado. El factor decisivo en las posibilidades de sustitución o aun de complementariedad entre productos es el precio. En las últimas décadas, la relación de precios entre carne vacuna y ovina por un lado frente a las de aves y cerdo por otro se ha ampliado a nivel mundial (Figura 6). Esto contribuyó a aumentar la demanda de estas dos últimas. Los cambios observados en la demanda de un producto como respuesta a cambios en los precios de productos alternativos se miden a través de la elasticidad precio cruzada ${ }^{16}$.

En el Reino Unido la producción intensiva de carne de ave y de cerdo estableció nuevos modelos de consumo al permitir a los consumidores sustituir carne bovina por estas otras dos a un menor precio (Corcoran, Bernués y Baines, 2000). Esto ha sido también evidente en EE.UU., donde el consumo anual per cápita de carne bovina cayó de cerca de 40 kilos a mediados de los 70 a poco más de 25 kilos a comienzos de la década actual (Figura 7).

La evolución en los patrones de consumo de carnes en EE.UU. constituye un buen ejemplo de lo ocurrido en la mayoría de los países desarrollados. Si bien la demanda ha venido creciendo en las últimas décadas, se ha venido observando una importante sustitución de la carne bovina fundamentalmente por carne de ave. El consumo de ésta última pasó de algo más de 15 kilos en 1965 hasta prácticamente 40 kilos por año sobre la segunda mitad de la década pasada. No obstante, en los últimos años, el consumo de

\footnotetext{
${ }^{14}$ En este caso, se dice que la elasticidad ingreso es menor a uno $(\eta<1)$. Si la ley de Engel se cumple para un producto, le elasticidad ingreso tiene que ser menor a la unidad. En contrario sensu, para los bienes de lujo, la elasticidad ingreso es mayor a uno $(\eta>1)$.

${ }^{15}$ En este caso la elasticidad precio directa es de signo negativo $(\varepsilon<0)$ y se dice que es un bien ordinario.

${ }^{16} \mathrm{Si}$ la demanda de un bien se incrementa en respuesta a un aumento en el precio de otro bien (y viceversa), se dice que el primero es sustituto de este último.
} 


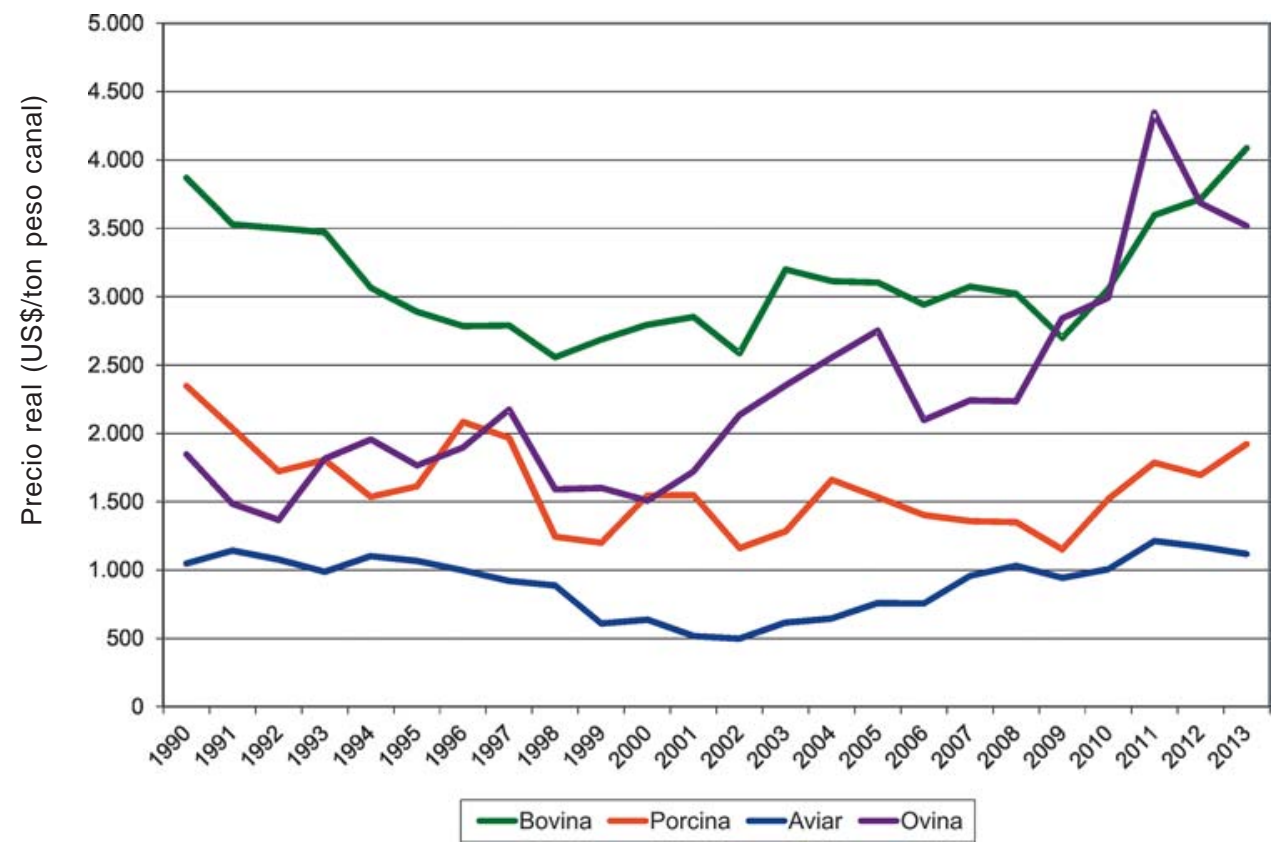

Figura 6. Precios mundiales para la carne bovina, porcina, ovina y aviar (1990-2013).

Nota: precio novillo calidad «USDA Choice» entre 500 y 550 kilos de peso canal, Nebraska; precio promedio grilla cordero todas las calidades, Nueva Zelandia; cerdos y cerdas jóvenes, №1-3, entre 105 y 115 kilos de peso canal, lowa/Sur de Minnesota; precio promedio al productor de pollo, listo para cocinar, Brasil. Fuente: Elaborado en base a OECD-FAO (2012).

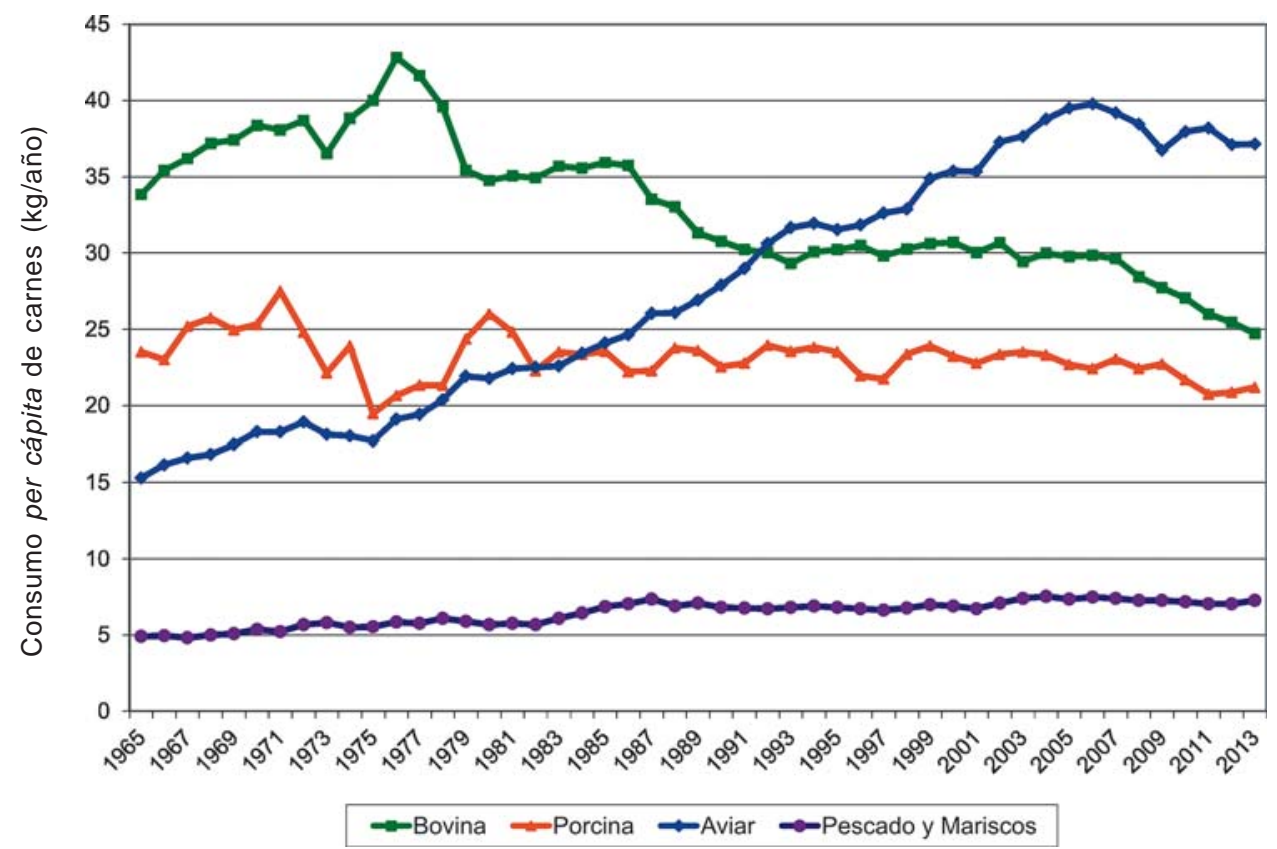

Figura 7. Evolución del consumo per cápita de carnes en los Estados Unidos (1965-2013). Fuente: Elaborado sobre la base de datos del USDA. 
carne aviar también parece haber entrado en una fase de lenta disminución, ubicándose en los últimos dos años en el entorno de los 37 kilos por persona y por año. El consumo total cayó de 100 a 90 kilos.

Además del ingreso y los precios, los factores culturales, incluyendo los demográficos y, dentro de ellos, la urbanización, han tenido un importante efecto en el cambio de las tendencias del consumo de productos pecuarios (FAO, 2009). La urbanización altera los hábitos de consumo alimentario, influyendo en la demanda de productos cárnicos. La población urbana suele comer más a menudo fuera de casa y mayores cantidades de alimentos precocinados, de rápida preparación y conveniencia, que la población en zonas rurales. Por lo tanto, la urbanización influye en la posición y la forma de las funciones de consumo de los productos alimenticios.

Los factores sociales y culturales y la disponibilidad de recursos naturales también muestran un efecto importante sobre las preferencias de los consumidores. Agregan un elemento más que hace que las carnes elegidas por distintos consumidores pueden ser marcadamente diferentes. Según OECD-FAO (2012), por ejemplo, Brasil y Tailandia exhiben similares niveles de ingresos per cápita y de urbanización pero el consumo de productos pecuarios es prácticamente el doble en el primero país que en el segundo.

Según el mismo informe, el $90 \%$ de la carne que los consumidores de los países desarrollados llevan a su canasta proviene de las aves de corral. Una excepción parece ser la de los consumidores en Europa Oriental $^{17}$, donde las carnes rojas aun tienen un espacio adicional para el crecimiento. En cambio, la composición promedio de la canasta de los consumidores de los países en desarrollo, en lo que a consumo de carnes se refiere, es más heterogénea: $62 \%$ aviar, $19 \%$ porcina, $13 \%$ vacuna y $6 \%$ ovina, con importantes variaciones de una región a otra en función de las tradiciones locales.

Haley (2001) ya había señalado que los cambios ocurridos en la estructura de preferencias de los consumidores en las últimas décadas del siglo $X X$ comenzaron a otorgar un peso importante a las cuestiones de salud, junto a otros aspectos como la disminución de la relación de precios entre la carne aviar y la carne bovina y la tendencia natural de los consumidores a escoger mayores cantidades de aquellos productos que exhiben un menor precio. Este autor destacó que algunos cambios en el modo de vida de la población, como la mayor participación de la mujer en el mercado laboral, fueron muy bien explotados por la industria avícola a través de una mayor variedad y presentación de productos dirigida a facilitar y agilitar la preparación de alimentos en el hogar.

Como señaló de Mattos (2000) la industria del pollo realizó importantes innovaciones en el desarrollo del concepto de «conveniencia», impulsando soluciones para que «el ama de casa pueda usar el microondas y en 15 minutos hacer una comida», un terreno en que la industria de la carne vacuna había hecho un muy escaso aporte por entonces. El marketing jugó un papel relevante. En el caso del pollo las campañas publicitarias destinadas a su promoción procuraron destacar características importantes para los consumidores, por ejemplo, el bajo contenido de colesterol y su menor precio frente a la carne bovina. Eso, junto a la aparición de nuevos y variados productos, asegurando la homogeneidad de los mismos y la estabilidad en el abastecimiento a lo largo del tiempo, también contribuyó a imponer esta carne frente a las de las otras especies.

Todas las innovaciones dirigidas a centrar las estrategias de producción en aquellos factores que resultan sensibles a los consumidores se han ido incorporando también a las restantes carnes. A modo de ejemplo, la industria cárnica bovina de EE.UU. ha venido realizando un claro esfuerzo por revertir esta situación y ponerse más a tono con los cambios ocurridos en el estilo de vida de la población. Haley (2001) consignó que la oferta de carne vacuna en ese país ha venido orientándose hacia características que hoy son más apreciadas por los consumidores, como ser carnes más tiernas y magras, productos de rápida preparación, etc.

\footnotetext{
${ }^{17}$ El informe OECD-FAO (2012) considera a todos los países de esta parte de Europa como desarrollados.
} 
Como una forma de competir con las otras carnes, los agentes vinculados a la cadena cárnica vacuna iniciaron una fuerte promoción, tratando de resaltar las ventajas que se relacionan con la salud humana, como ser el hecho de ser la principal fuente de proteínas de alto valor biológico, de hierro y de zinc, tener un bajo contenido de grasa intramuscular, un no muy alto contenido en colesterol, bajo contenido en sodio, etc. Sin embargo, los trabajos que han cuestionado las campañas contra la carne vacuna, demostrando las bondades de la carne vacuna producida «a pasto», incluso frente a productos como la carne de aves (Realini y otros, 2003), aún son recientes y no han recibido un destaque suficiente como para tener un impacto frente a los consumidores de carnes.

Los problemas sanitarios ocurridos en la última década, no solo ya con la carne vacuna sino también con las otras han alimentado la desconfianza en muchos consumidores, afectando a los mercados cárnicos en general. Esto supone un desafío para un sector llamado a jugar un papel importante en la promoción del crecimiento y la reducción global de la pobreza.

\subsection{Análisis empírico de la demanda por carnes}

\subsubsection{Estimaciones de demanda en la literatura internacional}

Las estimaciones de elasticidades precio e ingreso o gasto para productos cárnicos que aparecen en la literatura varían considerablemente entre estudios. La diversidad de modelos, métodos econométricos y bases de datos utilizados dificultan la comparación de los resultados, no sólo entre ellos sino también con los obtenidos en esta investigación. La mayoría de los estudios publicados han empleado modelos de ecuaciones independientes. Algunos utilizan series de tiempo mientras que otros utilizan datos transversales provenientes de encuestas a nivel de hogares. En la mayoría de los casos, sólo se considera carne como categoría general o se desagrega por especie: vacuna, cerdo, aves y ocasionalmente pescado y carne ovina.
El Cuadro 5 resume resultados de algunos estudios de demanda por carnes seleccionados que han estimado elasticidades ingreso o gasto $(\eta)$ y elasticidades precio directas $(\varepsilon)$ para estas categorías genéricas. La literatura es vasta y esta lista no pretende ser exhaustiva de manera alguna. Simplemente refiere a estudios llevados a cabo en diferentes períodos de tiempo y en diversos países, exceptuando al Uruguay. Estos trabajos han utilizado diferentes enfoques teóricos y empíricos para estimar elasticidades de demanda. Aunque algunos estimaron también elasticidades precio cruzadas, aquí se presenta solamente elasticidades directas derivadas de ecuaciones de demanda no compensadas (marshallianas).

A este nivel de desagregación, todos los estudios coinciden que los distintos tipos de carne son bienes normales y necesarios ( 0 $<\eta>1$ ) pero con algunas excepciones. La carne con mayor respuesta a cambios en el ingreso es la bovina, siendo reportada como un bien de lujo en varias ocasiones $(\eta>1)$. Los valores de $\eta$ computados varían entre 0,07 y 2,49 , dependiendo del período de estudio, el país y el nivel de ingreso de los hogares. En general, la carne aviar y la carne porcina reportan $\eta$ inferiores a la unidad; en algunos trabajos, las magnitudes son mayores para la primera que para la segunda. En los trabajos restantes, la de ave resultó ser la menos inelástica (menor magnitud) de entre las carnes. Sin embargo, los valores de $\eta$ variaron en un amplio espectro, desde $-0,19$ a 1,5 para cerdo y desde 0,09 a 1,65 para aves. Cuando fueron computadas, las $\eta$ estimadas para carne de pescado $(0,15$ a 1,60$)$ se ubicaron consistentemente entre las otras dos.

Con respecto a la elasticidad precio, los estudios referidos mostraron que todos los productos cárnicos se comportaron como bienes ordinarios $(\varepsilon<0)$ para el nivel de desagregación considerado. Con alguna excepción, todos los trabajos mostraron que la respuesta de la demanda a los cambios de precios fue relativamente inelástica 0 , como mucho, con elasticidad igual a la unidad $(|\varepsilon|$ $\leq 1)$. Dejando de lado dichas excepciones, los valores de $\varepsilon$ para carne vacuna se ubicaron en un rango entre $-0,37$ y $-1,02$. En el caso de la carne de cerdo, los valores estu- 
Cuadro 5. Estimaciones de elasticidades de demanda de carnes (trabajos internacionales seleccionados).

\begin{tabular}{|c|c|c|c|c|c|c|c|c|c|}
\hline \multirow{3}{*}{ Autores } & \multirow{3}{*}{$\begin{array}{l}\text { Lugar y } \\
\text { período de } \\
\text { estudio }\end{array}$} & \multicolumn{8}{|c|}{ Elasticidad ingreso/gasto $(\eta)$ y precio directa $(\varepsilon)$} \\
\hline & & \multicolumn{2}{|c|}{ Bovina/ovina } & \multicolumn{2}{|c|}{ Porcina } & \multicolumn{2}{|c|}{ Aviar } & \multicolumn{2}{|c|}{ Pescado } \\
\hline & & $\eta$ & $\varepsilon$ & $\eta$ & $\varepsilon$ & $\eta$ & $\varepsilon$ & $\eta$ & $\varepsilon$ \\
\hline George y King (1971) & E.U. posguerra & 1,27 & $-0,96$ & 0,33 & $-0,51$ & 0,33 & $-0,78$ & - & - \\
\hline Eales y Unnevehr (1988) & EE.UU. 1965-85 & 0,34 & $-0,57$ & 0,28 & $-0,76$ & 0,53 & $-0,28$ & - & - \\
\hline $\begin{array}{l}\text { Hayes, Whal y Williams } \\
\text { (1990) }\end{array}$ & Japón 1965-86 & 2,49 & $-0,46$ & 0,53 & $-0,76$ & 0,21 & $-0,59$ & 0,15 & $-0,70$ \\
\hline \multirow{2}{*}{ Moschini y Meilke (1989) } & EE.UU. 1967-83 & 1,22 & $-0,98$ & 1,04 & $-1,02$ & 0,24 & $-0,09$ & 0,43 & $-0,14$ \\
\hline & EE.UU. 1971-87 & 1,39 & $-1,05$ & 0,85 & $-0,84$ & 0,21 & $-0,10$ & 0,31 & $-0,20$ \\
\hline $\begin{array}{l}\text { Chalfant, Gray y White } \\
\text { (1991) }\end{array}$ & Canadá 1960-88 & - & $-0,95 /-0,96$ & - & $-0,72 /-0,73$ & - & $-0,89 /-0,93$ & - & $-0,12 /-0,55$ \\
\hline Park y otros (1996) & EE.UU. 1987-88 & $0,48 / 0,62$ & $-0,44 /-0,45$ & $0,49 / 0,61$ & $-0,44 /-0,49$ & $0,36 / 0,61$ & $-0,22 /-0,35$ & $0,47 / 0,74$ & $-0,58 /-0,61$ \\
\hline Cortez y Senauer (1996) & EE.UU. 1980-90 & $0,65 / 1,80$ & - & $0,50 / 1,50$ & - & $0,50 / 1,50$ & - & $0,60 / 1,60$ & - \\
\hline Huang (1996) & EE.UU. 1953-90 & 0,39 & $-0,62$ & 0,66 & $-0,73$ & 0,08 & $-0,37$ & 0,43 & - \\
\hline $\begin{array}{l}\text { Golan, Perloff y Shen } \\
\text { (2001) }\end{array}$ & México 1992 & 1,31 & $-0,60$ & 1,15 & $-0,42$ & 0,75 & $-0,40$ & 1,25 & $-2,09$ \\
\hline Fraser y Moosa (2002) & $\begin{array}{l}\text { Reino Unido } \\
1960-1994\end{array}$ & - & $-0,96 /-1,32$ & - & $-0,54 /-0,85$ & - & $-0,57 /-0,85$ & - & - \\
\hline $\begin{array}{l}\text { Dong, Gould y Kaiser } \\
\text { (2004) }\end{array}$ & México 1998 & 1,31 & $-0,63$ & 1,17 & $-0,13$ & 1,17 & $-0,83$ & 1,16 & $-0,63$ \\
\hline \multirow{2}{*}{ Thompson (2004) } & Japón 1981-2000 & 0,36 & $-1,28$ & 0,06 & $-0,91$ & 0,05 & $-0,73$ & - & - \\
\hline & Japón, 2000 & 0,34 & $-1,19$ & 0,05 & $-0,92$ & 0,04 & $-0,71$ & - & - \\
\hline Mazzocchi (2006) & $\begin{array}{l}\text { EE.UU. } \\
\text { 1982-1999 }\end{array}$ & $1,05 / 1,22$ & $-0,81 /-1,03$ & $0,55 / 1,05$ & $-0,65 /-0,82$ & $0,66 / 1,18$ & $-0,48 /-0,84$ & - & - \\
\hline Yen y Lin (2006) & China, 2000 & 0,77 & $-0,33$ & 0,85 & $-0,28$ & 1,08 & $-0,51$ & 1,16 & $-0,53$ \\
\hline \multirow{3}{*}{ Lema y otros (2006) } & $\begin{array}{l}\text { Argentina } \\
\text { 1996-97 }\end{array}$ & $0,21 / 0,22$ & $-0,36 /-0,37$ & - & - & 0,15 & $-0,09$ & - & - \\
\hline & $\begin{array}{l}\text { Paraguay } \\
2000-01\end{array}$ & $0,03 / 0,25$ & $-0,003 /-0,44$ & - & - & 0,11 & - & - & - \\
\hline & $\begin{array}{c}\text { Bolivia } \\
2003-2004\end{array}$ & $0,14 / 0,24$ & $-3,35 /-5,29$ & - & - & 0,12 & $-2,76$ & & \\
\hline Hupkova y Bielik (2009) & $\begin{array}{l}\text { Eslovaquia } \\
1993-2007\end{array}$ & 0,91 & $-0,47$ & 0,23 & $-0,98$ & 1,09 & $-1,00$ & - & - \\
\hline $\begin{array}{l}\text { Alboghdady y Ashary } \\
(2010)\end{array}$ & $\begin{array}{l}\text { Egipto } \\
1990-2005\end{array}$ & 0,75 & $-0,42$ & - & - & 1,65 & $-0,70$ & 1,35 & $-0,79$ \\
\hline $\begin{array}{l}\text { Resende Filho y otros } \\
\text { (2012) }\end{array}$ & $\begin{array}{c}\text { Brasil } \\
1975-2008\end{array}$ & 0,07 & -016 & $-0,19$ & $-0,05$ & 0,11 & $-0,47$ & - & - \\
\hline Motallebi y Pendell (2013) & $\begin{array}{c}\text { Irán } \\
\text { 1982-2007 }\end{array}$ & $1,36 / 1,71$ & $-1,00 /-1,15$ & - & - & $1,40 / 1,48$ & $-1,44 /-1,53$ & $1,07 / 1,30$ & $-1,72$ \\
\hline
\end{tabular}

vieron entre $-0,05$ y $-1,02$, mientras que para carne aviar variaron entre $-0,09$ y $-0,93$. Los trabajos que incluyeron pescado y frutos del mar reportaron valores de entre $-0,12$ y $-0,70$.

Entre los pocos estudios que consideraron una mayor desagregación en los productos cárnicos se destacan cuatro para una breve discusión. Eales y Unneveher (1988) computaron elasticidades $\eta$ para aves enteras $(-0,25)$, carne aviar troceada y procesada $(0,83)$, hamburguesas $(-1,59)$, cortes de vacunos $(1,57)$ y cortes de cerdo $(0,04)$. También reportaron valores de $\varepsilon$ para aves enteras $(-0,68)$, carne aviar troceada y procesada $(-0,61)$, hamburguesas $(-2,59)$, cortes de vacunos $(-0,68)$ y cortes de cerdo $(-0,57)$.
Capps Jr. (1989) estimó valores de elasticidad precio, directa y cruzada, para varios productos cárnicos desagregados a nivel de consumo minorista con datos de escáner. Los valores estimados de elasticidad directa e para productos de carne bovina fueron de 0,15 para carne picada, $-0,72$ para cortes para plancha y $-1,27$ para cortes para olla. Los valores de e directa estimados para carnes de cerdo fueron de $-0,70$ chuletas, $-0,36$ para jamón y -0,83 para lomo. Para carne como producto agregado, el valor de e directa fue 0,66 .

Nayga y Capps Jr. (1994) estimaron elasticidades ingreso y precio para diferentes productos cárnicos. Con referencia a la elasticidad ingreso $(\eta)$ se computaron valores 
para carne vacuna: pecho $(4,51)$, aguja $(1,85)$, carne picada $(0,70)$, bife angosto $(0,79)$, costillas $(1,03)$, nalga y peceto $(1,34)$ y otros cortes vacunos $(0,28)$; carne de cerdo: chuletas $(0,58)$, jamón $(1,31)$, costillar $(1,53)$, peceto $(1,19)$, carré $(0,92)$ y otros cortes de cerdo $(0,82)$; en el caso de carne aviar, se estimaron valores de $\eta$ para pechuga $(0,64)$, muslos y patas $(0,78)$ y otros productos $(0,96)$.

Con referencia a la elasticidad precio $(\varepsilon)$ las magnitudes estimadas por estos autores fueron superiores a la unidad en todos los casos. Para carne bovina: pecho $(-8,70)$, aguja $(-4,17)$, carne picada $(-1,22)$, bife angosto $(-2,40)$, costillas $(-1,57)$, nalga y peceto $(-$ $4,23)$ y otros productos $(-2,90)$; para cerdo incluyeron: chuletas $(-1,72)$, jamón $(-1,84)$, costillar $(-4,01)$, peceto $(-3,55)$, carré $(-2,34)$ y otros productos $(-3,50)$. Para carne aviar, las estimaciones se realizaron para: pechuga $(-1,88)$, muslos y patas $(-2,55)$ y otros cortes de ave $(-2,45)$.

Más reciente en el tiempo, Davis et al. (2007) calcularon elasticidades precio e ingreso a nivel de hogares para una amplia variedad de productos cárnicos. Los correspondientes valores de $\eta$ y $\varepsilon$ reportados fueron respectivamente 1,06 y $-1,07$ para carne picada, 1,25 y -0,67 para cortes para plancha, 1,18 y $-0,86$ para otros cortes vacunos, 1,17 y $-1,09$ para cerdo, 1,1 y $-1,33$ para carne aviar desosada , 1,12 y -1,06 para otros productos de carne aviar, 0,86 y $-0,84$ para otras carnes, 1,09 y -1,10 para camarones, 1,10 y $-1,09$ para otros mariscos, 1,12 y $-1,89$ para pescados de agua dulce, 0,98 y $-1,72$ para salmón, 1,18 y -1,35 para otros pescados de agua salada, 0,21 y $-0,64$ para atún en conserva y 0,38 y $-0,79$ para otros pescados en conserva.

\subsubsection{Estimaciones de demanda en la literatura nacional}

La enorme significación de las carnes como producto alimenticio en los hogares uruguayos contrasta con la escasez, a nivel nacional, de estudios empíricos dedicados a estimar elasticidades de demanda para estos productos. Una de las pocas excepciones la constituye el trabajo de Sáder (2000), quien estimó elasticidades precio e ingreso de corto y largo plazo para carne bovina en Montevideo durante el período 1990-99. Usando datos anuales de series de tiempo, este autor estimó un modelo de vectores autorregresivos (VAR) que incluyó como variables el ingreso medio de los hogares, el consumo de carne bovina y precios promedio de carne bovina y aviar. Las elasticidades de corto plazo calculadas para estimar los cambios en la demanda por carne bovina ante cambios en el ingreso del hogar, el precio de la carne bovina (directa) y el precio de la carne aviar (cruzada) fueron respectivamente $0,305,-0,237$ y 0,034 . Los correspondientes valores para el largo plazo fueron 0,81 , $-0,39$ y 0,43 . En base a estos resultados, la carne bovina puede ser calificada como un producto normal y necesario a la vez que puede ser considerada como un sustituto de la carne de ave.

Al analizar los efectos de los cambios en el ingreso de los hogares uruguayos sobre el consumo de alimentos de origen animal, Troncoso (2003) estimó elasticidades ingreso a partir de curvas de Engel, utilizando distintos métodos y formas funcionales, para hogares de Montevideo e interior y para distintos niveles de ingreso. Dentro de las carnes, consideró cuatro cortes vacunos (traseros sin hueso, traseros con hueso, delanteros y picada), uno de carne ovina (total) y uno de carne de aves (total). Consideró también un gran grupo incluyendo fiambres, embutidos y conservas y otro más genérico determinado por carnes preparadas en base a carnes. En el Cuadro 6 se presenta un resumen de sus estimaciones.

Lanfranco, García y Caputti (2006) investigaron los patrones de consumo de los consumidores uruguayos para cuatro grupos básicos de alimentos (carne vacuna, farináceos, arroz y lácteos) usando datos de la encuesta de hogares 1994-95. Encontraron que el consumo de carne bovina, tomada como categoría amplia, mostró una baja respuesta a los cambios tanto de ingreso como de precio. Los valores calculados para la elasticidad ingreso $(\eta)$ y elasticidad precio $(\varepsilon)$ fueron respectivamente 0,05 y $-0,04$. 
Cuadro 6. Elasticidades ingreso de productos cárnicos estimadas en base a cantidad y a gasto, 1994-95

\begin{tabular}{|l|cc|cc|}
\hline \multirow{2}{*}{ Rubros Seleccionados } & \multicolumn{2}{|c|}{ Montevideo } & \multicolumn{2}{c|}{ Interior } \\
\cline { 2 - 5 } & Cantidad & Gasto & Cantidad & Gasto \\
\hline Carnes & 0,29 & 0,43 & 0,41 & 0,59 \\
Carne Vacuna & 0,16 & 0,31 & 0,40 & 0,52 \\
- Traseros sin hueso & 0,37 & 0,44 & 0,42 & 0,48 \\
- Traseros con hueso & 0,10 & 0,12 & 0,42 & 0,48 \\
- Delanteros & 0,28 & 0,31 & 0,53 & 0,62 \\
- Picada & 0,27 & 0,27 & 0,31 & 0,37 \\
Carne Ovina & NS & NS & 0,38 & 0,50 \\
Carne Aviar & 0,37 & 0,47 & 0,35 & 0,56 \\
Fiambres, embutidos y conservas & 0,40 & 0,56 & 0,34 & 0,54 \\
Comidas preparadas con carne & 0,40 & 0,47 & 0,52 & 0,69 \\
\hline
\end{tabular}

Fuente: Adaptado de Troncoso (2003).

El mismo estudio computó elasticidades de demanda para algunos productos más desagregados de carne bovina. Los valores de elasticidad ingreso $(\eta)$ y precio $(\varepsilon)$ para carne picada fueron respectivamente 0,786 y -0.805 , en tanto que para cortes con hueso fueron 0,114 y $-0,789$. Para cortes sin hueso, el valor de elasticidad precio fue $-0,817$ mientras que el valor estimado de elasticidad ingreso no fue significativamente diferente de cero.

\section{MARCO TEÓRICO DE LA INVESTIGACIÓN}

\subsection{La demanda a nivel del consumidor: teoría vs. aplicación}

\subsubsection{Dificultades de la estimación empírica}

Cuando un investigador se dispone a iniciar un trabajo experimental en el campo de la economía aplicada, se enfrenta inmediatamente con dos dificultades básicas. La primera se refiere a la especificación del modelo. No se trata meramente de una cuestión matemática. La robustez del modelo no radica solamente en su bondad de ajuste o en su capacidad de predicción. Una de las virtudes más apreciadas en un modelo es su habilidad para explicar los resultados a la luz de una teoría. Si el objetivo de un modelo es brindar explicación acerca de un fenómeno, tanto como predecirlo, se requiere de un modelo de causalidad. En economía, esto requiere de teoría económica. Para ello es importante, entonces, que el modelo se comporte de acuerdo a la teoría o que, en todo caso, permita testarla adecuadamente.

La segunda dificultad se refiere a la elección de las técnicas de estimación. Una vez que se tiene un modelo con las características deseadas, el problema siguiente es emplear un método econométrico que realice la mejor estimación posible de los parámetros del modelo. En ese sentido se procura el uso de métodos que brinden estimadores que sean consistentes y asintóticamente eficientes. De igual forma, el método econométrico debe poder capturar adecuadamente las características distintivas del proceso que se está modelando.

La literatura especializada registra trabajos que enfatizan uno u otro aspecto, ya sea en la profundización de los procesos de modelización de los eventos económicos de interés o en el desarrollo de técnicas de estimación mejoradas. Un objetivo adicional de este estudio, a partir de los resultados empíricos obtenidos por Lanfranco (2001) sobre demanda de carnes en el mercado estadounidense, es proponer un paquete metodológico para la conducción de estudios empíricos de demanda por alimentos, que reúna 
ambas condiciones. Vale decir, que permita extraer conclusiones válidas desde el punto de vista estadístico y que éstas sean consistentes con la teoría que las sustenta. En particular, este paquete se basa en la idea de los sistemas incompletos de demanda y en el concepto de cuasi integrabilidad de las funciones de demanda desarrollado por LaFrance y Hanemann (1989). Este enfoque brinda un excelente marco teórico para la interpretación económica de los resultados empíricos así obtenidos.

Por otro lado, los avances actuales en el poder de procesamiento de las computadoras permiten el uso de técnicas econométricas sofisticadas para la estimación simultánea de sistemas de ecuaciones que contemplen las complejidades inherentes a los procesos de toma de decisión del consumidor. Concretamente, existen evidencias en el sentido de que los factores que determinan la decisión de consumir un determinado tipo de alimento no son necesariamente los mismos que determinan la cantidad a consumir del mismo (Haines, Guilkey y Popkin, 1988). Del mismo modo, cuando se trabaja a nivel de consumidores y con un grado de desagregación importante de los bienes, es frecuente observar individuos que no consumen un determinado alimento durante el período de relevamiento de datos.

Para cubrir estos aspectos, el paquete propuesto se basa en un procedimiento de estimación en dos pasos, desarrollado por Shonkwiler y Yen (1999). Dicha técnica permite la estimación simultánea de sistemas de ecuaciones censuradas a través de distintas técnicas estadísticas. En este trabajo se propone la estimación del modelo por el método de máxima verosimilitud.

Si bien existen trabajos que han utilizado el enfoque teórico de los sistemas incompletos de demanda o los métodos econométricos de estimación de sistemas de ecuaciones ordinarias, censuradas o truncadas, no ha habido esfuerzos sistemáticos en procura de combinar ambos aspectos a la vez. Muchos de los estudios han adolecido, o bien de inconsistencia desde el punto de vista de la teoría económica, o bien de debilidades desde el punto de vista econométrico.
Para cumplir con el objetivo propuesto, en las secciones siguientes se discuten, primeramente, las dificultades que aparecen comúnmente a la hora de llevar la teoría de la demanda al terreno de la investigación empírica. Esto da lugar al surgimiento del enfoque de sistemas incompletos como alternativa que habilita la estimación empírica de sistemas de demanda, manejables desde el punto de vista econométrico y, a la vez, consistentes desde el punto de vista teórico. Seguidamente, se discuten aspectos metodológicos de la estimación simultánea de sistemas de ecuaciones con variables dependientes limitadas y los fundamentos que justifican las técnicas sugeridas. Por último, se presenta un ejemplo muy breve y resumido de la aplicación práctica de todo el paquete a una situación real, dejando para la última sección de este artículo el resumen y las conclusiones del mismo.

\subsubsection{El problema de los grados de libertad}

La teoría neoclásica de la demanda postula la existencia de funciones de demanda con una cierta particularidad en su estructura. Las funciones de demanda no compensada o marshallianas se representan, por lo general, mediante un vector $\mathrm{N}$-dimensional $\mathbf{x}(\mathbf{p}, y)$, en donde cada elemento $\mathbf{x}_{i}(\mathbf{p}, \gamma)$ de este vector es, a su vez, función de un vector $\mathrm{N}$-dimensional $\mathbf{p}$ que representa los precios de los $\mathrm{N}$ bienes o servicios (en adelante simplemente bienes) presentes en la economía. La demanda de un consumidor por un determinado bien es, por tanto, función de su propio precio, del precio de los restantes bienes y del ingreso. Esto sugiere que las demandas por todos los bienes de la economía están interrelacionadas y que cualquier estudio empírico debería considerar la demanda simultánea por todos estos bienes (George y King, 1971).

Con el objetivo de investigar los efectos que tienen los cambios ocurridos en el ingreso del consumidor y en cada uno de los $\mathrm{N}$ precios sobre la demanda por cada uno de esos $\mathrm{N}$ bienes, se debe estimar una determinada cantidad de parámetros a partir de un sistema. Como fuera señalado por Capps 
y Havlicek (1987), dado un sistema de ecuaciones de demanda para $\mathrm{N}$ bienes, existen $\mathrm{N}^{2}$ elasticidades precio y $\mathrm{N}$ elasticidades ingreso. Esto significa que el número total de parámetros a ser estimados es de $\mathrm{N}(\mathrm{N}+1)$.

Sin embargo, a los efectos de realizar la estimación se requiere de al menos un número de observaciones igual a la cantidad de parámetros desconocidos. Esta condición seguramente no podría ser satisfecha si el número de bienes es muy grande, como cuando se considera toda la economía en su conjunto. Esto supondría la presencia de un problema de grados de libertad (Bieri y de Janvry, 1972).

Tomek (1977) puntualizó que aunque los análisis de demanda convencionales usualmente incluyen un número limitado de sustitutos, bajo el supuesto de que los coeficientes de las variables omitidas tendrán un valor muy próximo a cero, la agregación de todos los efectos cruzados puede ser, de todos modos, importante. El cambio en el precio de un bien desencadena eventos que influencian el consumo y los precios de muchos otros bienes. Esto hace que en muchos casos sea deseable la estimación de un sistema completo de demanda.

Las restricciones estructurales inherentes a las funciones de demanda derivadas a partir de la teoría neoclásica, proporcionan cierta ayuda. La condición de simetría provee $\mathrm{N}^{2}[(\mathrm{~N}-1) / 2]$ restricciones, la condición de homogeneidad provee $\mathrm{N}$ restricciones y la condición de agregación de Engel provee una restricción adicional. Las propiedades de las funciones de demanda permiten entonces reducir en $\left(\mathrm{N}^{2}+\mathrm{N}+2\right) / 2$ el número de parámetros, lo que deja un total de $\left(\mathrm{N}^{2}+\mathrm{N}\right.$ - 2)/2 parámetros a ser estimados en forma independiente. Este número aún puede ser muy grande, haciendo muy difícil la estimación directa del sistema.

George y King (1971) reconocieron en la literatura dos enfoques muy generales para lidiar con este problema: el análisis de un bien o subsector individual y el enfoque integracionista. En el primer caso, se formula una sola ecuación para estimar la elasticidad precio directa y unas pocas elasticidades precio cruzadas, asumiéndose que el efecto de todas las demás variables omiti- das es cero. La selección de las variables a ser incluidas en la estimación por lo general queda a juicio del investigador.

El enfoque integracionista, por otro lado, toma en cuenta las interrelaciones entre todos los bienes. Para hacer frente al problema de los grados de libertad y de identificación de los parámetros, hay que establecer una serie de supuestos, en adición a las restricciones teóricas, acerca de la interacción existente entre los bienes y la naturaleza de la función de utilidad.

Hassan y Johnson (1977) identificaron tres métodos comúnmente utilizados para imponer las restricciones adicionales necesarias para el trabajo empírico. Con el primer método, se asumen formas algebraicas especializadas y se imponen restricciones sobre la función de utilidad, para poder derivar relaciones de demanda empíricamente manejables. El segundo método focaliza su atención sobre restricciones impuestas directamente sobre las funciones de demanda. A veces, las restricciones impuestas sobre los parámetros de la función de demanda son consistentes con la teoría mientras que en otros casos son consecuencia de consideraciones ad hoc. Finalmente, la tercera aproximación saca ventajas de restricciones implícitas en los datos disponibles.

Por su lado, Capps y Havlicek (1987) clasificaron los diferentes enfoques que tratan empíricamente los sistemas completos de demanda, de acuerdo a su habilidad para ser sustentados en base a su fundamento teórico. Las aproximaciones ad hoc incluyen el uso de ecuaciones individuales o modelos sectoriales, en tanto que otros métodos han intentado una aproximación más sistemática, a través de supuestos específicos sobre la naturaleza de la función de utilidad y las reglas que gobiernan la interacción entre bienes, permitiendo una reducción sustancial en el número de parámetros a ser estimados en forma independiente. Conceptos como los de aditividad de preferencias (Frisch, 1959; Houthakker, 1960), cuasi-aditividad de preferencias (Barten, 1964) y condiciones de separabilidad (Green, 1964) pertenecen a esta clasificación. 
El debate acerca de la validez teórica del empleo de distintas versiones de aditividad y separabilidad en el campo empírico ha sido motivo de enormes esfuerzos para el desarrollo de métodos para mantener y examinar restricciones de separabilidad en sistemas completos de demanda (Pudney, 1981; Moschini, Moro y Green, 1994; Hayes, Wahl y Williams, 1990; Swofford y Whitney, 1987; Eales y Unnevehr, 1988; Nayga y Capps, 1994; Edgerton, 1997).

Con respecto a los problemas de agregación de información, Deaton y Muellbauer (1980a) señalaron que existen dos problemas a los que aún no se ha dado una respuesta satisfactoria. El primero es que el análisis econométrico es posible solamente con un número manejable de bienes que la teoría sitúa convenientemente como una abstracción algebraica, $\mathrm{N}$, la cual puede significar miles o millones de elementos. El problema es que las condiciones teóricas requeridas para realizar una agregación no son triviales de manera alguna. En segundo lugar, la teoría del comportamiento del consumidor fue desarrollada sobre una base individual y muy a menudo las inferencias del análisis empírico se realizan sobre datos agregados, como si se tratara de consumidores individuales.

La agregación sobre individuos, sobre bienes o sobre ambos ha sido lugar común en términos de hacer más manejable la estimación empírica de sistemas de demanda. Capps y Havlicek (1987) remarcaron que la agregación al nivel de consumidores es algo casi inevitable y que la mayoría de los análisis están sujetos a los problemas derivados de la misma. De la misma manera, un cierto nivel de agregación sobre bienes es también inevitable y aún esencial para posibilitar estimaciones de demanda (Huang, 1988; Barten, 1993; Chung, 1994; Ramezani, Rose y Murphy, 1995). Sin embargo, la diversidad y complejidad de los bienes, incluyendo diferencias de calidad, dificultan una distinción clara acerca de qué es lo que define a un bien en particular y cuál es el nivel más adecuado de agregación (George y King, 1971; Prato, 1977; Schrimper, 1977; Green, Hassan y Johnson, 1978; Cox y Wohlgenant, 1986;
Capps, 1989; Capps y Nayga, 1990; Nelson, 1991; Nayga y Capps, 1994).

\subsubsection{Formas funcionales en la estimación de demanda}

Manchester (1977) remarcó la importancia de obtener parámetros adecuados de demanda para su uso en análisis de predicción y de políticas. Este autor argumenta que, a menudo, los intentos para lograr una mayor comprensión acerca del comportamiento del consumo han fracasado debido a las imperfecciones de la propia teoría, a la carencia de medios adecuados para convertir las construcciones teóricas en comportamientos cuantificables y a que los estudios de demanda se han concentrado demasiado en precios, cantidades, ingreso y tamaño de población, excluyendo muchas otras variables que también afectan la demanda.

Al respecto, Deaton y Muellbauer (1980a) enfatizaron sobre la necesidad fundamental de lograr una cuidadosa transición desde la teoría a la aplicación práctica, como prerrequisito para conducir un estudio econométrico con fundamento. Dichos autores señalaron su convicción de que el esfuerzo en la construcción de representaciones creíbles de los comportamientos y de los fenómenos que se buscan comprender es más importante que concentrarse solamente en encontrar modelos que se comporten bien.

Barten (1993) señaló que al especificar formas funcionales, lo ideal es que sean consistentes con la teoría, fáciles de estimar y se ajusten a los datos, lo que incluye una buena capacidad predictiva. Sin embargo, la teoría del consumidor simplemente establece de forma muy genérica que la demanda observada por un bien en particular puede expresarse como una función del ingreso del consumidor, el precio del bien en cuestión y los precios de todos los demás bienes. La teoría no brinda ninguna otra pista acerca de la estructura de la función, más allá de las propiedades derivadas del proceso de maximización de la utilidad, las que a su vez resultan insuficientes para determinar su forma correcta. 
Los investigadores en economía aplicada han venido dirigiendo sus esfuerzos hacia la especificación de formas funcionales consistentes con la teoría, especialmente en el caso de los sistemas completos de demanda. Las propiedades estándar derivadas de la teoría de maximización individual de la utilidad han sido impuestas en forma rutinaria sobre los datos en los modelos econométricos aplicados de demanda, sea escogiendo la forma funcional o a través de restricciones sobre los parámetros (Kastens y Brester, 1996).

De acuerdo a Barten (1993), en la literatura sobre estudios empíricos de demanda pueden encontrarse cuatro enfoques básicos tendientes a la obtención de ecuaciones que satisfagan las propiedades de la demanda. El primero comienza a partir de la especificación de una función de utilidad creciente y cuasi cóncava, maximizada con respecto a una restricción presupuestal, a partir de lo cual se derivan las funciones de demanda. Dentro de este grupo entra el LES (Linear Expenditure System) desarrollado por Stone (1954) y sus sucesivas versiones y modificaciones, ELES-Extended Linear Expenditure System (Howe, 1977; Eastwood y Craven, 1981), QES-Quadratic Expenditure Systems (Howe, Pollak y Wales, 1979).

El segundo enfoque o enfoque diferencial, donde se destaca ampliamente el Modelo de Rotterdam (Theil, 1965), es un paso firme hacia la formulación de funciones de demanda más avanzadas, al permitir la estimación de parámetros y la imposición de restricciones en una forma que no había sido posible previamente. Este modelo fue el primero en permitir una matriz de sustitución con simetría como única restricción impuesta previamente, pudiendo entonces identificarse sustitutos y complementos, así como evaluar su condición de negativa semidefinida, a partir de la evidencia.

El tercer enfoque define a una amplia familia de modelos conocidos como FFF o Flexible Functional Forms (formas funcionales flexibles). Estos modelos se basan en el uso de las series de expansión de segundo orden de Taylor. Los ejemplos más populares incluyen a la ecuación generalizada de Leontief (Diewert, 1971) y a la translogarítmica indirecta (Christensen, Jorgensen y Lau, 1975). La idea básica es representar la función de utilidad directa, la indirecta o la función de gastos, cuya verdadera forma es desconocida, a través de una función específica que pueda ser considerada como una buena aproximación a la verdadera forma de la función. Las ventajas y limitaciones inherentes a las series de Taylor como aproximación a la verdadera forma de una función han sido motivo de controversia (Chiang, 1984; Wohlgenant, 1984; Moschini y Moro, 1996), dando lugar a la propuesta de diferentes versiones y «sabores» de las FFF, incluyendo la representación versiones «directas» e «indirectas» así como propuestas alternativas (Gallant, 1981; Cooper y McLaren, 1996; Ryan y Wales, 1999).

La aplicación de la teoría de la dualidad permitió el desarrollo de un cuarto enfoque, mediante el cual el conjunto de ecuaciones de demanda teóricamente plausibles se deriva de una función de costos explícita. El ejemplo más conocido es el llamado AIDS (Almost Ideal Demand System) propuesto por Deaton y Muellbauer (1980b). El modelo AIDS brinda una aproximación arbitraria de primer orden para cualquier sistema de demanda, a la vez que satisface los axiomas de la teoría del consumidor. Si bien el modelo AIDS original no es lineal en los parámetros, comúnmente se utiliza una aproximación lineal conocida como LA/AIDS (Capps, Tedford y Havlicek, 1985; Chalfant, 1987; Eales y Unnevehr, 1988; Moschini y Meilke, 1989; Hayes, Wahl y Williams, 1990; Gould, Cox y Perali, 1991). Las relaciones entre el modelo original y su aproximación lineal, así como del uso de los índices de precios en ésta última, han sido largamente debatidas en la literatura especializada (Green y Alston, 1990, 1991; Chalfant, Gray y White, 1991; Pashardes, 1993; Alston, Foster y Green, 1994; Buse, 1994, 1998; Moschini, 1995; Taniguchi y Chern, 1999; Asche y Wessells, 1997).

Como resumen de la discusión acerca de formas funcionales en estudios empíricos, Barten (1993) remarcó la gran cantidad de investigación tendiente al análisis de las fortalezas y debilidades de cada modelo, así como de comparación entre éstos. Todo esto 
derivó en el desarrollo de innumerables variantes a los efectos de mejorar las formulaciones originales, en la medida que ningún modelo ha demostrado ser perfecto. La mayoría no logra mantener las condiciones apropiadas de curvatura sobre todo el espacio ( $\mathbf{p}, y)$, lo cual hace que fracasen, al menos para ciertas combinaciones de las variables exógenas. Barten (1993) reconoció que resulta difícil saber cuán importante es esto en la práctica. En el mejor de los casos, los sistemas de demanda son una aproximación local del «verdadero estado de cosas».

Deaton y Muellbauer (1980a) señalaron que lo más impresionante es la uniformidad de los resultados, según los cuales las restricciones a la teoría no se verifican en la práctica, al menos en el caso de datos agregados. Todos los modelos, incluso el AIDS, utilizan aproximaciones diferentes, no obstante lo cual, entran todos en conflicto con la teoría al menos en esos casos.

\subsection{Una posible respuesta: los sistemas incompletos de demanda}

\subsubsection{Propiedades de los sistemas incompletos de demanda}

Muy a menudo, el interés del investigador se encuentra enfocado solamente en un pequeño grupo o subconjunto de bienes, como ser alimentos o productos cárnicos. $O$ bien no está interesado por la demanda de otros productos o no hay disponibilidad de datos sobre esos otros bienes. En primera instancia, la tentación sería llevar a cabo la investigación usando un enfoque parcial. Sin embargo, no sería posible, entonces, capturar el efecto potencial de otros bienes fuera de los incluidos explícitamente, tal como sugiere la teoría económica.

Por otro lado, el tratamiento apropiado de las interrelaciones existentes entre los distintos bienes requiere la estimación de un sistema de demanda completo. Sin embargo, el problema de la dimensionalidad, inherente a los mismos, hace virtualmente imposible la estimación empírica a menos que se establezcan supuestos adicionales. A mane- ra de resumen de lo discutido en la sección anterior, se puede argumentar que aún cuando el problema de grados de libertad sea reducido drásticamente mediante el aumento de los niveles de agregación de los bienes al sistema o asumiendo algún tipo de aditividad o separabilidad entre bienes, dichos enfoques implican mayores supuestos, a menudo muy restrictivos, acerca de la estructura de preferencias.

El uso de un sistema incompleto de demanda perecería ser una alternativa atractiva. Más aún cuando la mayoría de las veces las propias limitaciones de los datos disponibles obligan al investigador a lidiar con sistemas de demanda que son incompletos por naturaleza. Por todo esto, sería muy práctico contar con un método general que sea robusto desde el punto de vista teórico. En principio, la teoría de la dualidad y las condiciones de integrabilidad se pueden aplicar a los sistemas incompletos de demanda. Con este enfoque, la estimación de funciones de demanda especificadas directamente no requiere de ningún supuesto especial, fuera de los derivados a partir de la teoría neoclásica. Más aún, los sistemas incompletos de demanda permiten el empleo de formas funcionales más generales que las utilizadas con modelos de demanda completos y son aplicables a prácticamente cualquier situación práctica (LaFrance, 1986; LaFrance y Hanemann, 1989).

\subsubsection{Integrabilidad en sistemas incompletos de demanda}

El proceso de maximización de la utilidad genera un conjunto de funciones de demanda con ciertas propiedades. Estas resultan ser las únicas condiciones requeridas para la integración de dichas funciones, recobrando así las preferencias subyacentes.

A los efectos de analizar los sistemas incompletos, sea y la representación del ingreso total, el cual se gasta en su totalidad entre los $\mathrm{N}$ bienes disponibles en la economía (axioma de no saciedad). Sea $\mathbf{q}=\left(q_{1}\right.$, $\ldots, q_{\mathrm{K}}$ )' el vector de dimensión $\mathrm{K}$ que representa los niveles de consumo para las variables de interés y sea $\mathbf{p}=\left(p_{1}, \ldots, p_{\mathrm{K}}\right)$ ' el vector con los correspondientes $\mathrm{K}$ precios de los bienes de interés. El nivel de consumo para 
todos los demás bienes no incluidos en el grupo de interés está representado por el vector M-dimensional $\mathbf{z}=\left(z_{1}, \ldots, z_{\mathrm{M}}\right)^{\prime}$ y su correspondiente vector de precios es $\mathbf{r}=\left(r_{1}\right.$, $\left.\ldots, r_{\mathrm{M}}\right)^{\prime}$, de modo que $\mathrm{N}=\mathrm{K}+\mathrm{M}$.

De esta forma, la función directa de utilidad, la función indirecta, las funciones de demanda no compensadas (marshallianas) y las compensadas (hicksianas) se denominan respectivamente como $\mathrm{U}(\mathbf{q}, \mathbf{z}), \mathrm{V}(\mathbf{p}, \mathbf{r}$, y), e(p, r, U), $\mathbf{x}(\mathbf{p}, \mathbf{r}, y)$ y $\mathbf{h}(\mathbf{p}, \mathbf{r}, \boldsymbol{U})$. Solamente se observa la demanda por los $\mathrm{K}$ bienes de interés $\mathbf{x}_{a}(\mathbf{p}, \mathbf{r}, y)$. Además, hay un conjunto formado por las $M$ funciones de demanda marshallianas para los bienes incluidos en $\mathbf{z}$, denominado $\mathbf{x}_{\mathbf{z}}(\mathbf{p}, \mathbf{r}, y)$. Éstas «no son observadas» en el marco del sistema incompleto de demanda y no necesariamente tienen la misma forma funcional que la verificada en la demanda por q (LaFrance, 1985).

A partir de esta notación, podemos expresar las propiedades de la demanda (marshalliana):

(a) Un bien no puede ser demandado en cantidades negativas. $O$ sea, $\mathbf{x}(\mathbf{p}, \mathbf{r}, y) \geq 0$

(b) La demanda total valorizada debe ser igual al gasto total. En otras palabras, la suma del gasto en cada bien presente en la canasta de consumo debe agotar completamente el presupuesto total del consumidor. Esto es, $\mathbf{p}^{\prime} \mathbf{x}_{q}(\mathbf{p}, \mathbf{r}, y)+\mathbf{r}^{\prime} \mathbf{x}_{z}(\mathbf{p}, \mathbf{r}, y)=y$

(c) Las funciones marshallianas son homogéneas en grado cero para todos los precios $y$ el ingreso. Esto es, $\mathbf{x}(\lambda \mathbf{p}, \lambda \mathbf{r}, \lambda y)=$ $\mathbf{x}(\mathbf{p}, \mathbf{r}, y)$, para cualquier escalar $\lambda>0$

(d) La matriz $\mathbf{S}$ de términos de sustitución de Slutsky es simétrica y negativa semidefinida. O sea, cada elemento, $s_{i j} \leq 0$ para todo $i=j$, y $s_{i j}=s_{j i}$ para todo $i \neq j$.

La pregunta a plantearse es si para los sistemas incompletos de demanda se puede establecer un conjunto de condiciones de «integrabilidad», similares a las existentes para los sistemas completos. Dicho de otra manera, dado un conjunto de funciones de demanda, especificadas directamente para los q bienes de interés, se quiere saber si existe un listado exhaustivo de propiedades de $\mathbf{x}_{q}(\mathbf{p}, \mathbf{r}, y)$ que garantice la «recobrabilidad" de las preferencias del consumidor, como sucede con los sistemas completos de demanda. Si esto es posible, se trataría de un resultado muy atractivo desde el punto de vista empírico, pues sería equivalente a la existencia de una función $U(\mathbf{q}, \mathbf{z})$ a partir de la cual se derivan las funciones $\mathbf{x}_{q}(\mathbf{p}, \mathbf{r}$, y).

Epstein (1982) estableció las condiciones necesarias y suficientes para lo que definió como integrabilidad global, reconociendo que en el caso de sistemas incompletos de demanda, no resulta sino un resultado local. La integrabilidad a nivel global implica asumir una serie de restricciones complejas sobre $\mathbf{x}_{q}$. Aunque desde el punto de vista matemático la cuestión no representa mayor problema, Epstein (1982) señaló que, en general, no es válido suponer que cualquier función $\xi(\mathbf{p}, \mathbf{r}, U)$ que resulta de la integración de un conjunto incompleto de funciones de demanda, como puede ser $\mathbf{x}_{q}$, se comporte como una función de gastos para todo $(\mathbf{p}, \mathbf{r}, y) \in \Omega$, donde $\Omega \subset R_{++}^{\mathrm{K}+\mathrm{M}+1}$ es el dominio de $\left(\mathbf{x}_{q}, \mathbf{x}_{z}\right)$. En efecto, seguramente existe un conjunto de soluciones que podrían también ser admitidas como potenciales funciones de gasto. En otras palabras, no sería solamente una, sino muchas, las funciones que podrían haber generado ese grupo particular de funciones de demanda $\mathbf{x}_{q}$, no habiendo forma de saber cuál de ellas es la verdadera $\mathbf{e}(\mathbf{p}, \mathbf{r}, \mathbf{U})$. Esto es una propiedad distintiva de los sistemas incompletos de demanda (LaFrance y Hanemann, 1989).

\subsubsection{Dualidad bajo la condición de cuasi integrabilidad}

LaFrance y Hanemann (1989) desarrollaron un enfoque alternativo al problema de la integrabilidad en los sistemas incompletos de demanda, al que denominaron cuasi integrabilidad (en inglés, weak integrability). Estos autores sugirieron que cuando el tema se enfoca sobre las propiedades de la función indirecta de utilidad y de la función de gastos con respecto a $\mathbf{p}$ dado $\mathbf{r}$, así como en las propiedades de la función directa de utilidad con respecto a $\mathbf{q}$ dado $\mathbf{z}$, se pueden obtener los resultados deseados. En primer término, a los efectos prácticos no es necesario que ninguna de estas funciones deba comportarse de acuerdo a la teoría, para los 
precios $\mathbf{r}$. En segundo término, esto permite derivar y verificar empíricamente un nuevo listado de condiciones de integrabilidad. En tercer lugar, bajo estas nuevas condiciones, es posible recuperar la estructura de preferencias para los bienes de interés, $\mathbf{q}$, a partir de las ecuaciones de demanda $\mathbf{x}_{q}(\mathbf{p}, \mathbf{r}, y)$, con arreglo a la teoría del consumidor.

A los efectos de asegurar al menos la cuasi integrabilidad, dado un sistema incompleto de ecuaciones de demanda continuamente diferenciables en segundo orden $\left(\mathrm{C}^{2}\right)$, $\mathbf{x}_{q}(\mathbf{p}, \mathbf{r}, y)$, se deben satisfacer las condiciones siguientes:

(a') $\mathbf{x}(\mathbf{p}, \mathbf{r}, y) \geq 0$;

(b') $\mathbf{p}^{\prime} \mathbf{x}_{q}(\mathbf{p}, \mathbf{r}, y)<y$;

(c') $\mathbf{x}_{q}(\mathbf{p}, \mathbf{r}, y)$ es homogénea de grado cero en $(\mathbf{p}, \mathbf{r}, y)$; nida

(d') $\mathrm{S}$ es simétrica y negativa semidefi-

A diferencia de lo que ocurre con la integrabilidad local o global de Epstein (1982), donde la matriz $\mathbf{S}$ tiene que ser negativa definida, para la cuasi integrabilidad solamente se necesita que dicha matriz sea negativa semidefinida. Las propiedades (a'), (c') y (d') representan las condiciones estándar, independientemente que el sistema sea incompleto. La única diferencia radica en el no agotamiento del presupuesto, la propiedad (b'). Según LaFrance (1990), ésta es la principal fuente de pérdida de información en un sistema incompleto de demanda, al no cumplirse la condición original propia de los sistemas completos, establecida en (b).

Incorporando como numerario al sistema incompleto, conformado por $\mathbf{x}_{q}(\mathbf{p}, \mathbf{r}, y)$, un bien compuesto que estará determinado completamente por las $\mathrm{K}$ demandas $\mathbf{x}_{q}$ y la identidad presupuestal, $\mathbf{s} \equiv \mathbf{r}^{\prime} \mathbf{z} \equiv y-\mathbf{p}^{\prime} \mathbf{x}_{q}(\mathbf{p}, \mathbf{r}$, $y)>0$, y tratando al nuevo sistema así obtenido como un sistema completo de demanda, LaFrance y Hanemann (1989) demostraron que las condiciones (a')-(d') son necesarias y suficientes para que las demandas $\mathbf{x}_{q}(\mathbf{p}, \mathbf{r}, y)$ hayan sido generadas a partir de la maximización de utilidad del consumidor.

El mayor impacto de los resultados de LaFrance y Hanemann (1989) es su aplica- ción empírica a la investigación económica. El numerario utilizado para «completar» el sistema representa el gasto total en los bienes no incluidos en el grupo de interés. Así, el enfoque que considera la cuasi integrabilidad de los sistemas incompletos de demanda permite la realización de las tareas usuales del análisis económico aplicado, pudiendo utilizarse en casi cualquier aplicación práctica. No es necesario asumir a priori ningún supuesto adicional sobre la estructura de las preferencias, fuera de las propiedades estándar de la demanda.

\subsubsection{El modelo LinQuad}

Los sistemas incompletos de demanda permiten la especificación de formas funcionales más genéricas que las utilizadas en sistemas completos (LaFrance, 1985, 1990; LaFrance y Hanemann, 1989). Las funciones de demanda para los bienes de interés no tienen por qué tener la misma forma que las de los bienes incluidos en el bien compuesto. En principio, el sistema incompleto puede ser lineal con respecto al ingreso y a los precios de interés, algo que no es posible con sistemas completos. No obstante esta mayor flexibilidad, la identificación de las formas funcionales capaces de superar todos los requerimientos impuestos por las condiciones de cuasi integrabilidad, no es tampoco una tarea sencilla.

En particular, LaFrance $(1985 ; 1986 ; 1990)$ investigó una vasta cantidad de tipos de funciones (lineales, de elasticidad constante, semilogarítmicas), a los efectos de verificar si cumplían con las condiciones para ser racionalizadas a partir de un conjunto de preferencias bien definidas, concluyendo que ello sólo es posible considerando ciertas restricciones adicionales. De una manera u otra, todos los modelos considerados fueron bastante restrictivos. Finalmente, Agnew (1998) mostró que la única manera de derivar ecuaciones de demanda consistentes con el concepto de cuasi integrabilidad, lineales respecto al ingreso deflactado y lineales y cuadráticas respecto a precios deflactados es utilizando la función de cuasi-gasto conocida como modelo LinQuad.

En el marco de la cuasi integrabilidad, integrando con respecto a $\mathbf{p}$ las funciones 
de demanda $\mathbf{x}_{q}(\mathbf{p}, \mathbf{r}, y)$ de acuerdo a las condiciones (a')-(d') se obtiene la siguiente solución:

$$
\mathrm{e}(\mathbf{p}, \mathbf{r}, \mathrm{U}) \equiv \xi[\mathbf{p}, \mathbf{r}, \vartheta(\mathbf{r}, \mathrm{U})]
$$

La función $\xi[\mathbf{p}, \mathbf{r}, \vartheta(\mathbf{r}, U)]$, denominada función de cuasi-gasto, se relaciona con la verdadera función de gasto e (p, r, U) a través de la identidad (1). La constante arbitraria que surge de integrar un sistema parcial de ecuaciones diferenciales de demanda, está representada por el término $\vartheta(\mathbf{r}, \mathrm{U})$, función a su vez del vector $r$ correspondiente a los precios de bienes cuyas cantidades demandadas están contenidas en el vector, $\mathbf{z}$, y del nivel de utilidad, U. Nótese que dicho término no es una función de los precios $\mathbf{p}$. LaFrance y Hanemann (1989) señalaron que la clase de funciones, $\xi$, presentada en (1) agota en forma exhaustiva el conjunto de soluciones del sistema parcial de ecuaciones diferenciales que surge de la aplicación del Lema de Shephard, con respecto a $\mathbf{p}$ sobre la función de gastos e $(\mathbf{p}, \mathbf{r}, U)$ y apelando a la relación de identidad existente entre las funciones marshallianas y hicksianas. No es posible recobrar la estructura de $\vartheta(\mathbf{r}, U)$ a partir del subconjunto de las funciones incompletas de demanda. La razón es que simplemente no hay información suficiente que permita inferir su estructura.

Volviendo al modelo LinQuad, la correspondiente función de cuasi-gasto es:

$\xi[\mathbf{p}, \mathbf{r}, \vartheta(\mathbf{r}, \mathrm{U})]=\sum_{k=1}^{\mathrm{K}} \alpha(\mathbf{r})_{k} p_{k}+\frac{1}{2} \sum_{j=1}^{\mathrm{K}} \sum_{k=1}^{\mathrm{K}} \beta_{j k} p_{j} p_{k}+\vartheta(\mathbf{r}, \mathrm{U}) \times \mathrm{e}^{\gamma \mathrm{p}}$.

Invocando el Lemma de Shephard y derivando (2) con respecto a los precios $\mathbf{p}$, se obtienen las ecuaciones de demanda $\mathbf{h}_{q}(\mathbf{p}, \mathbf{r}$, $U)$, para a los bienes de interés en el estudio:

$q_{i}=\alpha(\mathbf{r})+\sum_{k=1}^{\mathrm{K}} \beta_{i k} p_{k}+\gamma_{i}\left[\vartheta(\mathbf{r}, \mathrm{U}) \times \mathrm{e}^{\gamma} \mathrm{p}\right] \quad i=1, \ldots, \mathrm{K}$.

A partir de la identidad $\mathbf{x}_{q}(\mathbf{p}, \mathbf{r}, y) \equiv \mathbf{h}_{q}[\mathbf{p}, \mathbf{r}$, donde $\vartheta \equiv Y(\mathbf{p}, \mathbf{r}, y)$, es la función cuasi indirecta de utilidad, la expresión (2) puede despejarse para $\vartheta(\mathbf{r}, U)^{\prime} \mathrm{e}^{\gamma / p}$; asumiendo no saciedad, el ingreso $y \equiv \xi[\mathbf{p}, \mathbf{r}, \vartheta(\mathbf{r}, U)]$, obteniéndose las $\mathrm{K}$ ecuaciones de demanda marshallianas $\mathbf{x}_{q}(\mathbf{p}, \mathbf{r}, y)$ para el modelo LinQuad original (LaFrance, 1990; Agnew, 1998) al sustituir en la expresión entre paréntesis recto de (3). Para $i=1, \ldots, \mathrm{K}$ :

$q_{i}=\alpha_{i}+\sum_{k=1}^{\mathrm{K}} \beta_{i k} p_{k}+\gamma_{i}\left[y-\sum_{k=1}^{\mathrm{K}} \alpha_{k} p_{k}-\frac{1}{2} \sum_{j=1}^{\mathrm{K}} \sum_{k=1}^{\mathrm{K}} \beta_{j k} p_{j} p_{k}\right]$

Agnew (1998) mostró que el modelo LinQuad admite especificaciones generales diferentes, incluyendo una versión logarítmica. Este autor encontró que tanto el LinQuad como sus generalizaciones satisfacen todas las condiciones de integrabilidad, algo no muy común en el campo empírico. En razón de ello, se sugiere el empleo de este modelo.

$\mathbf{p}^{\prime} \mathbf{x}_{q}[\mathbf{p}, \mathbf{r}, e(\mathbf{p}, \mathbf{r}, U)]+s[\mathbf{p}, \mathbf{r}, \mathrm{e}(\mathbf{p}, \mathbf{r}, U)] \equiv \mathrm{e}(\mathbf{p}$,
$\mathbf{r}, U)$

La restricción de aditividad se cumple a través de la expresión (5), cuando se aumenta el sistema de $\mathrm{K}$ ecuaciones mediante el bien compuesto $\mathrm{S} \equiv \mathbf{r}$ 'z. Para evitar la singularidad de la matriz de varianza-covarianza durante la estimación, se debe desestimar una ecuación. Como la condición (b') para cuasi integrabilidad establece que $\mathbf{p}^{\prime} \mathbf{x}_{q}(\mathbf{p}, \mathbf{r}$, $y)<y$, se puede desestimar la ecuación de demanda para los bienes que no son el centro de interés del estudio y de esta forma proceder con la estimación utilizando solamente las ecuaciones de demanda para los bienes de interés.

El bien compuesto s se define como el numerario, de modo que, deflactando todos los precios y el ingreso mediante $\pi(\mathbf{r})$, una función arbitraria de todos los precios $\mathbf{r}$, que cumple con las propiedades de ser positiva, no decreciente (estrictamente creciente para algunos precios $r_{k}$ ), cóncava, linealmente homogénea y doblemente diferenciable, se obtiene la condición de homogeneidad de grado cero (Agnew, 1998).

El deflactor admite diferentes especificaciones para $\pi(\mathbf{r})$, como podría ser el índice de precios al consumo (IPC) para los bienes no incluidos en el estudio (LaFrance, 1986; Agnew, 1998). Al respecto, LaFrance (1986) sostiene que la forma específica de los precios en $\pi(\mathbf{r})$ no influye sustancialmente la 
estructura de las preferencias condicionales por los $\mathbf{q}$ bienes de interés.

La simetría de la matriz de Slutsky está determinada completamente por la simetría de la matriz $\mathbf{B}$, de dimensión $\mathrm{K} \times \mathrm{K}$, formada por los parámetros desconocidos $\beta_{i j}$, donde $i, j=1, \ldots, \mathrm{K}$. Por tanto, la condición de simetría se obtiene mediante la restricción $\beta_{i j}$ $=\beta_{j i}$ (Agnew, 1998). La condición de concavidad se puede imponer restringiendo la matriz $\mathbf{B}$ a ser negativa semidefinida, usando la factorización de Cholesky (Lau, 1978). Sin embargo, LaFrance (1990) advirtió que esto no brinda ninguna ventaja en términos de reducir los $(1 / 2) \mathrm{K}^{2}+(5 / 2) \mathrm{K}+1$ parámetros que deben ser estimados en forma independiente. Por esta razón, se considera mejor no imponer esta restricción al modelo.

Para evitar un tipo muy común de heterosquedasticidad que surgiría si el modelo se estimara con $q_{i}$ en el lado izquierdo de la ecuación (4), se considera más adecuado utilizar el gasto deflactado $e_{i}$ como variable dependiente. Esto se obtiene multiplicando ambos lados de cada ecuación por el precio correspondiente.

Finalmente, el modelo permite la incorporación de un número $L$ de variables demográficas y socioeconómicas, de manera de poder investigar sus efectos en la demanda. Identificando a la lésima variable socioeconómica como $g_{l}$ y como $c_{i l}$ a su parámetro asociado en la iésima ecuación, se obtiene la expresión final propuesta para utilizar en estudios empíricos que utilizan sistemas de ecuaciones de demanda por alimentos, para $i=1, \ldots, \mathrm{K}$ :

\subsubsection{Sistemas de ecuaciones con variables dependientes limitadas}

Tradicionalmente, la estimación de elasticidades de consumo de alimentos se limitaba al uso de ecuaciones individuales. Los modelos Tobit representan una especificación muy común para el caso de regresiones truncadas y censuradas (Kennedy, 1998). Un supuesto implícito importante del modelo Tobit estándar es que tanto la decisión de consumir como la decisión de la cantidad a consumir es la misma. Con referencia a la demanda por alimentos, Haines, Guilkey y Popkin (1988) han argumentado que los factores que determinan la decisión de consumir no son necesariamente los mismos que los que definen las cantidades consumidas. En este caso, si se ignora la verdadera secuencia del proceso de decisión, no se puede capturar el patrón de comportamiento del consumidor, lo cual conduce inevitablemente a resultados erróneos en el proceso de estimación.

Los métodos de estimación que involucran procesos de decisión en dos pasos o etapas, implican el análisis de dos variables dependientes (Guilkey, Haines y Popkin, 1990): (a) una variable dicotómica que indica si un individuo consume o no una cantidad no negativa de un determinado alimento; $y$ (b) la cantidad efectivamente consumida por aquellos individuos que eligieron consumir. De acuerdo a esta idea, un proceso de consumo de este tipo puede ser descrito en la

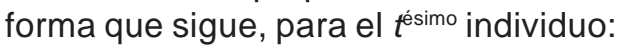

$$
e_{i}=p_{i}\left\{\alpha_{i}+\sum_{k=1}^{\mathrm{K}} \beta_{i k} p_{k}+\sum_{l=1}^{\mathrm{L}} \chi_{i l} g_{l}+\gamma_{i}\left[y-\sum_{k=1}^{\mathrm{K}} \alpha_{k} p_{k}-\frac{1}{2} \sum_{j=1}^{\mathrm{K}} \sum_{k=1}^{\mathrm{K}} \beta_{j k} p_{j} p_{k}-\sum_{k=1}^{\mathrm{K}} \sum_{l=1}^{\mathrm{L}} \chi_{k l} p_{k} g_{l}\right]\right\}
$$



$d_{t}^{*}=\mathbf{v}_{t}^{\prime} \varphi+e_{t}^{*} \quad \begin{aligned} & \text { Ecuación Dicotómica o } \\ & \text { de Decisión }\end{aligned}$

$q_{t}^{*}=f\left(\mathbf{w}_{t}, \theta\right)+u_{t}^{*} \quad \begin{aligned} & \text { Ecuación de Nive Regresión } \\ & \text { de }\end{aligned}$

La variable dependiente $d_{t}^{*}$ en (7) es un valor de reserva y no es observable. Lo que se observa es la relación binaria $d_{t}$, la cual toma el valor $d_{t}=1$ (sí) cuando $d_{t}^{*}>0 \mathrm{y}$ $d_{t}=0$ (no) cuando $d_{t}^{*} \leq 0$. La variable dependiente en (8) contiene la información de consumo de aquellos individuos para los cuales $d_{t}=1$ (sí). Esto es, $q_{t}=q_{t}^{*}$ cuando $d_{t}^{*}>0$, de lo contrario su consumo es cero $\left(q_{t}=0\right)$. Los vectores $\mathbf{v}_{t}$ y $\mathbf{w}_{t}$ representan a los regresores incluidos en las ecuaciones de decisión y de nivel, respectivamente, los que pueden o no tener variables en común. Los vectores $\theta$ y $\varphi$ representan a sus parámetros asociados. El término $f\left(\mathbf{w}_{t}\right.$ , $\theta$ ) es un componente determinístico general que puede ser no lineal en $\theta$. Si $\mathbf{v}_{t}=\mathbf{w}_{t}$ y las disturbancias en (7) y (8) tienen una función de densidad normal $\left(e_{t}^{*} \equiv u_{t}^{*}\right)$. Entonces, $\theta \equiv \varphi$, resultando en el modelo Tobit estándar (Heckman, 1979).

Cuando se trabaja con microdatos transversales, aparece comúnmente un problema de respuestas censuradas, conocido como sesgo por selectividad, debido a observaciones que registran niveles de consumo nulos para algunos bienes (Davidson y MacKinnon, 1993). Bajo esta hipótesis, se asume que los errores de las ecuaciones (7) y (8) están correlacionados a través del coeficiente de correlación $\rho$ (rho), distribuyéndose en forma normal bivariada. Dejando de lado los subíndices para las observaciones individuales y asumiendo que $\sigma_{e}^{2}=1$ a los efectos de la identificación de parámetros, podemos simplificar $\sigma_{u}^{2}=\sigma^{2}$, de modo que:

$$
\left(e^{*}, u^{*}\right) \sim N\left[\left(\begin{array}{l}
0 \\
0
\end{array}\right),\left(\begin{array}{cc}
1 & \sigma_{e u} \\
\sigma_{u e} & \sigma^{2}
\end{array}\right)\right]
$$

Algunas alternativas que tratan este problema consideran la estimación de cada par individual de ecuaciones mediante técnicas como el procedimiento bietápico de Heckman (Heckman, 1976; 1979) o el Tobit de tipo II de Amemiya (Amemiya, 1985), ambos derivados a partir del Tobit original y conocidos genéricamente como modelos de selección muestral.

El supuesto de distribución bivariada tiene importantes consecuencias. Lo que intentan estos modelos es separar los procesos de selección y de nivel en dos ecuaciones diferentes aunque relacionadas entre sí. Las ecuaciones de decisión y de nivel solamente son independientes si y sólo si el coeficiente de correlación $r$ entre $e^{*}$ y $u^{*}$ es cero (Hogg y Tanis, 2001). Leung y Yu (1996) señalaron que la distinción fundamental entre los modelos de selección muestral y los que no consideran este punto radica en el supuesto acerca de $e^{*}$ y $u^{*}$. Mientras que los modelos que no consideran la selectividad asumen $\rho=0$, de donde $E\left(u_{t}^{*} \mid d_{t}^{*}>0\right)=0$, los modelos de selección muestral asumen que $E\left(u_{t}^{*}\right)=0$, de modo que $E\left(u_{t}^{*} \mid d_{t}^{*}>0\right)$ $=\rho \sigma \times \lambda_{t}\left(\mathbf{v}_{t}^{\prime} \varphi\right)$, lo cual significa que $\rho \neq 0$. Si $\sigma$ (sigma) se define como anteriormente, la expresión $\lambda_{t}\left(\mathbf{v}_{t}^{\prime} \varphi\right)$, conocida como «razón inversa de Mills» se computa a partir del modelo probabilístico (probit) definido en (7) como:

$$
\lambda_{t}=\lambda\left(\mathbf{v}_{t}{ }^{\prime} \phi\right)=\frac{\phi\left(\mathbf{v}_{t}{ }^{\prime} \phi / \sigma_{e}\right)}{\Phi\left(\mathbf{v}_{t}{ }^{\prime} \phi / \sigma_{e}\right)}
$$

Nuevamente, $\sigma_{e}=1$, $\phi$ es la función de densidad de probabilidad normal estándar (pdf) y $\mathrm{F}$ es la función de distribución de probabilidad acumulada normal estándar (cdf). Esta diferencia es el corazón de un vigoroso debate entre los defensores de una y otra clase de modelos.

Siguiendo a Heckman (1979, p. 154), la función de regresión para para la ecuación (8), con la muestra completa, puede escribirse como $E\left(q_{t}^{*} \mid \mathbf{w}_{t}\right)=f\left(\mathbf{w}_{t}, \theta\right)$. Sea $d_{t}^{*}>0$ la regla de selección y $\delta=\rho \sigma$, un nuevo parámetro a ser estimado, la función de regresión para las observaciones que registran consumo positivo de los bienes en estudio se expresa como:

$$
E\left(q_{t}^{*} \mid \mathbf{w}_{t}, d_{t}^{*}>0\right)=f\left(\mathbf{w}_{t}, \theta\right)+E\left(u_{t}^{*} \mid d_{t}^{*}>0\right)=f\left(\mathbf{w}_{t}, \theta\right)+\delta \times \lambda_{t}\left(\mathbf{v}_{t}^{\prime} \varphi\right) .
$$


En presencia de sesgo por selectividad, $E\left(u_{t}^{*} \mid d_{t}^{*}>0\right) \neq 0$. Sin embargo, si la esperanza condicional $E\left(u_{t}^{*} \mid d_{t}^{*}>0\right)=0$, la función de regresión para la submuestra seleccionada se reduce a la misma expresión de la función de regresión para la población. El único costo de utilizar una muestra incompleta es una pérdida de eficiencia (Heckman, 1979).

\subsubsection{Estimación en dos pasos de sistemas de ecuaciones censuradas}

Actualmente, los avances en poder computacional permiten el uso de herramientas más sofisticadas para la estimación de sistemas de ecuaciones con variables dependientes limitadas. Claros ejemplos lo constituyen los métodos de estimación propuestos por Heien y Wessells (1990), Shonkwiler y Yen (1999) y Perali y Chavas (2000). La aplicación de estos métodos resulta en matrices de varianza-covarianza asintóticamente más pequeñas, de manera que se obtienen estimaciones más eficientes que con técnicas basadas en la estimación de ecuaciones individuales (Kennedy, 1998).

La técnica propuesta por Heien y Wessells (1990) implica, como primer paso. la estimación de un conjunto de ecuaciones probabilísticas del tipo definido en (7). A partir de las cuales se estima un regresor $d \epsilon$ selectividad (la razón inversa de Mills) que se utiliza para aumentar cada una de las ecuaciones de nivel presentadas en (8). Este primer paso es idéntico al procedimiento bietápico de Heckman.

En el segundo paso de esta versión multivariada de Heckman, las ecuaciones aumentadas con (9) se estiman en forma simultánea utilizando la técnica de regresiones al parecer no correlacionadas o SUR (seemingly unrelated regressions). Aplicaciones prácticas de este método se pueden encontrar en Nayga (1995) y Byrne, Capps y Saha (1996).
Shonkwiler y Yen (1999) criticaron el estimador Heien-Wessells argumentando que las estimaciones obtenidas son inconsistentes. Como alternativa, estos autores propusieron un método consistente de estimación en dos pasos que, de acuerdo a sus resultados obtenidos a través de simulaciones de Monte Carlo, supera el procedimiento de Heien y Wessells.

Para un sistema de demanda compuesto por $\mathrm{K}$ bienes, se deben estimar $\mathrm{K}$ diferentes ecuaciones. En ese marco, la expresión (11) representa un sistema de $\mathrm{K}$ ecuaciones de nivel aumentadas que pueden ser estimadas mediante SUR (Heien y Wessells, 1990). Shonkwiler y Yen (1999) sugirieron que la estimación de sistemas censurados requiere de procedimientos que utilicen la totalidad de la muestra ${ }^{18}$. Siguiendo a Maddala (1983), si para cada una de las K ecuaciones en (8), en vez de utilizar solamente las observaciones distintas de cero, se utilizan todas las observaciones de la muestra, la media incondicional de $q_{t}$ es, si $E\left(q_{t} \mid d_{t}^{*}>0\right)$ se define como tal como aparece en (11):

$$
\begin{aligned}
& E\left(q_{t}\right)=\operatorname{Pr}\left(d_{t}^{*}>0\right) \times E\left(q_{t} \mid d_{t}^{*}>0\right)+\operatorname{Pr}\left(d_{t}^{*} \leq 0\right) \times E\left(q_{t} \mid d_{t}^{*} \leq 0\right) \\
& =\Phi_{t}\left(\mathbf{v}_{t}^{\prime} \varphi\right) \times\left[f\left(\mathbf{w}_{t}, \theta\right)+\delta \frac{\phi_{t}\left(\mathbf{v}_{t}^{\prime} \varphi\right)}{\Phi_{t}\left(\mathbf{v}_{t}^{\prime} \varphi\right)}\right]+\left[1-\Phi_{t}\left(\mathbf{v}_{t}^{\prime} \varphi\right)\right] \times 0 \\
& =\Phi_{t}\left(\mathbf{v}_{t}^{\prime} \varphi\right) \times f\left(\mathbf{w}_{t}, \theta\right)+\delta \phi_{t}\left(\mathbf{v}_{t}^{\prime} \varphi\right) . \quad t=1, \ldots, \mathrm{T}
\end{aligned}
$$

Si $\phi\left(\mathbf{v}_{t}^{\prime} \varphi\right)$ es la función de densidad de probabilidad normal estándar para la ecuación probabilística, $\Phi\left(\mathbf{v}_{t}^{\prime} \varphi\right)$ es la función de distribución acumulada y $\delta$ es un parámetro adicional a ser estimado; para un sistema de $\mathrm{K}$ ecuaciones (bienes de interés) y T observaciones (hogares), la ecuación (12) puede escribirse, agregando un término para las disturbancias, como:

\footnotetext{
${ }^{18}$ Shonkwiler y Yen (1999) argumentaron que este es un método que se fundamenta en el uso de únicamente de las observaciones no limitadas, o sea de un subconjunto de la muestra total, tal como el procedimiento de Heckman. La esperanza condicional en (11) implica entonces una esperanza incondicional $E\left(q_{t}\right)=f\left(\mathbf{w}_{t}, \theta\right)+$ $2 \delta \times \phi\left(\mathbf{v}_{t}^{\prime} \varphi\right)$ que se desvía de las expresiones de medias incondionales de las especificaciones convencionales para variables dependientes censuradas (Shonkwiler y Yen, 1999, pp. 972-73).
} 


$$
q_{t k}=\Phi\left(\mathbf{v}_{t k}{ }^{\prime} \varphi_{k}\right) \times f\left(\mathbf{w}_{t k}, \theta_{k}\right)+\delta_{k} \phi\left(\mathbf{v}_{t k}{ }^{\prime} \varphi_{k}\right)+\varepsilon_{t k}, t=1, \ldots, \mathrm{T} ; k=1, \ldots, \mathrm{K}
$$

La estimación del sistema se lleva a cabo mediante un procedimiento en dos pasos, usando todas las observaciones. En el primer paso, los parámetros $\varphi_{k}$ de las ecuaciones probabilísticas en (7) se estiman en forma consistente mediante el método de máxima verosimilitud o MMV. La función de verosimilitud es globalmente cóncava en $\varphi$, el máximo local y el global es el mismo y la iteración por Newton-Raphson brinda una estimación directa (Amemiya, 1994).

Johnston y Dinardo (1997) sostienen que no es de gran utilidad presentar meramente los coeficientes de un modelo probabilístico, a menos que lo único que interese realmente sea el signo y la significancia estadística de los mismos. Los coeficientes de un Probit no tienen ninguna interpretación per se. Por esta razón, se recomienda computar los efectos marginales de las variables que se estima determinan la probabilidad de adquirir un producto específico para su consumo. Así, la derivada de la iésima ecuación en (7), con respecto a su $h^{\text {ésimo }}$ regresor, $v_{i h}$, representa el cambio en la probabilidad de gastar dinero en el producto de interés debido al cambio unitario en $v_{i h}$. Para $h=1, \ldots, \mathrm{H}$ regresores y para $i=1, \ldots, \mathrm{K}$ ecuaciones Probit presentes en (7):

$$
\frac{\partial P_{i}}{\partial v_{i h}}=\varphi_{h} \times \phi\left(\mathbf{v}_{i}{ }^{\prime} \varphi\right) .
$$

La ecuación (14) ofrece una medida del efecto marginal que la variable $v_{h}$ tiene sobre la probabilidad de consumir el producto $i$.

En el segundo paso, las estimaciones obtenidas para $\varphi$ son utilizadas para compu$\operatorname{tar} \phi$ y $\Phi$. El sistema de ecuaciones en (8) se puede estimar en forma simultánea mediante MMV o SUR para obtener estimaciones consistentes para los parámetros $\theta_{k}$ y $\delta_{k}$. Como parte del paquete propuesto en este estudio, se sugiere el uso del MMV. Cuando se utiliza esta técnica, el proceso de estimación implica la iteración simultánea sobre todos los parámetros y la matriz de covarianza de los residuos. Es de esperar que aún con modelos lineales, el proceso pueda tomar bastante más que una iteración antes de lograr convergencia.

El término de error, $\varepsilon_{t k}$ in (13) tiene media cero pero es heterosquedástico. Como consecuencia, las estimaciones obtenidas mediante MMV o SUR son consistentes pero ineficientes. Como procedimiento de ajuste de la matriz de varianza-covarianza de los parámetros estimados se sugiere seguir el procedimiento desarrollado por Murphy y Topel (1985), tal como recomiendan Shonkwiler y Yen (1999).

En realidad, Murphy y Topel (1985) propusieron la corrección para un estimador bietápico proveniente de un modelo con una sola ecuación de decisión (probit) y una de nivel (regresión). Yen (comunicación personal), advirtió esta importante diferencia con el estimador de Shonkwiler y Yen (1999), que prevé múltiples ecuaciones de decisión en la primera etapa y un sistema de ecuaciones a ser estimadas simultáneamente en la segunda. Como consecuencia, la estimación por separado de los modelos probit podría ser considerada como un único modelo probit multivariado con una única matriz de covarianza de errores bloque-diagonal.

Siguiendo a Yen y Kan (2000), para proceder a la corrección de la matriz de varianzas-covarianzas primero se denotan las $\mathrm{H}$ funciones logarítmicas de verosimilitud de las ecuaciones probit como $L_{11}\left(\varphi_{1}\right), L_{12}\left(\varphi_{2}\right), \ldots$, $L_{H}\left(\varphi_{H}\right)$, y el modelo de sistema de ecuaciones de la segunda etapa como $L_{2}\left(\theta_{1}, \varphi_{1}, \varphi_{2}, \ldots\right.$, $\left.\varphi_{\mathrm{H}}, \theta\right)$. Extendiendo los resultados de Murphy y Topel (1985), la matriz K×K de varianzascovarianzas de $\theta$ es:

$\Sigma=R_{2}^{-1}+R_{2}^{-1}\left[R_{3}{ }^{\prime} R_{1}^{-1} R_{3}-R_{4}{ }^{\prime} R_{1}^{-1} R_{3}-\right.$
$\left.R_{3}^{\prime} R_{1}^{-1} R_{4}\right] R_{2}^{-1}$

El término $R_{2}$ es la matriz de varianzascovarianzas no ajustada que surge de la estimación por el MMV. Las matrices $R_{1}(\varphi)$, $R_{3}(\varphi, \theta)$ y $R_{4}(\varphi, \theta)$ se definen como: 
$R_{1}(\varphi)=\operatorname{diag}\left[L_{11}\left(\varphi_{1}\right), L_{12}\left(\varphi_{2}\right), \ldots, L_{1 \mathrm{H}}\left(\varphi_{\mathrm{H}}\right)\right]$,

$R_{3}(\varphi, \theta)=\left[R_{31}{ }^{\prime}\left(\varphi_{1}, \theta\right)|\ldots| R_{3 \mathrm{H}^{\prime}}\left(\varphi_{\mathrm{H}}, \theta\right)\right]^{\prime}$,

$R_{4}(\varphi, \theta)=\left[R_{41}{ }^{\prime}\left(\varphi_{1}, \theta\right)|\ldots| R_{4 \mathrm{H}^{\prime}}\left(\varphi_{\mathrm{H}}, \theta\right)\right]^{\prime}$

y $\operatorname{para} h=1,2, \ldots, \mathrm{H}$,

$R_{1 h}\left(\varphi_{h}\right)=E \frac{\partial L_{1 h}}{\partial \varphi_{h}}\left(\frac{\partial L_{1 h}}{\partial \varphi_{h}}\right)^{\prime}=-E \frac{\partial L_{1 h}}{\partial \varphi_{h} \partial \varphi_{h}{ }^{\prime}}$,

$R_{3 h}\left(\varphi_{h}, \theta\right)=E \frac{\partial L_{2}}{\partial \varphi_{h}}\left(\frac{\partial L_{2}}{\partial \theta}\right)^{\prime}=-E \frac{\partial L_{2}}{\partial \varphi_{h} \partial \theta^{\prime}}$,

$R_{4 h}\left(\varphi_{h}, \theta\right)=E \frac{\partial L_{1 h}}{\partial \varphi_{h}}\left(\frac{\partial L_{2}}{\partial \theta}\right)^{\prime}$.

En resumen, el procedimiento en dos pasos propuesto Shonkwiler y Yen (1999) para la estimación de sistemas de ecuaciones censuradas se destaca como una alternativa interesante, cuando la aplicación directa de los métodos de máxima verosimilitud se torna difícil de implementar debido a las complejidades de la forma funcional escogida o al tamaño del sistema.

Posteriormente, Yen y Kan (2000) estimaron un sistema translogarítmico compuesto de tres ecuaciones, para analizar la demanda por grasas y aceites usando datos transversales. Por otro lado Schmit y otros (2000) aplicaron este método con ecuaciones de demanda, al nivel de hogares, para diferentes tipos de quesos y otros productos lácteos. En Uruguay, Lanfranco, García y Caputi (2006) utilizaron el modelo LinQuad en el marco de un sistema incompleto de ecuaciones censuradas y estimaron elasticidades de demanda para cuatro grandes categorías de alimentos (farináceos, arroz, carne bovina y productos lácteos).

\subsubsection{Sistemas incompletos de demanda con datos censurados}

En este trabajo, la expresión general de la función de demanda, representada en la expresión (8) como $q_{i}=f_{i}\left(\mathbf{w}_{t}, \theta\right)$ se especifica como una relación lineal en todos sus parámetros. El análisis empírico de un sistema de demanda por alimentos como el discutido hasta aquí, considera la posibilidad de trabajar con un número considerablemente alto de bienes (ecuaciones) y una gran cantidad de observaciones (tamaño de muestra), como las que normalmente aparecen en las encuestas de datos transversales. En ese marco, el paquete metodológico propuesto se convierte en una alternativa muy atractiva.

A los efectos de cerrar el círculo que combina el enfoque de sistemas incompletos de demanda con la estimación de sistemas de ecuaciones censuradas, resta definir la expresión final que liga ambas ideas. Esto se obtiene mediante la sustitución del término $f\left(\mathbf{w}_{t}, \theta\right)$ que aparece en (13) por la expresión final de la función de demanda de tipo LinQuad presentada en (6).

Como el nivel de censura de cada variable dependiente está determinado por diferentes procesos estocásticos, el desempeño del modelo no es insensible a la elección de la ecuación a ser desestimada, a los efectos de evitar la singularidad de la matriz de varianza-covarianza. En el marco de un sistema incompleto de demanda, la elección se torna fácil, optándose lógicamente por el descarte de la ecuación que representa al bien compuesto.

Como uno de los objetivos del análisis empírico de un sistema de demanda es la de obtener estimaciones de las elasticidades precio (directas y cruzadas) e ingreso, la presentación del paquete propuesto se completa con el cómputo de las mismas. Para ello se definen $\bar{p}, \bar{q}$, e $\bar{y}$ como las medias muestrales para $p, q$ e $y$, respectivamente. Aplicando la fórmula general que define a la elasticidad punto de una función $y=f(x)$, $E=(\partial y / \partial x) .(x / y)$ a la ecuación (13), las respectivas elasticidades ingreso $\left(\eta_{i}\right)$ y precio $\left(\varepsilon_{i j}\right)$, con respecto a la media, para $i, j=1$, ..., $\mathrm{K}$, se estiman respectivamente como:

$$
\eta_{i}=\Phi\left(\mathbf{v}_{i}^{\prime} \varphi_{i}\right) \times \gamma_{i} \times \frac{\bar{y}}{q_{i}},
$$

$\varepsilon_{i j}=\Phi\left(\mathbf{v}_{i}^{\prime} \varphi_{i}\right) \times\left\{\beta_{i j}-\gamma_{i} \times\left[\alpha_{j}+\sum_{k=1}^{\mathrm{K}} \beta_{k j} \bar{p}_{j}+\sum_{l=1}^{\mathrm{L}} \chi_{k l} \bar{g}_{l}\right]\right\} \times \frac{\bar{p}_{j}}{\bar{q}_{i}}$, 
La práctica, muy frecuente en los estudios de demanda, de presentar solamente las estimaciones punto de las elasticidades ha sido muy criticada por diversos autores (Miller, Capps y Wells, 1984; Dorfman, Kling y Sexton, 1990). Por esta razón, se recomienda que, aunque las elasticidades se calculen con respecto a las medias, cada estimación punto se vea acompañada de los límites inferior y superior de un intervalo de confianza definido, por ejemplo 90\%. Una de las posibilidades para lograr esto es mediante el llamado «método delta» (Hogg y Craig, 1995). En forma resumida, expresando la elasticidad en forma genérica como $\kappa=f(\Theta$, $Z$ ), una función del vector de parámetros $\Theta$, los cuales son a su vez variables aleatorias cuyo valor real es desconocido, y de la matriz de observaciones $Z$, la varianza estimada para la elasticidad $k$ se puede calcular como:

$\operatorname{Var}(\kappa) \approx\left(\frac{\partial f}{\partial \Theta}\right) \operatorname{Var}(\Theta)\left(\frac{\partial f}{\partial \Theta}\right)$.

Si el nivel de significación perseguido para el cálculo de los límites inferior y superior es $a$, el intervalo de confianza de nivel (1- $\alpha) \%$ se construye como:

$$
(1-\alpha) \% \text { C.I. }=\kappa \pm t_{(\alpha / 2)} \times \sqrt{\operatorname{Var}(\kappa)}
$$

Finalmente y tal como surge del análisis desarrollado hasta aquí, las elasticidades precio estimadas a partir de (17) son elasticidades no compensadas (marshallianas). Definiendo como $w_{i}$ a la proporción del ingreso del hogar destinada al consumo del producto $j=1, \ldots, \mathrm{K}$, la obtención de elasticidades precio compensadas (hicksianas) es posible a partir de las no compensadas utilizando la ecuación de Slutsky, tal que:

$$
\xi_{i j}=\varepsilon_{i j}+\eta_{i} \times w_{j} \quad i, j=1, \ldots, \mathrm{K},
$$

\section{MATERIALES Y MÉTODOS}

\subsection{Construcción de la base de datos para el estudio}

\subsubsection{Características de las encuestas de gastos e ingresos}

La presente investigación utilizó micro datos de la Encuesta de Gastos e Ingresos de los Hogares de 1994-1995 (EGIH95) y de la Encuesta Nacional de Gastos e Ingresos de los Hogares de 2005-2006 (ENGIH05), ambas conducidas por el INE. Una vez cada 10 años, el INE realiza este tipo de encuesta a los efectos de estimar la estructura del consumo privado y su relación con los ingresos de los hogares, con el objetivo de actualizar las ponderaciones del IPC. La gran riqueza de la información relevada permite otros usos, potenciando los análisis en el área económica y social (INE, 1996; 2008).

Según lo establecido por el INE, las estadísticas de ingresos y gastos generadas por las encuestas se utilizan para generar distribuciones de los ingresos y gastos de consumo entre los hogares con el fin de estudiar los grupos de población que se encuentran en el nivel más bajo de esa distribución (pobreza) o medir su dispersión (desigualdad). Adicionalmente, le permite analizar las características de los grupos de población correspondientes a los diferentes niveles de distribución de ingresos y de gastos de consumo.

La información recabada posibilita medir el nivel, la naturaleza y la estructura de las condiciones de vida de los hogares en el transcurso del tiempo, de subgrupos de población como los ancianos, los jóvenes y diversas categorías de trabajadores (INE, 2008). Dichas estadísticas también se utilizan para formular, aplicar, supervisar y evaluar la repercusión de las políticas económicas y el bienestar social, como ser los efectos redistributivos de la tributación y políticas fiscales en los ingresos de los hogares, los efectos de las políticas estatales de prestaciones en la distribución de ingresos y consumo, y los programas de apoyo de ingresos de la seguridad social, entre otros. 
La unidad de análisis utilizada en el presente estudio fue el hogar particular, definido por la EGIH95 como el conjunto de personas que compartían un único fondo común para sus gastos y residían en una misma vivienda (INE, 1996). En la ENGIH05, esta definición se ajustó y abarcó al conjunto de personas que vivían bajo el mismo techo y compartían al menos los gastos en alimentación. En esta última encuesta se agregaron como unidades de análisis la vivienda y los miembros del hogar (INE, 2008).

La EGIH95 se llevó a cabo en ciudades de más de 10.000 habitantes, siguiendo las pautas del Censo de Población y Vivienda de 1985. La encuesta abarcó a los hogares particulares, registrándose ingresos y gastos mensuales, así como los componentes principales del gasto. El tamaño de la muestra fue de 1.916 hogares en Montevideo y 1.833 hogares en el interior urbano, comprendiendo los departamentos de Colonia, Durazno, Maldonado, Salto, Rivera. El universo de interés se definió como el conjunto de los hogares particulares (no colectivos) que residían en las zonas geográficas cubiertas por la encuesta (urbanas). La unidad de muestreo a través de la cual se llegó a los hogares fue la vivienda (INE, 1996).

Por su parte, el universo investigado en la ENGIH05 abarcó al conjunto de todos los hogares particulares residentes en el país, independientemente que dichos hogares residieran en viviendas particulares o en viviendas colectivas (INE, 2008). Este universo es más amplio que el considerado en la encuesta anterior. Su alcance se extendió a Montevideo (urbano y rural), localidades urbanas pequeñas, medianas y grandes del interior así como las áreas rurales del interior.

La unidad de muestreo continuó siendo la vivienda ocupada como asiento principal de uno o más hogares, mientras se definió a la vivienda principal del hogar como la unidad de observación. En la muestra final se consideraron todos los hogares residentes en las viviendas seleccionadas, con excepción de viviendas en las que residían más de dos hogares, donde se sortearon dos de ellas para ser incluidas en la muestra final (INE, 2008).

El tamaño de la muestra teórica de la ENGIH05 fue de 2.780 hogares en Montevi- deo y 4.540 hogares en el interior urbano y rural, totalizando 7.320 viviendas. Finalmente, se entrevistaron 7.043 hogares ubicados en 7.009 viviendas. Estas diferencias hacen que la comparación intertemporal de las encuestas (1994-1995 vs 2005-2006) deba hacerse con reparos. Mientras que en la encuesta 1994-1995 sólo se incluyeron en la muestra los hogares del interior de cinco localidades grandes, en 2005-2006 se encuestaron hogares de todo el interior del país.

Una de las principales variables indagadas en ambas encuestas fue el ingreso corriente de los perceptores del hogar. Este ingreso fue definido como el surgido de «entradas con periodicidad regular que contribuyen al bienestar económico», excluyendo entradas resultantes de la reducción del patrimonio neto (INE, 2008). Se consideraron perceptores aquellos miembros del hogar con 14 años o más que recibían algún ingreso corriente sin importar la fuente generadora. Como período de referencia se consideró el ingreso mensual. Los ingresos provinieron de diferentes fuentes: empleo (asalariado o independiente), propiedad de activos reales, propiedad de activos financieros, producción de servicios en el hogar para consumo propio o transferencias percibidas como servicios o en efectivo del Estado (jubilaciones, pensiones) (INE, 2008).

El gasto de consumo de los hogares fue entendido como el valor de los bienes (duraderos y no duraderos) y servicios de consumo adquiridos (utilizados o pagados) por un hogar para la satisfacción directa de las necesidades de sus miembros (INE, 2008). Esta definición consideró el criterio de valoración de «lo adquirido» a precio comprador, que es el «precio contado pagado efectivamente, incluyendo los impuestos indirectos abonados por el comprador y excluyendo los intereses por las compras a crédito, en el momento en que se realizó la compra, cuando se adquirió la propiedad del bien o se realizó la prestación del servicio, independientemente que se consumieran o pagaran durante el período de referencia» (INE, 1996).

Las encuestas relevaron información sobre valores y cantidades consumidas, para la mayoría de los bienes consumidos y con 
especial énfasis en los gastos de alimentación (INE, 2008). En el caso de alimentos y bebidas las encuestas consideraron un período de referencia de una semana. Por otro lado, el gasto de «no consumo» incluyó multas, impuestos, cuotas de pago de vivienda, primas de seguros, entre otros. Finalmente, tanto la EGIH95 como la ENGIH05 recogieron información sobre las características del hogar y la vivienda y características sociodemográficas de sus miembros.

\subsubsection{Selección y descripción de las variables de interés}

A partir de los datos completos de cada encuesta (EGIH95 y ENGIH05) se construyó una nueva base de datos para cada período, con las variables de interés para la presente investigación. Cada base quedó conformada con las mismas variables por lo que la descripción de dichas variables es común para ambas. En el caso de que la misma variable tuviera distinto nombre en la EGIH95 y en la ENGIH05, se adoptó una denominación común para evitar confusiones.

La unidad de análisis fue el hogar particular por lo que cada observación de la muestra se correspondió con un hogar encuestado. Cada hogar fue caracterizado a través de variables demográficas y socioeconómicas que incluyeron el ingreso y el gasto en alimentación contemplando productos y cantidades adquiridas, así como el gasto en todos los demás rubros, tanto de consumo como de no consumo.

No todas las variables seleccionadas fueron utilizadas en su forma original dentro del modelo de análisis empírico. Mientras que algunas debieron ser transformadas antes de ser incluidas en el modelo, otras fueron dejadas de lado en tanto que cumplían una función meramente descriptiva o informativa. Las variables finalmente utilizadas en la estimación se describen a continuación:

\section{Variables demográficas y socioeconómicas}

HH (Hogar): En las encuestas del INE se consideró que cada vivienda podía albergar hasta dos hogares. Por esa razón, a partir de las variables originales 'vivienda' (VIV) y 'número de hogar' (HOG) se configuró una variable denominada 'hogar' $(\mathrm{HH})$. Se trata de una variable numérica única incluida en el modelo al solo efecto de mantener la identificación de cada observación (hogar).

MVD (Montevideo/Interior): Es una variable binaria que adquirió valor MVD = 1 cuando el hogar estaba radicado en Montevideo y valor MVD $=0$ cuando el hogar estaba radicado en el interior del país. Se construyó a partir de la variable original 'departamento' (DEPTO).

THG (Tamaño del Hogar): Es una variable numérica entera que indica la cantidad de personas integrantes del hogar.

EQH (Total de Equivalente Adultos en el Hogar): Es una variable numérica que indica la cantidad de personas integrantes del hogar expresada en una unidad denominada equivalente adulto o $\mathrm{EQH}$. El uso de esta medida obedece a que el tamaño de hogar, expresado simplemente por la cantidad de integrantes (THG) puede no ser adecuada para la estimación de elasticidades de demanda. En efecto, se espera que adultos y menores tengan hábitos diferentes respecto a la demanda de alimentos en un hogar, tanto en cantidad como en tipo. Esto es esperable incluso entre individuos de la misma edad pero de distinto sexo. La forma más frecuente de enfocar este problema ha sido asignar ponderadores o pesos diferentes a los distintos integrantes, de acuerdo al sexo y la edad. En la literatura han existido diferentes formas de establecer dichos pesos (Price, 1970; Buse y Salathe, 1978; Muellbauer, 1980; Brown y Johnson, 1984; Deaton, 1997; Demoussis y Mihalopoulos, 2001). En este estudio se optó por utilizar la llamada Escala de Ámsterdam. Esta escala representa a los miembros del hogar en relación a una unidad referencial (que adopta el valor $\mathrm{EQH}=1$ ), correspondiente a un adulto de sexo masculino, de 18 años o mayor. En el mismo sentido, una mujer adulta representa 0,9 EQH; jóvenes de sexo masculino y entre 14 y 17 años de edad equivalen a 0,98 EQH en tanto que si son de sexo femenino equivalen a 0,90 . Finalmente, individuos de ambos sexos por debajo de los 14 años de edad se consideran como 0,52 EQH 
(Deaton y Muellbauer, 1980a). La variable agregada EGHT se construyó admitiendo hasta dos lugares decimales.

M18 (Cantidad de Menores de 18 Años en el Hogar): Es una variable numérica entera que indicó la cantidad integrantes del hogar por debajo de los 18 años de edad al momento de la encuesta.

P18 (Presencia de Menores de 18 Años en el Hogar): Es una variable binaria que adquirió valor M18 = 1 cuando en el hogar había al menos un menor de edad y valor M18 = 0 cuando no lo había. Se construyó a partir de la variable anterior (MEN18).

S64 (Cantidad de Mayores de 64 Años en el Hogar): Es una variable numérica entera que indicó la cantidad integrantes del hogar que eran mayores a 64 años de edad al momento de la encuesta.

P64 (Presencia de Mayores de 64 Años en el Hogar): Es una variable binaria que adquirió valor S64 = 1 cuando en el hogar había al menos un integrante mayor a 64 años edad y valor S64 = 0 cuando no lo había. Se construyó a partir de la variable anterior (MAY64).

EJH (Edad del Jefe de Hogar): Es una variable numérica entera para la edad del jefe de hogar (en años).

MUJ (Mujer al frente del Hogar): Es una variable binaria que adquirió valor $\mathrm{MUJ}=1$ cuando el jefe de hogar era de sexo femenino y valor $\mathrm{MUJ}=0$ cuando era de sexo masculino. Se construyó a partir de la variable original 'Sexo del Jefe de Hogar' (SEXO).

ED1 (Jefe de Hogar con Educación Máxima hasta Primaria Completa): Es una variable binaria que adquirió valor ED1 = 1 cuando el nivel de educación declarado para el jefe de hogar era de 'Preescolar o Jardín' o 'Primaria'. La variable adquirió valor ED1 = 0 cuando se declaró otro nivel de educación. Se construyó a partir de la variable original 'Nivel de Educación del Jefe de Hogar' (EDUC).

ED2 (Jefe de Hogar con Educación Máxima hasta Secundaria Completa): Es una variable binaria que adquirió valor ED2 = 1 cuando el nivel de educación declarado para el jefe de hogar era de 'Secundaria 1er ciclo' o 'Secundaria 2do ciclo'. La variable adquirió valor ED2 $=0$ cuando se declaro otro nivel de educación. Se construyó a partir de la variable original 'Nivel de Educación del Jefe de Hogar' (EDUC).

ED3 (Jefe de Hogar con un Máximo de Educación Técnica u Otra): Es una variable binaria que adquirió valor ED3 = 1 cuando el nivel de educación declarado para el jefe de hogar era de 'UTU', 'Magisterio o Profesorado', 'Instituto Militar' u 'Otro'. La variable adquirió valor ED3 = 0 cuando se declaro otro nivel de educación. Se construyó a partir de la variable original 'Nivel de Educación del Jefe de Hogar' (EDUC).

ED4 (Jefe de Hogar con Educación Máxima hasta Universidad o Superior): Es una variable binaria que adquirió valor ED4 = 1 cuando el nivel de educación declarado para el jefe de hogar era 'Universidad'. Adquirió ED4 = 0 cuando se declaro otro nivel de educación. Se construyó a partir de la variable original 'Nivel de Educación del Jefe de Hogar' (EDUC).

EDS (Jefe de Hogar con Nivel de Educación Mayor a Primaria): Es una variable binaria que adquirió valor EDS = 1 cuando el nivel de educación declarado para el jefe de hogar era superior a 'Primaria'. La variable adquirió valor EDS = 0 cuando se declaró un nivel educativo máximo correspondiente a 'Primaria Completa' (ED1) otro nivel de educación. Se construyó a agrupando las restantes variables (ED2+ED3+ED4).

ISH (Ingreso Semanal del Hogar): Es una variable numérica entera que contabiliza el ingreso total del hogar, tomado a nivel semanal y expresado en pesos corrientes (\$/semana). Antes de ser utilizado en el modelo, el ingreso fue deflactado por el precio PO de todos los demás bienes de la economía, definido más adelante. Las encuestas del INE presentan los datos de consumo y gasto a nivel semanal, razón por la cual se adoptó dicho lapso para los ingresos. Asumiendo el axioma de «no saciedad» se consideró que el ingreso total del hogar es análogo al gasto total del hogar realizado por todo concepto (bienes durables, no durables, servicios, etc.) durante el período. Para las ecuaciones de decisión se consideró el logaritmo del ingreso semanal (LIS). 


\section{Variables de consumo semanal en alimentos de origen cárnico}

Las variables referidas al consumo de los distintos tipos de carnes no eran exactamente iguales en ambas encuestas, por lo que en varios casos debieron ser reagrupadas en variables análogas para ambos períodos de estudio con una excepción (asado y cortes del delantero en el caso carne bovina) que será especificada en esta sección.

Por lo general, la apertura de las variables referidas al consumo de productos alimenticios cárnicos fue mayor en la ENGIH05 que en la EGIH95, por lo que el grado de desagregación de los productos estuvo limitado, en primera instancia, por dicha circunstancia. Se consideró un total de trece productos: seis de carne bovina, uno de carne ovina, uno de carne porcina, uno de carne aviar, uno de pescados y mariscos, dos referidos a fiambres, embutidos y conservas de carne y uno de comidas preparadas en base a carne. El consumo de carne bovina se analizó a través de seis grandes productos (variables): 'cortes del trasero sin hueso' (TSH), 'cortes del trasero con hueso' (TCH), 'carne picada' (PIC), 'asado' (ASA), 'cortes del delantero' (DEL) y 'otros cortes de carne vacuna' (VOT).

El Cuadro 7 permite apreciar la conformación de los productos considerados en base a las variables originales de las dos encuestas. En este caso particular, el grado de desagregación estuvo limitado básicamente por la EGIH95. Como excepción y debido a la relevancia del consumo de asado en el mercado interno, para el período 2005-2006 la estimación de demanda consideró las variables ASA y DEL por separado en tanto que para el período 1994-1995 la estimación debió considerarlas como un solo producto, denominado 'asado y delantero' (AYD).

Cuadro 7. Variables definidas para los productos de carne bovina.

\begin{tabular}{|c|c|c|c|}
\hline \multicolumn{2}{|r|}{ Período 1994-1995 (EGIH95) } & \multicolumn{2}{|r|}{ Período 2005-2006 (ENGIH05) } \\
\hline Código & Descripción & Código & Descripción \\
\hline \multicolumn{4}{|c|}{ TRASERO SIN HUESO (TSH) } \\
\hline \multirow{4}{*}{112110} & \multirow{4}{*}{ Carne vacuna, corte trasero sin hueso } & 0067 & Nalga, vacío y bola de lomo \\
\hline & & 0068 & Lomo \\
\hline & & 0069 & $\begin{array}{l}\text { Cuadril, nalga, picaña, peceto, bife } \\
\text { angosto, colita de cuadril }\end{array}$ \\
\hline & & 0070 & Carne para milanesa \\
\hline \multicolumn{4}{|c|}{ TRASERO CON HUESO (TCH) } \\
\hline \multirow{3}{*}{112111} & \multirow{3}{*}{ Carne vacuna, corte trasero sin hueso } & 0071 & Cadera, rueda \\
\hline & & 0078 & Costillas con lomo \\
\hline & & 0079 & Costilla redonda, costilla sin lomo \\
\hline \multicolumn{4}{|c|}{ CARNE PICADA (PIC) } \\
\hline 112121 & Carne picada común & 0072 & Carne picada común \\
\hline \multirow{2}{*}{112123} & \multirow{2}{*}{ Carne picada especial } & 0073 & Carne picada especial \\
\hline & & 0074 & Carne picada magra \\
\hline \multicolumn{4}{|c|}{ ASADO Y DELANTERO (AYD en 1994-95; ASA y DEL en 2005-06) } \\
\hline \multirow{2}{*}{112122} & \multirow{2}{*}{$\begin{array}{l}\text { Carne vacuna, cortes delanteros } \\
\text { (incluyendo asado) }\end{array}$} & 0075 & Asado de tira \\
\hline & & 0076 & Aguja, falda, paleta matambre \\
\hline \multicolumn{4}{|c|}{ CARNE VACUNA OTROS (VOT) } \\
\hline 112123 & Puchero, cogote, garrón, osobuco & 0077 & Osobuco, cogote, garrón \\
\hline 112130 & Achuras de vaca & \multirow{2}{*}{0121} & \multirow{2}{*}{$\begin{array}{l}\text { Menudencias, achuras de vaca, } \\
\text { mondongo }\end{array}$} \\
\hline 112131 & Menudencias & & \\
\hline 112132 & Seso, molleja & 0122 & Seso, molleja \\
\hline
\end{tabular}


En el caso de otras carnes, diferentes a la bovina, si bien el desglose considerado en las encuestas hubiera permitido definir al menos dos o tres productos para cada una, esto no fue posible debido al bajo número de observaciones de las variables originales. Como consecuencia, éstas, debieron ser representadas por una única variable: 'carne ovina' (OVI), 'carne porcina' (POR), 'carne aviar' (AVE) y 'pescados y mariscos' (PYM). En el caso de carnes de otras especias (conejo, liebre y otros animales de caza), no fue posible manejar un número mínimo de observaciones para el análisis estadístico, razón por la cuál fueron descartadas. En el Cuadro 8 se aprecia cómo se conformaron dichas variables.

Cuadro 8. Variables definidas para los productos de otras carnes.

\begin{tabular}{|c|c|c|c|}
\hline \multicolumn{2}{|r|}{ Período 1994-1995 (EGIH95) } & \multicolumn{2}{|r|}{ Período 2005-2006 (ENGIH05) } \\
\hline Código & Descripción & Código & Descripción \\
\hline \multicolumn{4}{|c|}{ CARNE OVINA (OVI) } \\
\hline 112210 & Cordero entero & 0080 & Cordero entero, oveja entera \\
\hline 112220 & Carne ovina (cortes) & 0081 & Carne ovina, cortes de cordero y oveja \\
\hline \multicolumn{4}{|c|}{ CARNE PORCINA (POR) } \\
\hline 112310 & Lechón y cerdo entero & 0082 & Lechón y cerdo entero \\
\hline \multirow[t]{2}{*}{112320} & \multirow[t]{2}{*}{ Carne de cerdo } & 0083 & $\begin{array}{l}\text { Cost. de cerdo, pechito, asado de } \\
\text { espinazo }\end{array}$ \\
\hline & & 0084 & Carré y pulpa de cerdo \\
\hline 112321 & Partes del cerdo, otras & 0085 & $\begin{array}{l}\text { Partes de cerdo, otras (cortes tras. } \\
\text { c/hueso) }\end{array}$ \\
\hline \multicolumn{4}{|c|}{ CARNE AVIAR (AVE) } \\
\hline \multirow{4}{*}{112410} & \multirow{4}{*}{ Pollo } & 0086 & $\begin{array}{l}\text { Entero congelado o fresco, con o sin } \\
\text { menudo }\end{array}$ \\
\hline & & 0087 & Pollo, cortes con hueso \\
\hline & & 0088 & Pulpa de pechuga, supremas \\
\hline & & 0089 & Pamplona de pollo, cruda \\
\hline 112430 & Menudos de ave, otros & 0123 & Menudos de ave, otros \\
\hline \multicolumn{4}{|c|}{ PESCADOS Y MARISCOS (PYM) } \\
\hline 112110 & Pescados frescos & 0124 & Pescados frescos (no fileteado) \\
\hline \multirow{4}{*}{112120} & \multirow{4}{*}{ Bifes de pescado } & 0125 & $\begin{array}{l}\text { Bifes: merluza, corvina, cazón, brótola, } \\
\text { pejerrey, pescadilla }\end{array}$ \\
\hline & & 0126 & $\begin{array}{l}\text { Atún en rodajas, fresco y envasado al } \\
\text { vacío }\end{array}$ \\
\hline & & 0127 & $\begin{array}{l}\text { Bifes de pez espada, lomos de } \\
\text { abadejo }\end{array}$ \\
\hline & & 0128 & Bifes de salmón ahumado \\
\hline 113150 & Bacalao & - & \\
\hline 113140 & Bifes de pescado congelado & 0129 & $\begin{array}{l}\text { Pescado congelado fileteado (merluza, } \\
\text { atún, tronquitos de mar }\end{array}$ \\
\hline 113130 & $\begin{array}{l}\text { Pescados congelados (no fileteados), } \\
\text { otros }\end{array}$ & 0130 & $\begin{array}{l}\text { Pescados congelados (no fileteados), } \\
\text { otros }\end{array}$ \\
\hline- & & 0133 & Pescados secos, ahumados o salados \\
\hline 113160 & Pescados enlatados & 0134 & Pescados enlatados \\
\hline 113170 & $\begin{array}{l}\text { Comidas preparadas en base a } \\
\text { pescado }\end{array}$ & 0136 & $\begin{array}{l}\text { Comidas preparadas en base a } \\
\text { pescado, empanados congelados }\end{array}$ \\
\hline 113210 & Mariscos frescos & 0131 & Mejillones frescos con cáscara \\
\hline 113220 & Mariscos congelados & 0132 & Pulpa de mariscos: mejillones, etc. \\
\hline 113230 & Mariscos en conserva & 0135 & Mariscos en conserva \\
\hline
\end{tabular}


A los efectos de analizar el consumo de fiambres, embutidos, chacinados y conservas se conformaron dos variables, agrupando los productos de acuerdo a si son consumidos en frío o mediante cocción: 'fiambres, embutidos y chacinados - en frío' (FEF) y 'fiambres, embutidos y chacinados - para cocinar' (FEC) (Cuadro 9).

Finalmente, la última variable considerada agrupó a las 'comidas preparadas en base a carnes' (CPC). En este caso se optó por no discriminar los productos según el tipo de carne (Cuadro 10).
Tanto la EGIH95 como la ENGIH05 registraron los datos de consumo semanal de alimentos en cantidades físicas (gramos) y monetarias (pesos). Para los trece productos cárnicos elegidos en este estudio, las variables de consumo en cantidades físicas se diferenciaron anteponiendo la letra $Q$ a las tres letras que identificaban al producto. Las trece variables de cantidades físicas quedaron entonces definidas respectivamente como: QTSH, QTCH, QPIC, QDEL, QASA, QVOT, QOVI, QPOR, QAVE, QPYM, QFEF, QFEC y QCPC. En el caso del gasto mone-

Cuadro 9. Variables definidas para fiambres, embutidos, chacinados y conservas.

\begin{tabular}{|c|c|c|c|}
\hline \multicolumn{2}{|r|}{ Período 1994-1995 (EGIH95) } & \multicolumn{2}{|r|}{ Período 2005-2006 (ENGIH05) } \\
\hline Código & Descripción & Código & Descripción \\
\hline \multicolumn{4}{|c|}{ FIAMBRES, EMBUTIDOS, CHACINADOS Y CONSERVAS-CONSUMO EN FRÍO (FEF) } \\
\hline \multirow{3}{*}{112551} & \multirow{3}{*}{$\begin{array}{l}\text { Jamón, lomito, paleta, bondiola, } \\
\text { salame, pastrami }\end{array}$} & 0095 & $\begin{array}{l}\text { Jamón, lomito, paleta, bondiola, } \\
\text { pastrami, de corte }\end{array}$ \\
\hline & & 0096 & $\begin{array}{l}\text { Jamón, lomito, paleta, bondiola, } \\
\text { pastrami, cortado, envasado al vacío }\end{array}$ \\
\hline & & 0097 & Jamón crudo \\
\hline \multirow{2}{*}{112552} & \multirow{2}{*}{ Fiambres, otros } & 0098 & $\begin{array}{l}\text { Leonesa, mortadela, matambre de } \\
\text { carne relleno, de corte }\end{array}$ \\
\hline & & 0099 & $\begin{array}{l}\text { Leonesa, mortadela, matambre de } \\
\text { carne relleno, envasado al vacío }\end{array}$ \\
\hline \multirow{3}{*}{112554} & \multirow{3}{*}{ Longaniza, salchichón, salame } & 0102 & $\begin{array}{l}\text { Longaniza, salchichón, salame, de } \\
\text { corte }\end{array}$ \\
\hline & & 0103 & $\begin{array}{l}\text { Longaniza, salchichón, salame, al } \\
\text { vacío }\end{array}$ \\
\hline & & 0104 & $\begin{array}{l}\text { Longaniza, chacarero, cantimpalo, } \\
\text { secos }\end{array}$ \\
\hline \multirow[b]{2}{*}{112510} & \multirow[b]{2}{*}{ Conservas de carnes rojas } & 0105 & Carnes secas, saladas, ahumadas \\
\hline & & 0106 & $\begin{array}{l}\text { Corned beef, pasta de jamón, ternera } \\
\text { y salchichas de Viena enlatadas }\end{array}$ \\
\hline 112521 & $\begin{array}{l}\text { Butifarra, longaniza, paté de carne o } \\
\text { hígado }\end{array}$ & 0107 & $\begin{array}{l}\text { Paté de carne o hígado, embutidos, } \\
\text { butifarra }\end{array}$ \\
\hline \multicolumn{4}{|c|}{ FIAMBRES, EMBUTIDOS, CHACINADOS Y CONSERVAS - PARA COCINAR (FEC) } \\
\hline \multirow{2}{*}{112553} & \multirow{2}{*}{ Panceta y tocino } & 0100 & Panceta y tocino, de corte \\
\hline & & 0101 & Panceta y tocino, envasados al vacío \\
\hline 112522 & Chorizos y morcillas & 0111 & Chorizos \\
\hline 112520 & Morcillas & 0108 & Morcillas \\
\hline \multirow[t]{2}{*}{112523} & \multirow{2}{*}{$\begin{array}{l}\text { Frankfurters, pildoritas, húngaras, } \\
\text { salchichas }\end{array}$} & 0109 & $\begin{array}{l}\text { Frankfurters sueltos o envasados al } \\
\text { vacío }\end{array}$ \\
\hline & & 0110 & Salchichas alemanas, suizas \\
\hline 112320 & Carne de cerdo & 0112 & Húngaras \\
\hline- & & 0113 & Pildoritas sueltas o envasadas al vacío \\
\hline 112321 & Partes del cerdo, otras & 0114 & Salchicha parrillera (rueda) \\
\hline
\end{tabular}


Cuadro 10. Variable definida para comidas preparadas en base a carne.

\begin{tabular}{|c|c|c|c|}
\hline \multicolumn{2}{|r|}{ Período 1994-1995 (EGIH95) } & \multicolumn{2}{|c|}{ Período 2005-2006 (ENGIH05) } \\
\hline Código & Descripción & Código & Descripción \\
\hline \multicolumn{4}{|c|}{ COMIDAS PREPARADAS EN BASE A CARNES (CPC) } \\
\hline 112618 & $\begin{array}{l}\text { Milanesa de carne roja, milanesa de } \\
\text { pollo, con fritas. }\end{array}$ & 0115 & $\begin{array}{l}\text { Milanesa de carne, preparada para } \\
\text { freír }\end{array}$ \\
\hline 112622 & Milanesa de pollo, preparada para freír & 0120 & Milanesa de pollo, preparada para freír \\
\hline - & & 4095 & $\begin{array}{l}\text { Milanesa de jamón y queso, preparada } \\
\text { para freír }\end{array}$ \\
\hline \multirow{2}{*}{112621} & \multirow{2}{*}{ Hamburguesas para cocinar } & 0116 & Hamburguesas de carne, para cocinar \\
\hline & & 0119 & Hamburguesas de pollo, para cocinar \\
\hline 112560 & Patés de pollo o pavita & 0117 & Patés de pollo o pavita \\
\hline 112561 & Frankfurters de pollo, lionesa de pollo & 0118 & $\begin{array}{l}\text { Frankfurters y lionesa de pollo, } \\
\text { matambre de pollo, jamón de pavo }\end{array}$ \\
\hline
\end{tabular}

tario, se antepuso la letra E, de modo que las correspondientes quedaron definidas como ETSH, ETCH, EPIC, EDEL, EASA, EVOT, EOVI, EPOR, EAVE, EPYM, EFEF, EFEC y ECPC.

Las encuestas del INE no registran los precios unitarios de compra, los cuales pueden obtenerse directamente para cada observación dividiendo el gasto realizado entre la cantidad física en cada producto consumido. Las correspondientes variables de precios así obtenidas se identificaron respectivamente como: PTSH, PTCH, PPIC, PDEL, PASA, PVOT, POVI, PPOR, PAVE, PPYM, PFEF, PFEC y PCPC. En aquellos casos en que un determinado hogar no hubiera consumido una cantidad positiva de algún producto, el precio del mismo debió ser asignado en forma indirecta. Para cada uno de esos casos se asignó un precio al azar de entre los calculados a partir de hogares que consumieron cantidades positivas del producto de interés durante la misma 'semana' (SEM), en el mismo 'departamento' (DEPTO), 'localidad' (LOC) y 'estrato' (EST) que el hogar en cuestión.

Como ya fue señalado, la encuesta EGIH95 no permitía discriminar el consumo de 'asado' (ASA) del consumo de 'cortes del delantero' (DEL), de modo que para al análisis de dicho período estos debieron utilizarse en forma conjunta, como 'delantero y asado' (AYD). En este caso, las correspondientes variables de cantidad, gasto y precio fueron definidas como QAYD, EAYD y PAYD, respectivamente.
El precio de los restantes bienes de la economía fue identificado mediante la variable P0 y se computó a partir del índice mensual de precios al consumo para 'no alimentos' (IPC-NA), para cada uno de los períodos mencionados. Tanto el ingreso como los precios fueron deflactados mediante $\mathrm{PO}$, de modo que el precio de los restantes bienes de la economía quedó definido como numerario.

\subsection{Métodos econométricos y técnicas de estimación}

\subsubsection{Estimación de las ecuaciones de decisión}

Las ecuaciones dicotómicas o de decisión, $d_{k}=\mathbf{v}_{k}{ }^{\prime} \varphi+e_{k}$, una por cada uno de los productos cárnicos de interés, se modelaron como funciones probabilísticas (probit) y se estimaron mediante el método de máxima verosimilitud o MMV. La variable dicotómica dependiente para cada una de las $k=1,2, \ldots, K$ ecuaciones se creó asignado valor $\mathrm{BE}_{k}=1$ si el hogar consumió el producto de interés en cantidades positivas y $\mathrm{BE}_{k}$ $=0$. Para el período 1994-1995 se consideraron $\mathrm{K}=12$ ecuaciones (productos) mientras que para 2005-2006 el número de ecuaciones (productos) fue $\mathrm{K}=13$.

Las $\mathrm{H}=8$ variables independientes que conformaron el vector $\mathbf{v}_{k}$ fueron: C, LIS, MVD, THG, P18, P64, MUJ y EDS, donde C corresponde a la constante de regresión. A partir 
de los coeficientes $\hat{\varphi}_{k}$ estimados para los correspondientes parámetros y de la función de densidad de probabilidad normal estándar $\varphi_{k}\left(\mathbf{v}_{k}^{\prime} \varphi_{k}\right)$ obteniđa en este primer paso, se computaron los efectos marginales de cada variable $h$ sobre la probabilidad de adquirir el producto $k$. Adicionalmente, se obtuvo la función de densidad acumulada $\Phi_{k}\left(\mathbf{v}_{k}^{\prime} \varphi_{k}\right)$ a ser utilizađa en el segundo paso.

\subsubsection{Estimación del sistema de ecuaciones de regresión}

El sistema de $\mathrm{K}$ ecuaciones de nivel o regresión fue estimado por MMV. La variable dependiente fue el gasto deflactado $e_{k}$. Tras descartarse la ecuación que representa el gasto en todos los demás bienes (bien compuesto), la cantidad de ecuaciones quedó definida como $\mathrm{K}=12$ para 1994-95 (ETSH, ETCH, EPIC, EAYD, EVOT, EOVI, EPOR, EAVE, EPYM, EFEF, EFEC y ECPC) y $\mathrm{K}=$ 13 para 2005-2006 (ETSH, ETCH, EPIC, EDEL, EASA, EVOT, EOVI, EPOR, EAVE, EPYM, EFEF, EFEC y ECPC). Así, cada una de las $k=1, \ldots, K$ ecuaciones del sistema pudo ser expresada como una relación lineal en todos sus parámetros:

$e_{k}=p_{k}\left\{\Phi\left(\mathbf{v}_{k}^{\prime} \hat{\varphi}_{k}\right) \times f\left(\mathbf{w}_{k}, \theta_{k}\right)+\delta_{k} \phi\left(\mathbf{v}_{k}{ }^{\prime} \hat{\varphi}_{k}\right)\right\}+\varepsilon_{k}$

dónde:

$f\left(\mathbf{w}_{k}, \theta_{k}\right)=\alpha_{k}+\sum_{i=1}^{\mathrm{K}} \beta_{k i} p_{i}+\sum_{z=1}^{\mathrm{Z}} \chi_{k z} g_{z}+\gamma_{k}\left[y-\sum_{i=1}^{\mathrm{K}} \alpha_{i} p_{i}-\frac{1}{2} \sum_{j=1}^{\mathrm{K}} \sum_{i=1}^{\mathrm{K}} \beta_{j i} p_{j} p_{i}-\sum_{i=1}^{\mathrm{K}} \sum_{z=1}^{\mathrm{Z}} \chi_{i z} p_{i} g_{z}\right]$

La heterosquedasticidad del término de error, $\varepsilon_{k}$ fue corregida ajustando la matriz de varianza-covarianza mediante el procedimiento desarrollado en la sección 2.1.8.

El vector $\mathbf{w}_{k}$ de variables independientes estuvo conformado por una constante de regresión (c), las $Z$ = 8 variables socioeconómicas $g_{z}$ que caracterizaron a los hogares $(\mathrm{EQH}, \mathrm{M} 18, \mathrm{~S} 64, \mathrm{MUJ}, \mathrm{EJH}, \mathrm{ED} 2, \mathrm{ED} 3$, ED4), dado que ED1 fue descartada para evitar colinearidad, y los $\mathrm{K}$ precios $p_{k}$. Al igual que en el primer paso, como $\mathrm{K}=12$ para 1994-95 (PTSH, PTCH, PPIC, PAYD, PVOT, POVI, PPOR, PAVE, PPYM, PFEF, PFEC Y PCPC) y $K=13$ para 2005-2006 (PTSH,
PTCH, PPIC, PDEL, PASA, PVOT, POVI, PPOR, PAVE, PPYM, PFEF, PFEC y PCPC).

La cantidad de parámetros independientes a ser estimados en el sistema de $\mathrm{K}$ ecuaciones está dada por $\mathrm{L}$, involucrando $\mathrm{K}$ parámetros $\delta$ y un número de parámetros agrupados en $\theta$. Este último vector estuvo conformado por $[\mathrm{K}(\mathrm{K}+1)] / 2$ parámetros $\beta, \mathrm{K}$ parámetros $\alpha, \mathrm{K}$ parámetros $\gamma$, y $\mathrm{K} \times \mathrm{Z}$ parámetros $\chi$. Es así que en el período 19941995 el total de parámetros independientes estimados fue $L=210$ mientras que en 20052006 fue $L=234$.

\subsubsection{Cálculo de las elasticidades de demanda}

Las $\mathrm{K}$ elasticidades ingreso $(\eta)$ y las $\mathrm{K}^{2}$ elasticidades precio no compensadas $(\varepsilon)$ fueron computadas respectivamente a partir de las expresiones (16) y (17). La significación estadística de los coeficientes de regresión no implica necesariamente que las elasticidades estimadas a partir de los mismos también lo sean. Por esa razón, los valores de elasticidad ingreso y elasticidad precio no compensada (directa y cruzada) se acompañaron de los límites inferior y superior respectivos, para un intervalo de confianza de $90 \%$. El intervalo de confianza de las elasticidades se construyó utilizando el método delta, de acuerdo a la expresión (19). Las K²

elasticidades precio compensadas $(\xi)$, en tanto, fueron estimadas utilizando la ecuación de Slutsky especificada en (20) aunque no se presentan en esta serie técnica por no ser el principal interés del estudio.

\section{RESULTADOS Y DISCUSIÓN}

\subsection{Características generales de los hogares}

De los 3.749 hogares incluidos en la muestra del período 1994-95 (EGIH95), la cantidad cuyo jefe de hogar era de sexo fe- 
menino fue 1.002, representando algo más de la cuarta parte $(26,7 \%)$, en tanto que los restantes 2.747 hogares $(73,3 \%)$ declararon que el jefe de hogar era un hombre. La edad promedio del jefe de hogar fue de 53 años para toda la muestra, alcanzando a 59 años en el caso de mujeres jefes de hogar y 51 años en el caso de hombres.

Poco más de la mitad de los hogares considerados en la muestra de EGIH95 se localizó en Montevideo (51\%) mientras que prácticamente la otra mitad se localizó en el interior (49\%). La distribución se mantuvo idéntica aun cuando los hogares se diferenciaran en base al sexo del jefe de hogar.

Para el período 2005-06 (ENGIH05), la cantidad de hogares cuyo jefe era una mujer fue algo mayor a un tercio. Un total de 2.514 hogares sobre $6.931(36,3 \%)$ declararon que el jefe de hogar era una mujer, quedando los restantes 4.417 identificados como hogares cuyo jefe era un hombre $(63,7 \%)$. La edad promedio del jefe de hogar fue de 53 años, al igual que en el período anterior. Para los hogares cuyo jefe de edad era de sexo femenino la edad promedio fue de 56 años mientras que cuando era de sexo masculino alcanzó a 51 años.

Con respecto a la localización geográfica, el $37 \%$ de los hogares que compusieron la muestra para 2005-06 estaba localizado en Montevideo, contra un $63 \%$ del interior. Esta diferencia en comparación con la distribución 50-50 verificada para el primer período se debió a que la encuesta ENGIH05 amplió el universo de hogares encuestados hacia todo el interior del país, incluyendo localidades urbanas y áreas rurales.
El Cuadro 11 presenta la distribución de los hogares participantes de acuerdo al nivel educativo alcanzado por el jefe del hogar. Cada categoría indica el máximo nivel declarado en cada encuesta. La categoría 'Primaria' incluye personas que declararon no haber recibido ninguna educación formal, que cursaron o completaron jardín o educación inicial y que cursaron o declararon tener primaria completa. En esta categoría se encontraron alrededor del $47,8 \%$ de los hogares en el período $1994-95$ y el $45,7 \%$ de los hogares en el período 2005-06. La categoría 'Secundaria' incluye a quienes cursaron o completaron uno o ambos ciclos de educación secundaria (básico y orientado). La proporción de hogares cuyo jefe de hogar su ubicó en este nivel fue de $26,5 \%$ en $1994-95$ y $28,8 \%$ en $2005-06$.

La proporción de jefes de hogar que cursaron o alcanzaron un título universitario llegó a 9,7\% en el primer período de interés y a $11,9 \%$ en el segundo. Para los que cursaron o completaron otras carreras técnicas (UTU - Universidad del Trabajo del Uruguay, magisterio, profesorado, escuela militar) la proporción fue de 16,0\% en 1994-95 y 13,6\% en 2005-06. Considerando, al solo fin de este estudio, como 'educación superior' aquella que considera haber recibido educación secundaria o superior, el porcentaje de hogares con este nivel fue de $52,2 \%$ en $1994-95$ y $54,3 \%$ en $2005-06$.

Si se realiza la apertura de acuerdo al sexo del jefe de hogar (Cuadro 12) se observa que en el período 1994-95, el 51,2\% de las mujeres jefe de hogar tenía un nivel máximo de educación equivalente a la categoría

Cuadro 11. Distribución de hogares según nivel educativo del jefe de hogar (94-95 y 05-06).

\begin{tabular}{|c|c|c|c|c|}
\hline \multirow{2}{*}{$\begin{array}{l}\text { Nivel Máximo de Educación } \\
\text { alcanzado por el Jefe } \\
\text { de Hogar }\end{array}$} & \multicolumn{2}{|c|}{ 1994-1995 } & \multicolumn{2}{|c|}{ 2005-2006 } \\
\hline & \# Hogares & Porcentaje & \# Hogares & Porcentaje \\
\hline Primaria & 1.791 & $47,8 \%$ & 3.167 & $45,7 \%$ \\
\hline Secundaria & 994 & $26,5 \%$ & 1.996 & $28,8 \%$ \\
\hline Otras carreras técnicas ${ }^{(1)}$ & 599 & $16,0 \%$ & 945 & $13,6 \%$ \\
\hline Universidad & 365 & $9,7 \%$ & 823 & $11,9 \%$ \\
\hline Total & 3.749 & $100,0 \%$ & 6.931 & $100,0 \%$ \\
\hline
\end{tabular}

(1)Incluye enseñanza técnica y UTU, magisterio o profesorado e institutos militares. 
Cuadro 12. Distribución de hogares según educación por sexo del jefe de hogar (94-95 y 05-06).

\begin{tabular}{|l|r|r|r|r|}
\hline \multirow{2}{*}{$\begin{array}{l}\text { Nivel Máximo de Educación } \\
\text { alcanzado por el Jefe } \\
\text { de Hogar }\end{array}$} & \multicolumn{2}{|c|}{$1994-1995$} & \multicolumn{2}{c|}{$\mathbf{2 0 0 5 - 2 0 0 6}$} \\
\cline { 2 - 5 } & Hombre & Mujer & Hombre & \multicolumn{1}{c|}{ Mujer } \\
\hline Primaria & $46,5 \%$ & $51,2 \%$ & $47,1 \%$ & $44,1 \%$ \\
Secundaria & $27,1 \%$ & $25,0 \%$ & $27,5 \%$ & $30,6 \%$ \\
Otras carreras técnicas & $(1)$ \\
Universidad & $15,7 \%$ & $16,7 \%$ & $14,1 \%$ & $12,6 \%$ \\
Total & $10,7 \%$ & $7,1 \%$ & $11,3 \%$ & $12,7 \%$ \\
\hline
\end{tabular}

(1)Incluye enseñanza técnica y UTU, magisterio o profesorado e institutos militares.

'Primaria'. Dicha proporción cayó a 44,1\% en 2005-06. En el caso de jefes de hogar 'hombre', los porcentajes fueron similares para ambos períodos $(46,5 \%$ y $47,1 \%$, respectivamente).

También fueron similares los porcentajes referidos a la categoría 'Secundaria' entre jefes de hogar de sexo masculino $(27,1 \%$ y $27,5 \%$, respectivamente). En el caso de jefes de hogar de sexo femenino, dicho porcentaje subió de $25 \%$ a $30,6 \%$ entre ambos períodos. En el caso de 'Otras carreras técnicas' no hubo diferencias importantes entre sexos. Mientras que en 1994-95 la proporción de jefes de hogar en esta categoría fue $15,7 \%$ para el sexo masculino y $16,7 \%$ para el femenino, en 2005-06 las mismas alcanzaron respectivamente $14,1 \%$ y $12,6 \%$.

Donde sí se registraron diferencias fue en la categoría 'Universidad'. En 1994-95, la cantidad de jefes de hogar con formación universitaria, completa o sin terminar, fue $10,7 \%$ para hombres y $7,1 \%$ para mujeres. En 2005-06, la proporción de jefes de hogar hombres en esta categoría fue de $11,3 \%$, en tanto que para mujeres aumentó a $12,7 \%$, revirtiéndose de alguna manera la brecha entre jefes de hogar de ambos sexos. Esto se aprecia con mayor claridad al considerar la cate- goría 'educación superior'. Mientras que la proporción de hogares cuyo jefe de hogar declaró poseer un nivel de educación superior a primaria fue de $53 \%$ en ambos períodos, el porcentaje de mujeres ejerciendo como jefe de hogar creció sustancialmente de $49 \%$ a $56 \%$.

Como se observa en el Cuadro 13, el tamaño promedio del hogar, medido a través del número de integrantes, fue levemente superior en el período 2005-06 que en el 199495 (2,92 contra 2,86). No obstante, medido a través del índice 'equivalente adulto' (EQH) el tamaño del hogar resultó menor en el primer período $(2,44)$ que en el segundo $(2,77)$. Discriminando los hogares en base el sexo del jefe de hogar se observa que, en promedio, los hogares comandados por una mujer eran de menor tamaño que los comandados por un hombre, tanto en total de integrantes como en equivalente adultos.

También se concentraron diferencias en el tamaño de hogar de acuerdo a su localización. En promedio, los hogares situados en el interior del país resultaron de mayor tamaño que en la capital, en el período 199495. En cantidad total de integrantes, el promedio alcanzó a 2,93 en el Interior y a 2,79 integrantes en hogares de Montevideo. Ex-

Cuadro 13. Tamaño promedio de hogar, total y según el sexo del jefe de hogar (94-95 y 05-06).

\begin{tabular}{|l|c|l|l|c|l|c|}
\hline \multirow{2}{*}{$\begin{array}{l}\text { Tamaño del Hogar } \\
\text { medido a } \\
\text { través de }\end{array}$} & \multicolumn{4}{|c|}{ Tamaño del Hogar según Sexo del Jefe de Hogar } \\
\cline { 2 - 7 } & \multicolumn{3}{|c|}{ Período 1994-1995 } & \multicolumn{2}{c|}{ Período 2005-2006 } \\
\cline { 2 - 7 } & General & Mujer & Hombre & General & Mujer & Hombre \\
\hline Número de Integrantes & 2,86 & 2,18 & 3,11 & 2,92 & 2,48 & 3,16 \\
Equivalente Adulto & 2,77 & 2,06 & 3,03 & 2,44 & 2,07 & 2,65 \\
\hline
\end{tabular}


presado en términos de 'equivalente adulto', el tamaño promedio fue de 2,89 y 2,68 , respectivamente.

Similar situación se observó en el período 2005-06. El tamaño promedio de los hogares ubicados en el Interior fue de 3,05 en cantidad total de miembros y 2,51 en EQH. En Montevideo, los valores fueron inferiores, con un promedio de 2,7 integrantes y 2,32 $\mathrm{EQH}$.

Cuando se analiza la composición etaria de los hogares a través de la presencia de integrantes menores de 18 años y mayores de 64 años, se observa que, en términos generales, hubo una disminución de 5 puntos en la proporción de menores de edad entre 1994-95 y 2005-06, pasando de $49 \%$ a $44 \%$ (Cuadro 14). Esta caída fue mayor, alcanzando a 7 puntos porcentuales, en los hogares cuyo jefe de hogar era hombre, siendo amortiguada en el promedio general debido a un incremento en los hogares comandados por una mujer, donde creció de 34\% a 37\%. En ambos períodos, sin embargo, la mayor proporción de menores ocurrió en los hogares con jefe de hogar 'hombre'.

En el caso de la presencia de personas mayores de 64 años en el hogar, no hubo diferencias entre períodos, con una proporción de $33 \%$. En ambos casos, la proporción fue bastante más alta en los hogares con jefe de hogar de sexo femenino, no obstante la brecha entre hogares de acuerdo al sexo del jefe de hogar se redujo en el segundo período. En 1994-95, la presencia de mayores de 64 años alcanzó al $47 \%$ de los hogares conducidos por mujeres y $28 \%$ en los conducidos por hombres. En 2005-06, dichos valores alcanzaron respectivamente $42 \%$ y $30 \%$.

\subsection{Demanda de productos cárnicos: efectos sobre la decisión de consumo}

\subsubsection{Frecuencia de consumo de productos cárnicos}

El consumo de alimentos fue modelado de forma tal que involucró un proceso en dos etapas. La primera etapa involucró la decisión de consumir, es decir, de adquirir o no determinado producto para su consumo. El primer indicador considerado para analizar esta decisión es la frecuencia de consumo. En ese sentido, se observó que los hogares uruguayos disminuyeron la frecuencia de consumo de productos cárnicos entre los dos períodos considerados. Esto es, la proporción de hogares que consumieron carne durante la semana de referencia disminuyó entre 1994-95 y 2005-06. Esto se verificó tanto a nivel general, para todos los tipos de carne (bovina, ovina, porcina, aviar, pescados y mariscos) como de productos más específicos de carne bovina, fiambres y embutidos y carnes preparadas en base a carnes.

De los 3.749 hogares encuestados en el período 1994-95, un total de 3.646 consumieron al menos algún tipo de carne durante la semana de referencia, lo cual representó un $98 \%$. Esto significa que prácticamente la totalidad de los hogares hicieron algún tipo de consumo de carne. Al considerar los hogares que consumieron algún producto de carne bovina, el número alcanzó a 3.264 hogares, representando un $87 \%$.

En 2005-06, el número de hogares que adquirió algún tipo de producto cárnico alcanzó a 6.161, lo que representó un 89\% entre un total de 7.043 que formaron parte

Cuadro 14. Hogares con menores de 18 y mayores de 64 según el sexo del jefe de hogar (94-95 y 05-06).

\begin{tabular}{|l|c|c|c|c|c|c|}
\hline \multirow{2}{*}{$\begin{array}{l}\text { Hogares con al } \\
\text { menos un } \\
\text { integrante }\end{array}$} & \multicolumn{4}{|c|}{ Proporción de Hogares según Sexo del Jefe de Hogar } \\
\cline { 2 - 7 } & \multicolumn{3}{|c|}{ Período 1994-1995 } & \multicolumn{2}{c|}{ Período 2005-2006 } \\
\cline { 2 - 7 } & General & Mujer & Hombre & General & Mujer & Hombre \\
\hline Menor de 18 años & $49 \%$ & $34 \%$ & $55 \%$ & $44 \%$ & $37 \%$ & $48 \%$ \\
Mayor de 64 años & $33 \%$ & $47 \%$ & $28 \%$ & $33 \%$ & $42 \%$ & $30 \%$ \\
\hline
\end{tabular}


Cuadro 15. Hogares que consumieron alguna cantidad de los 13 productos cárnicos (94-95 y 0506).

\begin{tabular}{|c|c|c|c|c|c|c|}
\hline \multirow{2}{*}{ Producto Cárnico } & \multicolumn{3}{|c|}{ Período 1994-1995 } & \multicolumn{3}{|c|}{ Período 2005-2006 } \\
\hline & Cantidad & $\%$ & \# & Cantidad & $\%$ & $\#$ \\
\hline TSH - carne bovina, trasero sin hueso & 1.827 & $48,7 \%$ & 1 & 1.740 & $25,1 \%$ & 5 \\
\hline $\mathrm{TCH}$ - carne bovina, trasero con hueso & 1.448 & $38,6 \%$ & 7 & 480 & $6,9 \%$ & 11 \\
\hline PIC - carne bovina, picada & 1.600 & $42,7 \%$ & 5 & 2.513 & $36,3 \%$ & 2 \\
\hline ASA - carne bovina, asado y delantero & \multirow{2}{*}{1.792} & \multirow{2}{*}{$47,8 \%$} & \multirow{2}{*}{3} & 1.038 & $15,0 \%$ & 9 \\
\hline DEL - carne bovina, cortes del delantero & & & & 1.259 & $18,2 \%$ & 6 \\
\hline VOT - carne bovina, otros & 1.328 & $35,4 \%$ & 8 & 582 & $8,4 \%$ & 10 \\
\hline OVI - carne ovina, todas & 1.178 & $31,4 \%$ & 10 & 442 & $6,4 \%$ & 12 \\
\hline POR - carne porcina, todas & 110 & $2,9 \%$ & 13 & 199 & $2,9 \%$ & 13 \\
\hline AVE - carne aviar, todas & 1.240 & $33,1 \%$ & 9 & 2.196 & $31,7 \%$ & 3 \\
\hline PYM - pescado y mariscos & 1.067 & $28,5 \%$ & 11 & 1.215 & $17,5 \%$ & 7 \\
\hline FEF - fiambres y embutidos - fríos & 1.814 & $48,4 \%$ & 2 & 2.798 & $40,4 \%$ & 1 \\
\hline FEC - fiambres y embutidos, para cocinar & 1.460 & $38,9 \%$ & 6 & 2.005 & $28,9 \%$ & 4 \\
\hline CPC - comidas prontas en base a carne & 412 & $11,0 \%$ & 12 & 1.211 & $17,5 \%$ & 7 \\
\hline TOTAL DE HOGARES & 3.749 & \multicolumn{2}{|c|}{$100 \%$} & 6.931 & \multicolumn{2}{|c|}{$100 \%$} \\
\hline Consumo de al menos algún tipo de carne & 3.646 & \multicolumn{2}{|c|}{$98 \%$} & 6.161 & \multicolumn{2}{|c|}{$89 \%$} \\
\hline Consumo de algún tipo de carne bovina & 3.264 & \multicolumn{2}{|c|}{$87 \%$} & 4.523 & \multicolumn{2}{|c|}{$65 \%$} \\
\hline
\end{tabular}

Nota: Para 1994-95 los productos ASA y DEL conformaron un solo grupo 'asado y delantero' (AYD). Si se toma de esta forma para 2005-06, la proporción de AYD alcanza 33,1\% y se ubica en tercer lugar en proporción de hogares que declararon su consumo durante el período de la encuesta (semana). En negrita se destacan los 5 productos consumidos por mayor proporción de hogares.

de la muestra. La frecuencia de consumo de algún producto de carne bovina, declarada por 4.523 hogares, representó el $65 \%$.

Las cantidades y proporciones listadas en el Cuadro 15 refieren al número y porcentaje de hogares que consumieron cada uno de los productos cárnicos durante la semana de la encuesta y no a las cantidades consumidas. Esto es, que un producto sea consumido por una mayor cantidad y proporción de hogares no significa que el consumo total de dicho producto sea mayor. La tercer columna (\#) indica la posición que ocupó el producto en términos del porcentaje de hogares que lo consumieron en cada período.

En orden decreciente, los productos cárnicos adquiridos por una mayor proporción de hogares en el período 1994-95 fueron TSH $(48,7 \%), \operatorname{FEF}(48,4 \%)$, AYD $(47,8 \%)$ y PIC $(42,7 \%)$. Es interesante observar que los 5 productos de carne bovina se ubicaron en los ocho primeros lugares, cada uno con una frecuencia mínima de consumo superior al $35 \%$. Es así que el producto $\mathrm{TCH}(38,6 \%)$ se ubicó en el séptimo lugar y VOT $(35,4 \%)$ en octavo. Por otro lado, las otras carnes, AVE $(33,1 \%)$, OVI $(31,4 \%)$, PYM $(28,5 \%)$ y POR $(2,9 \%)$ estuvieron entre las menos consumidas por los hogares, junto a CPC $(11,0 \%)$. El otro producto que involucra distintos tipos de carnes, FEC $(38,9 \%)$, se ubicó en el sexto lugar de las preferencias en términos de frecuencia de consumo.

Una década más tarde, el consumo de ninguno de los productos considerados superó largamente el $40 \%$ de los hogares. Los fiambres, embutidos y chacinados aumentaron su importancia relativa en la dieta de los uruguayos. El producto $\operatorname{FEF}(40,4 \%)$ pasó del segundo al primer lugar de la lista en tanto FEC $(28,9 \%)$ pasó del sexto al cuarto lugar. Entre los de carne bovina, PIC $(36,3 \%)$ mejoró su posición pasando del quinto al segundo lugar, mientras que la frecuencia de TSH $(25,1 \%)$ lo hizo caer del primero al quinto lugar. 
Debe tenerse en cuenta que el producto AYD fue desagregado para el período 200506 en DEL $(18,2 \%)$ y ASA $(15,0 \%)$ los que se ubicaron en el sexto y noveno lugar respectivamente; de haberse mantenido como uno solo, se hubieran mantenido en el tercer lugar. Los restantes productos de carne bovina, TCH $(6,9 \%)$ y VOT $(8,4 \%)$ fueron desplazados respectivamente del séptimo al onceavo lugar y del octavo al décimo lugar.

La mejora relativa más importante fue observada en la frecuencia de consumo de AVE $(31,7 \%)$. Aunque individualmente la proporción de hogares consumidores cayó poco más de un punto respecto el primer período, su ubicación relativa mejoró sensiblemente al saltar del noveno al tercer lugar. También mejoró la proporción de hogares consumidores de CPC $(17,5 \%)$, pasando del doceavo al séptimo lugar, el cual fue compartido con PYM (17,5\%) que en el período 1994-95 se había ubicado en el lugar once de la lista.

Por último, mientras que OVI $(6,4 \%)$ perdió importancia relativa cayendo del lugar diez al doce de la lista, la carne POR $(2,9 \%)$ continuó siendo la menos importante de todas, en términos de frecuencia de consumo semanal por parte de los hogares.

\subsubsection{Efectos sobre la probabilidad de consumo}

Las razones que motivan la decisión de consumir o no un determinado producto alimenticio no tienen por qué ser las mismas que determinan las cantidades a consumir. Al evaluar la incidencia de las características socioeconómicas más relevantes del hogar en la probabilidad de comprar o no comprar un producto cárnico, se procuró identificar: primero, cuáles de ellas mostraron un efecto significativo en dicha decisión; segundo, la dirección o signo de dicho efecto, es decir, si el efecto favoreció una decisión positiva o negativa respecto al consumo; tercero, la magnitud de dicho efecto, es decir, el impacto sobre la probabilidad de consumir. Todo esto se presenta en el Cuadro 16.

Lo primero que se observa es que el nivel de ingreso de los hogares mostró un efecto positivo sobre la decisión de consumir carne, a excepción de algunos cortes de carne bovina, donde el efecto fue negativo o no significativo. El ingreso, medido a través de la variable LIS, mostró un efecto significativo y positivo sobre la probabilidad de consumir TCH, TSH, POR, AVE, PYM, FEF, FEC y CPC, en los dos períodos considerados.

Aunque en 1994-95 el ingreso mostró un impacto negativo sobre la decisión de consumir PIC y VOT, el mismo no volvió a constatarse en 2005-06. Si bien en el primer período considerado el ingreso no tuvo un efecto significativo apreciable en la decisión de consumir AYD, en 2005-06 se verificó un efecto positivo en el consumo de ASA pero negativo en DEL. En ningún caso se pudo observar un efecto sobre la decisión de consumir carne ovina.

En el caso de la localización de los hogares, los ubicados en Montevideo mostraron un efecto significativo positivo sobre la probabilidad de consumir OVI, POR, PYM, FEF y FEC, para el período 1994-95, no siendo significativo para ninguno de los restantes productos. En 2005-06, se volvió a verificar el mismo efecto positivo en el caso de PYM, FEF y FEC, además de TSH y CPC. En el caso de OVI se observó el efecto contrario. Los hogares situados en Montevideo mostraron una asociación negativa con la probabilidad de consumir este tipo de carne, al igual que para TCH, ASA y DEL.

El tamaño del hogar (THG) resultó ser la característica más consistente en términos de exhibir un efecto positivo sobre la decisión de consumo de carnes. Este efecto fue verificado en ambos períodos de estudio en el caso de PIC, ASA, DEL y VOT, así como para el caso de FEF y FEC. En adición, también se verificó un efecto positivo en 1994-95 para el caso de TSH, TCH y OVI. En 200506, el efecto positivo se constató para POR, AVE y CPC. En este último caso, el efecto había sido de signo negativo en 1994-95.

En lo que respecta a la composición del hogar, se verificó un efecto positivo en la decisión de consumir PIC y CPC en ambos períodos de estudio, cuando se constató la presencia de menores de edad (P18) en los hogares. En 1994-95 la presencia de P18 estuvo asociada a una menor probabilidad de consumir TCH, AYD y PYM. Sin embargo estas relaciones no se encontraron en 200506. En el segundo período tan solo se verifi- 


\begin{tabular}{|c|c|c|c|c|c|c|c|c|c|c|c|c|c|c|}
\hline & 㞻 & 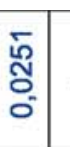 & ' & $\frac{m}{\tilde{m}}$ & \begin{tabular}{l}
$\mathscr{8}$ \\
$\vdots$ \\
0 \\
\hdashline
\end{tabular} & 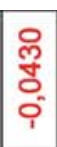 & ' & 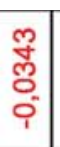 & ' & ' & $\begin{array}{l}\mathscr{D} \\
\text { đ్ } \\
0 \\
0\end{array}$ & $\begin{array}{l}\mathscr{0} \\
\stackrel{0}{0} \\
0 \\
0 \\
0\end{array}$ & $\begin{array}{l}\text { N } \\
\text { हू } \\
\text { O. }\end{array}$ & \begin{tabular}{l}
$\mathscr{\infty}$ \\
\multirow{f}{\delta}{} \\
0
\end{tabular} \\
\hline & $\stackrel{7}{\Sigma}$ & ' & ' & \begin{tabular}{|c|} 
N \\
הั \\
0 \\
-1
\end{tabular} & 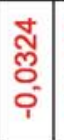 & 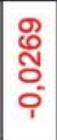 & ' & 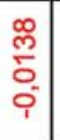 & ' & ' & ' & ' & '] & ' \\
\hline ஜ & $\begin{array}{l}\text { ठे } \\
\text { ฉ }\end{array}$ & $\begin{array}{l}\text { ్ㅠ } \\
\text { ర్ }\end{array}$ & ' & ' & ' & 空 & $\begin{array}{l}\frac{8}{5} \\
\\
\circ\end{array}$ & I & $\frac{}{5}$ & $\begin{array}{l}\infty \\
0 \\
0 \\
0 \\
0\end{array}$ & 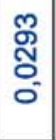 & 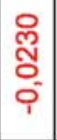 & $\begin{array}{l}0 \\
\overline{8} \\
0 \\
0 \\
1\end{array}$ & $\begin{array}{l}\overline{0} \\
\dot{0} \\
0 \\
\end{array}$ \\
\hline 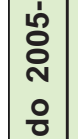 & $\begin{array}{l}\infty \\
\stackrel{-1}{a}\end{array}$ & ' & . & 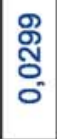 & ' & ' & ' & ' & ' & ' & ' & ' & $\begin{array}{l}\text { 芯 } \\
\text { O. } \\
0\end{array}$ & סू- \\
\hline 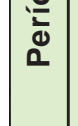 & 울 & ' & ' & 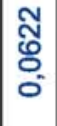 & $\begin{array}{l}n \\
5 \\
8 \\
0 \\
0\end{array} \mid$ & 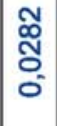 & $\frac{\infty}{\sigma}$ & ' & $\begin{array}{l}\mathscr{0} \\
\bar{\delta} \\
0 \\
0\end{array}$ & $\begin{array}{l}\stackrel{N}{\leftarrow} \\
\stackrel{0}{\circ}\end{array}$ & ' & $\begin{array}{l}\hat{\sigma} \\
0 \\
0 \\
0\end{array}$ & $\begin{array}{l}0 \\
0 \\
0 \\
0 \\
0\end{array}$ & 产 \\
\hline & $\stackrel{Q}{\Sigma}$ & 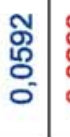 & $\begin{array}{l}\text { న్ } \\
\text { ర్ } \\
\mathbf{\Upsilon}^{-}\end{array}$ & ' & $\begin{array}{l}\hat{0} \\
\overline{0} \\
\overline{0}\end{array}$ & $\begin{array}{l}0 \\
\infty \\
0 \\
0 \\
0 \\
\end{array}$ & ' & $\begin{array}{l}\infty \\
\bar{\delta} \\
0 \\
1 \\
1\end{array}$ & . & ' & $\begin{array}{l}\infty \\
0 \\
0 \\
0 \\
0\end{array}$ & 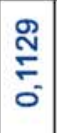 & $\begin{array}{l}\hat{H} \\
\text { 岁 } \\
0 \\
0\end{array}$ & స్ల్ \\
\hline & $\stackrel{\omega}{\beth}$ & 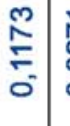 & $\begin{array}{l}\overline{\widehat{N}} \\
\text { O. } \\
0\end{array}$ & ' & $\begin{array}{l}\hat{g} \\
\delta \\
0\end{array}$ & 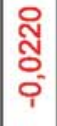 & ' & ' & $\begin{array}{l}\text { J } \\
0 \\
0\end{array}$ & 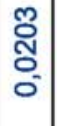 & $\begin{array}{l}\frac{0}{8} \\
8 \\
0\end{array}$ & $\frac{\hat{0}}{0}$ & 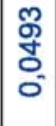 & 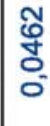 \\
\hline & 嵒 & ' & 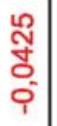 & 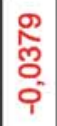 & $\frac{\stackrel{\circ}{\circ}}{\text { i্ }}$ & $\frac{v^{\circ}}{b^{\circ}}$ & $\begin{array}{l}\text { స్్․ } \\
0 \\
0 \\
\end{array}$ & $\begin{array}{l}\bar{n} \\
\tilde{\delta} \\
0 \\
\bar{i}\end{array}$ & , & 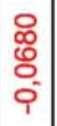 & ' & 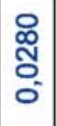 & . & 离 \\
\hline & $\stackrel{3}{\Sigma}$ & 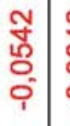 & $\begin{array}{l}0 \\
0 \\
0 \\
0 \\
0\end{array}$ & ' & $\frac{\text { \%̊ }}{\text { ó }}$ & ?. & $\begin{array}{l}0 \\
0 \\
0 \\
0 \\
0\end{array}$ & ' & ' & ' & ' & . & ' & స్ \\
\hline 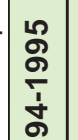 & $\begin{array}{l}\text { ठे } \\
\text { Q }\end{array}$ & $\begin{array}{l}\overline{1} \\
\text { 岁 } \\
0 \\
0\end{array}$ & ' & 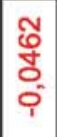 & & I & ' & ' & ' & 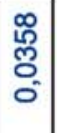 & $\begin{array}{l}\infty \\
\bar{\delta} \\
0\end{array}$ & ' & 1 & 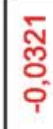 \\
\hline 응 & \begin{tabular}{l}
$\infty$ \\
$\stackrel{-1}{a}$ \\
\multicolumn{1}{|c}{}
\end{tabular} & ' & $\begin{array}{l}\text { :్ర్ర్ } \\
0 \\
\varnothing^{-}\end{array}$ & 兽 & $\begin{array}{l}\text { ळ. } \\
\vdots \\
\end{array}$ & 'מ & $\begin{array}{l}\hat{0} \\
0 \\
0 \\
0 \\
\end{array}$ & ' & ' & ' & $\begin{array}{l}\text { o } \\
\text { d. } \\
\text { i }\end{array}$ & ' & ' & స్ల్ \\
\hline & 울 & 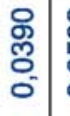 & 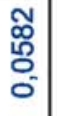 & $\begin{array}{l}\text { : } \\
\text { : } \\
\\
0 \\
0\end{array}$ & 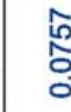 & ". & $\begin{array}{l}\widehat{\tilde{O}} \\
\bar{\delta} \\
0\end{array}$ & $\begin{array}{l}\text { : } \\
\text { 영 } \\
0\end{array}$ & ' & ' & ' & $\begin{array}{l}0 \\
0 \\
0 \\
0\end{array}$ & \begin{tabular}{l}
0 \\
\multirow{O}{0}{} \\
0 \\
0
\end{tabular} & ஜ \\
\hline & $\stackrel{O}{\Sigma}$ & ' & ' & ' & & ' & ' & 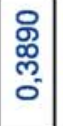 & 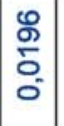 & ' & $\frac{\circ}{\stackrel{6}{\circ}}$ & $\frac{\stackrel{2}{\circ}}{\circ}$ & $\begin{array}{l}\bar{\sigma} \\
\delta \\
0 \\
0\end{array}$ & 1 \\
\hline & $\stackrel{\varrho}{\beth}$ & 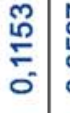 & $\begin{array}{l}\hat{\tilde{O}} \\
\text { Oे } \\
0\end{array}$ & 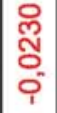 & & ' & 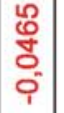 & ' & $\begin{array}{l}\text { స్ } \\
\text { ర్ } \\
0\end{array}$ & 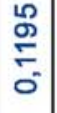 & $\frac{\stackrel{N}{~}}{\overleftarrow{0}}$ & 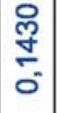 & 苍 & 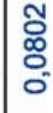 \\
\hline 0 & & ঙ & 工 & $\frac{0}{2}$ & ङ & 岀 & ○ & z & $\begin{array}{l}\text { 営 } \\
\text { 음 }\end{array}$ & $\stackrel{\mathrm{W}}{\mathrm{\Psi}}$ & $\sum_{\Sigma}^{\Sigma}$ & 嵹 & 导 & U \\
\hline
\end{tabular}

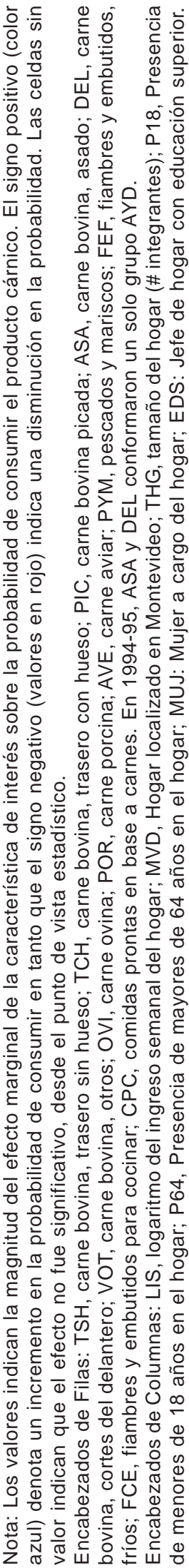


có un efecto significativo positivo sobre la decisión de consumir FEC, lo cual no sucedió en el primero.

La presencia de mayores de 65 años (P64) en el hogar tuvo un efecto positivo sobre la decisión de consumir TSH, AVE y PYM, en los dos períodos. Lo mismo sucedió con CPC aunque en ese caso el efecto fue de signo negativo. El efecto fue también negativo con PIC pero esto solo en 1994-95, mientras que en 2005-06, la presencia de P64 tuvo también un efecto negativo sobre la probabilidad de consumir FEF y FEC. Esta relación no se constató, no obstante, en 1994-95.

En el caso de los hogares cuyo jefe era de sexo femenino (MUJ), esta característica mostró un efecto negativo sobre la posibilidad de consumir AYD, ASA y DEL en ambos períodos. El mismo efecto negativo observado en 1994-95 tanto en TSH, TCH y VOT no pudo ser verificado en 2005-06; tampoco el efecto positivo registrado en el primer período para CPC ni el efecto negativo observado en OVI.

Finalmente, en los dos períodos estudiados se observó un efecto significativo y de signo positivo de los hogares cuyo jefe de- claró poseer un nivel de educación superior (EDS) para el caso de FEF y CPC. También en ambos períodos se encontró un efecto negativo entre esta variable y la decisión de consumo de AYD, ASA, DEL y OVI. Por el contrario, el efecto negativo registrado en 1994-95 para el caso de TCH, VOT y AVE no pudieron ser corroborados en el 2005-06. Tampoco fueron evidentes los efectos positivos de EDS sobre las probabilidades de consumir TSH, PYM y FEC. Es más, mientras que la presencia de jefes de hogar con educación superior mostró un efecto significativo y negativo sobre la probabilidad de consumir PIC en 1994-95, dicho efecto cambió de signo en 2005-06, haciéndose positivo.

\subsection{Demanda de productos cárnicos: efectos sobre el nivel de consumo}

\subsubsection{Efecto del ingreso del hogar sobre la demanda}

La elasticidad de la demanda por los productos seleccionados con respecto al ingreso $(\eta)$ se presenta en el Cuadro 17, para los

Cuadro 17. Elasticidad ingreso de la demanda para 13 productos cárnicos (94-95 y 05-06).

\begin{tabular}{|c|c|c|c|c|c|c|}
\hline \multirow{2}{*}{$\begin{array}{l}\text { Elasticidad } \\
\text { Ingreso }(h)\end{array}$} & \multicolumn{3}{|c|}{ Período 1994-1995 } & \multicolumn{3}{|c|}{ Período 2005-2006 } \\
\hline & L. Inferior & Valor & L. Superior & L. Inferior & Valor & L. Superior \\
\hline TSH & $-0,03403$ & 0,01408 & 0,06219 & $-0,03556$ & 0,03827 & 0,11209 \\
\hline $\mathrm{TCH}$ & $-0,09552$ & $-0,03301$ & 0,02949 & $-0,10260$ & 0,05313 & 0,20885 \\
\hline PIC & 0,04981 & 0,11137 & 0,17292 & $-0,01435$ & 0,00883 & 0,03202 \\
\hline ASA & \multirow{2}{*}{0,05920} & \multirow{2}{*}{0,11346} & \multirow{2}{*}{0,16772} & $-0,10249$ & $-0,03169$ & 0,03911 \\
\hline DEL & & & & $-0,07246$ & 0,15191 & 0,37627 \\
\hline VOT & 0,00821 & 0,12681 & 0,24541 & 0,01318 & 0,05199 & 0,09080 \\
\hline OVI & 0,38600 & 0,56534 & 0,74468 & 0,26322 & 0,51573 & 0,76824 \\
\hline POR & $-0,19987$ & $-0,07388$ & 0,05210 & $-0,00237$ & 0,02978 & 0,06193 \\
\hline AVE & $-0,05827$ & 0,01293 & 0,08414 & $-0,01660$ & $-0,00592$ & 0,00476 \\
\hline PYM & 0,00164 & 0,09521 & 0,18878 & $-0,02283$ & 0,01005 & 0,04293 \\
\hline FEF & 0,04292 & 0,09942 & 0,15591 & $-0,00786$ & 0,02669 & 0,06125 \\
\hline FEC & 0,05788 & 0,11245 & 0,16702 & $-0,03564$ & 0,00658 & 0,04879 \\
\hline CPC & $-0,06682$ & $-0,00375$ & 0,05933 & $-0,00936$ & 0,07085 & 0,15107 \\
\hline
\end{tabular}

Nota: La estimación de elasticidad punto del ingreso se acompañan de su límite inferior e inferior para un intervalo de confianza del $90 \%$. Los valores resaltados en azul son significativamente distintos de cero y de signo positivo debido a que el signo no cambia en todo el intervalo. 
dos períodos considerados. El valor de elasticidad punto se expresa con 5 posiciones decimales y es acompañado de sus respectivos límites inferior y superior construidos para un intervalo de confianza del $90 \%$. En todos los casos en que el valor hallado para la elasticidad punto resultó significativo para el nivel elegido, su signo fue positivo y su magnitud menor a la unidad, confirmando que todos los productos cárnicos considerados se comportaron como bienes normales $(\eta>$ 0 ); ninguno se comportó ni como un bien de lujo $(\eta>1)$ ni como un bien inferior $(\eta<0)$.

Los resultados obtenidos muestran que solamente para dos de los trece productos cárnicos se encontraron magnitudes significativamente distintas de cero para el intervalo de confianza considerado, en los dos períodos. Uno de estos casos fue OVI, cuya elasticidad ingreso fue 0,565 para 1994 95 y 0,516 para 2005-06, siendo, además, el único producto cárnico en donde la magnitud superó 0,2. En el caso de VOT, los valores fueron respectivamente 0,127 y 0,052.

Otros cinco productos registraron una elasticidad ingreso significativamente distin- ta de cero aunque solamente para el período 1994-95, a saber: PIC con 0,111, AYD con 0,113 , PYM con 0,095, FEF con 0,099 y FEC con 0,112 . En todos los casos restantes, no hubo evidencia estadística como para sugerir que la elasticidad ingreso fuera diferente de cero $(\eta \cong 0)$, en la medida que el mismo estuvo incluido dentro del intervalo de confianza.

\subsubsection{Efecto directo del precio sobre la demanda}

Los valores de elasticidad punto de la demanda de cada producto con respecto a su propio precio (e) en los dos períodos considerados, se presentan en el Cuadro 18. En todos los casos, la elasticidad precio directa se acompaña de los límites inferior y superior para un intervalo de confianza del $90 \%$. En todos los casos, el valor estimado resultó significativo para dicho nivel de significación y tuvo signo positivo, confirmando que todos los productos cárnicos considerados se comportaron como bienes ordinarios $(\varepsilon<0)$.

Cuadro 18. Elasticidad precio directa de la demanda para 13 productos cárnicos (94-95 y 05-06).

\begin{tabular}{|c|c|c|c|c|c|c|}
\hline \multirow{2}{*}{$\begin{array}{l}\text { Elasticidad } \\
\text { Ingreso }(\varepsilon)\end{array}$} & \multicolumn{3}{|c|}{ Período 1994-1995 } & \multicolumn{3}{|c|}{ Período 2005-2006 } \\
\hline & L. Inferior & Valor & L. Superior & L. Inferior & Valor & L. Superior \\
\hline TSH & $-1,43523$ & $-1,32039$ & $-1,20556$ & $-1,60953$ & $-1,46664$ & $-1,32375$ \\
\hline $\mathrm{TCH}$ & $-2,50402$ & $-2,22973$ & $-1,95543$ & $-2,33197$ & $-1,94626$ & $-1,56055$ \\
\hline PIC & $-2,44112$ & $-2,23975$ & $-2,03838$ & $-2,36239$ & $-2,21091$ & $-2,05943$ \\
\hline ASA & \multirow{2}{*}{$-1,95035$} & \multirow{2}{*}{$-1,79761$} & \multirow{2}{*}{$-1,64487$} & $-1,17190$ & $-0,99231$ & $-0,81271$ \\
\hline DEL & & & & $-1,59831$ & $-1,38603$ & $-1,17374$ \\
\hline VOT & $-0,43868$ & $-0,34063$ & $-0,24258$ & $-0,11264$ & $-0,09381$ & $-0,07498$ \\
\hline OVI & $-1,77826$ & $-1,53279$ & $-1,28731$ & $-2,38911$ & $-1,97001$ & $-1,55091$ \\
\hline POR & $-0,73329$ & $-0,49039$ & $-0,24749$ & $-1,13539$ & $-0,81331$ & $-0,49123$ \\
\hline AVE & $-1,90701$ & $-1,75366$ & $-1,60030$ & $-0,47396$ & $-0,43818$ & $-0,40239$ \\
\hline PYM & $-0,38861$ & $-0,33476$ & $-0,28090$ & $-0,51610$ & $-0,45976$ & $-0,40341$ \\
\hline FEF & $-1,34704$ & $-1,23322$ & $-1,11940$ & $-0,10438$ & $-0,09045$ & $-0,07652$ \\
\hline FEC & $-1,02317$ & $-0,94274$ & $-0,86232$ & $-1,26161$ & $-1,18322$ & $-1,10483$ \\
\hline CPC & $-0,29411$ & $-0,23846$ & $-0,18281$ & $-0,21313$ & $-0,19065$ & $-0,16817$ \\
\hline
\end{tabular}

Nota: La estimación de elasticidad precio punto directa se acompañan de su límite inferior e inferior para un intervalo de confianza del $90 \%$. Los valores resaltados en rojo son significativamente distintos de cero y de signo negativo debido a que el signo no cambia en todo el intervalo. 
En general, los productos de carne bovina fueron los más responsivos a las variaciones de precio, en ambos períodos. Esto era esperable en virtud de su mayor nivel de desagregación frente a los de las otras carnes, que fueron más genéricos. Es, por lo tanto, importante tener en cuenta esta distinción al interpretar los resultados.

Dentro de los cortes bovinos, es interesante notar la alta sensibilidad mostrada en ambos períodos por PIC y por TCH frente al precio. Los valores absolutos de elasticidad precio directa disminuyeron aunque muy levemente entre 1994-95 y 2005-06; en el primer caso pasaron de $-2,24$ a $-2,21$ mientras que en el segundo de -2,23 a -1,95.

En el caso de AYD, la caída entre los dos períodos analizados fue un tanto mayor aunque mostrando una importante respuesta a la variación del precio en ambos. Tomados en forma conjunta en 1994-95, la elasticidad precio mostró un valor de -1,80. Al ser calculados por separado en 2005-06, los valores obtenidos fueron -0,99 para ASA y -1,39 para DEL. Por el contrario, la elasticidad precio de TSH en 1994-95 fue -1,32, incrementándose levemente en valor absoluto para alcanzar -1,47 en 2005-06.

La elasticidad precio de VOT fue estimada en -0,34 para 1994-95, cayendo en valor absoluto a -0,09 para 2005-06. Cabe señalar que en este último caso también se trata de un producto heterogéneo y con mayor nivel de agregación que los anteriores, lo cual puede explicar una menor respuesta al precio.

Al analizar los restantes tipos de carnes se verificó que la menor respuesta a las variaciones de precio correspondió a PYM, cuyo valor de elasticidad fue estimado en 0,33 para 1994-95 y -0,46 para 20005-06. Posiblemente, este el grupo de productos más heterogéneo, con un alto grado de sustitución interna que le permite exhibir valores absolutos relativamente reducidos.

También se observó una baja respuesta relativa en el caso de POR, con valores de elasticidad precio menores a la unidad. El valor encontrado en 1994-95 alcanzó -0,49, aumentando hasta -0,81 en 2005-06. La respuesta al precio de OVI, en tanto, fue más alta que en los casos anteriores. Para 1994-
95, la elasticidad precio directa se estimó en -1,79 mientras que para $2005-06$ se estimó en $-1,97$. Un caso a destacar fue la sensible caída registrada en la elasticidad de AVE, la cual pasó de -1,91 en 1994-95 a -0,47 en 2005-06.

Con respecto a los productos mixtos, esto es, que utilizan distintos tipos de carnes como los fiambres, embutidos, chacinados y comidas preparadas en base a carnes, también se destacó una drástica caída de la elasticidad precio en el caso de FEF. Este producto pasó de un valor de -1,23 en 1994-95 a -0,09 en 2005-06. Esto significa que pasó de tener una respuesta importante al precio a una casi inelástica, en tan solo 10 años. Cabe señalar que, junto a la carne aviar, estos productos fueron los que registraron el mayor incremento relativo en la frecuencia de consumo por parte de los hogares, entre ambos períodos.

Mientras tanto, la elasticidad precio directa estimada para FEC sufrió un incremento moderado entre 1994-95 y 2005-06. El valor computado para el primer período fue 0,94 y $-1,18$ para el segundo. Finalmente, para CPC, el valor estimado de la elasticidad precio fue $-0,24$ para $1994-95$ y $-0,19$ para 2005-06.

\subsubsection{Efecto de los restantes precios sobre la demanda}

Para ambos períodos en estudio se estimó una matriz completa de elasticidades precio de la demanda por los trece productos cárnicos de interés. Los elementos que ocupan la diagonal de cada matriz corresponden a las elasticidades directas, las que miden el cambio marginal en la demanda de cada producto ante un cambio marginal de su propio precio. Los elementos situados fuera de la matriz corresponden a las elasticidades cruzadas. Estas miden el cambio en la demanda de cada bien como consecuencia del cambio en el precio de cada uno de los otros productos cárnicos.

La matriz de elasticidades para el período 1994-95 se presenta en el Cuadro 19 mientras que la correspondiente al período 200506 se presenta en el Cuadro 20. El listado que aparece en la primera columna refiere al 


\begin{tabular}{|c|c|c|c|c|c|c|c|c|c|c|c|c|c|c|c|}
\hline & $\begin{array}{l}\mathscr{0} \\
0 \\
0 \\
0 \\
0\end{array}$ & $\begin{array}{l}\frac{10}{6} \\
0 \\
0 \\
0\end{array}$ & एक & สิ & นิ & & 年 & $\begin{array}{l}\mathscr{W} \\
\text { స్ } \\
\text { ¿ }\end{array}$ & 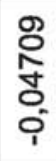 & $\begin{array}{l}\infty \\
\text { ஸ్ } \\
\text { ஸ్ } \\
0 \\
\end{array}$ & & & & 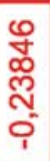 & 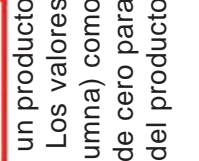 \\
\hline & $\begin{array}{l}\frac{0}{\sigma} \\
\delta \\
\delta\end{array}$ & $\begin{array}{l}\text { 여 } \\
8 \\
\varnothing \\
\end{array}$ & 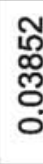 & $\begin{array}{l}\text { ח. } \\
0 \\
\text { đ్ } \\
0\end{array}$ & Lे & & 告 & 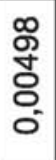 & 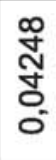 & 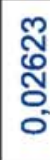 & g & & & $\begin{array}{l}\text { No } \\
\text { Ō } \\
\text { O } \\
0\end{array}$ & 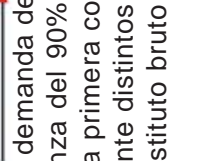 \\
\hline & 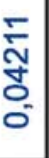 & 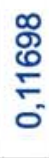 & 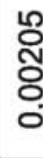 & 웅 & 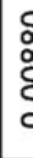 & & $\begin{array}{c}? \\
5 \\
b\end{array}$ & $\begin{array}{l}\text { மొ } \\
\text { ల్ } \\
\text { ర } \\
\text { ○ }\end{array}$ & 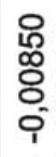 & 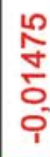 & స్ল & & & $\begin{array}{l}\text { ల్ } \\
\text { లి } \\
\text { ᄋ } \\
\text { ᄋ }\end{array}$ & 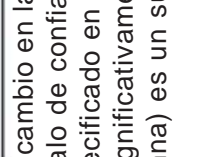 \\
\hline & $\begin{array}{l}\mathscr{0} \\
\mathbb{0} \\
0 \\
0 \\
0\end{array}$ & $\begin{array}{l}\text { ฟ్ } \\
\text { స్ } \\
0\end{array}$ & $\frac{0}{8}$ & ల్ & 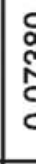 & & 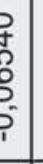 & 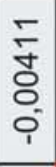 & $\begin{array}{l}\bar{N} \\
\text { ల్ } \\
0 \\
0 \\
\end{array}$ & 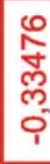 & ¿ & & & 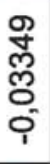 & $\begin{array}{l}\frac{U}{\sigma} \\
\frac{\pi}{\omega}\end{array}$ \\
\hline & 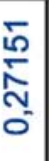 & $\begin{array}{l}\text { గ్ల్ల } \\
\text { ర్ } \\
0\end{array}$ & ָָ స̃ & 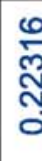 & & & $\begin{array}{l}8 \\
\vdots \\
\vdots \\
\vdots \\
\end{array}$ & $\begin{array}{l}8 \\
\text { ণ } \\
\text { ठ } \\
\circ\end{array}$ & 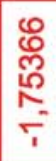 & $\begin{array}{l}\bar{\infty} \\
\infty \\
\varnothing \\
0 \\
0 \\
1\end{array}$ & $\Xi$ & & & 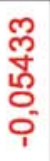 & \\
\hline$\frac{r}{2}$ & 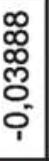 & 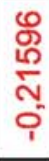 & 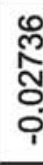 & $\frac{1}{0}$ & 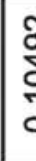 & & $\frac{5}{5}$ & 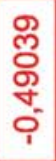 & $\begin{array}{l}\text { N̂ } \\
\text { రి } \\
0 \\
0\end{array}$ & $\begin{array}{l}\text { ㅇ } \\
\text { ల్ } \\
\text { ల్ } \\
\text { ర }\end{array}$ & 9 & & & 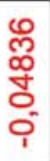 & \\
\hline 5 & 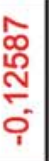 & 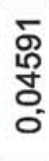 & 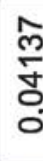 & 응 & گู & & 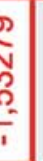 & $\begin{array}{l}\mathscr{N} \\
\infty \\
\infty \\
\varnothing \\
0 \\
0\end{array}$ & \begin{tabular}{l}
$\infty$ \\
$\stackrel{1}{f}$ \\
\multirow{0}{0}{} \\
0
\end{tabular} & $\begin{array}{l}\text { N } \\
\text { N } \\
0 \\
\text { O }\end{array}$ & & & & $\begin{array}{l}\text { N } \\
\text { N } \\
\text { O } \\
\text { O }\end{array}$ & \\
\hline $\bar{\gamma}$ & 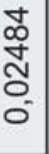 & $\begin{array}{l}\stackrel{+}{m} \\
\underset{N}{0} \\
0\end{array}$ & $\begin{array}{l}5 \\
\text { 유 } \\
0 \\
\text { ㅇ. }\end{array}$ & $\frac{0}{\tilde{\Delta}}$ & & & ? & 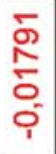 & $\begin{array}{l}\bar{N} \\
\infty \\
0 \\
0 \\
\end{array}$ & $\begin{array}{l}\text { N } \\
\text { m్ } \\
\text { O } \\
\text { O }\end{array}$ & & & & $\begin{array}{l}\text { ㅇ } \\
\text { 음 } \\
\text { ㅇ }\end{array}$ & \\
\hline t) & $\begin{array}{l}\hat{y} \\
0 \\
0 \\
0\end{array}$ & 을 & 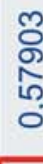 & ลั & & & है & $\begin{array}{l}\text { స్. } \\
\text { ర్ } \\
\end{array}$ & 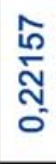 & : & & & & 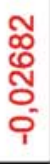 & \\
\hline 2 & $\begin{array}{l}\frac{m}{\sigma} \\
\frac{\sigma}{0} \\
\frac{-}{0}\end{array}$ & $\begin{array}{l}\text { ㅇ } \\
\text { S } \\
\text { மீ } \\
0\end{array}$ & $\begin{array}{l}\text { బ } \\
\text { } \\
\text { } \\
\text { }\end{array}$ & $=$ & & & ?: & $\begin{array}{l}\hat{0} \\
\frac{0}{\circ} \\
0 \\
\end{array}$ & 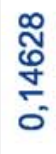 & $\begin{array}{l}\text { స } \\
\text { 寸 } \\
\text { ర }\end{array}$ & 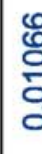 & & & 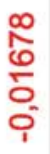 & \\
\hline U & 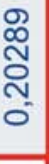 & $\begin{array}{l}\text { N } \\
\text { N } \\
\text { N }\end{array}$ & $\begin{array}{l}\infty \\
0 \\
0 \\
0 \\
0\end{array}$ & $c$ & & & & 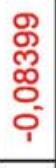 & $\begin{array}{l}\hat{\omega} \\
\text { Nิ } \\
0 \\
0\end{array}$ & đ్ & & & & $\begin{array}{l}\text { 守 } \\
\text { ల్ } \\
\text { O } \\
\end{array}$ & \\
\hline$\frac{1}{5}$ & $\begin{array}{l}\text { ల్ల } \\
\text { ల్ } \\
\text { ల్ } \\
\end{array}$ & $\begin{array}{l}\overline{\text { }} \\
\text { ळ్ } \\
\text { ర }\end{array}$ & 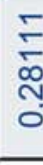 & $\frac{c}{d}$ & & & ? & 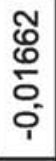 & 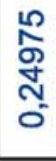 & $\begin{array}{l}0 \\
0 \\
0 \\
0 \\
0 \\
0\end{array}$ & & & & $\begin{array}{l}0 \\
\stackrel{0}{\circ} \\
\text { ㅇ } \\
0^{\circ}\end{array}$ & \\
\hline & あ & ড় & $\bar{a}$ & & & & 5 & 음 & $\stackrel{\text { W }}{\mathrm{Z}}$ & 6 & & & & U & \\
\hline
\end{tabular}




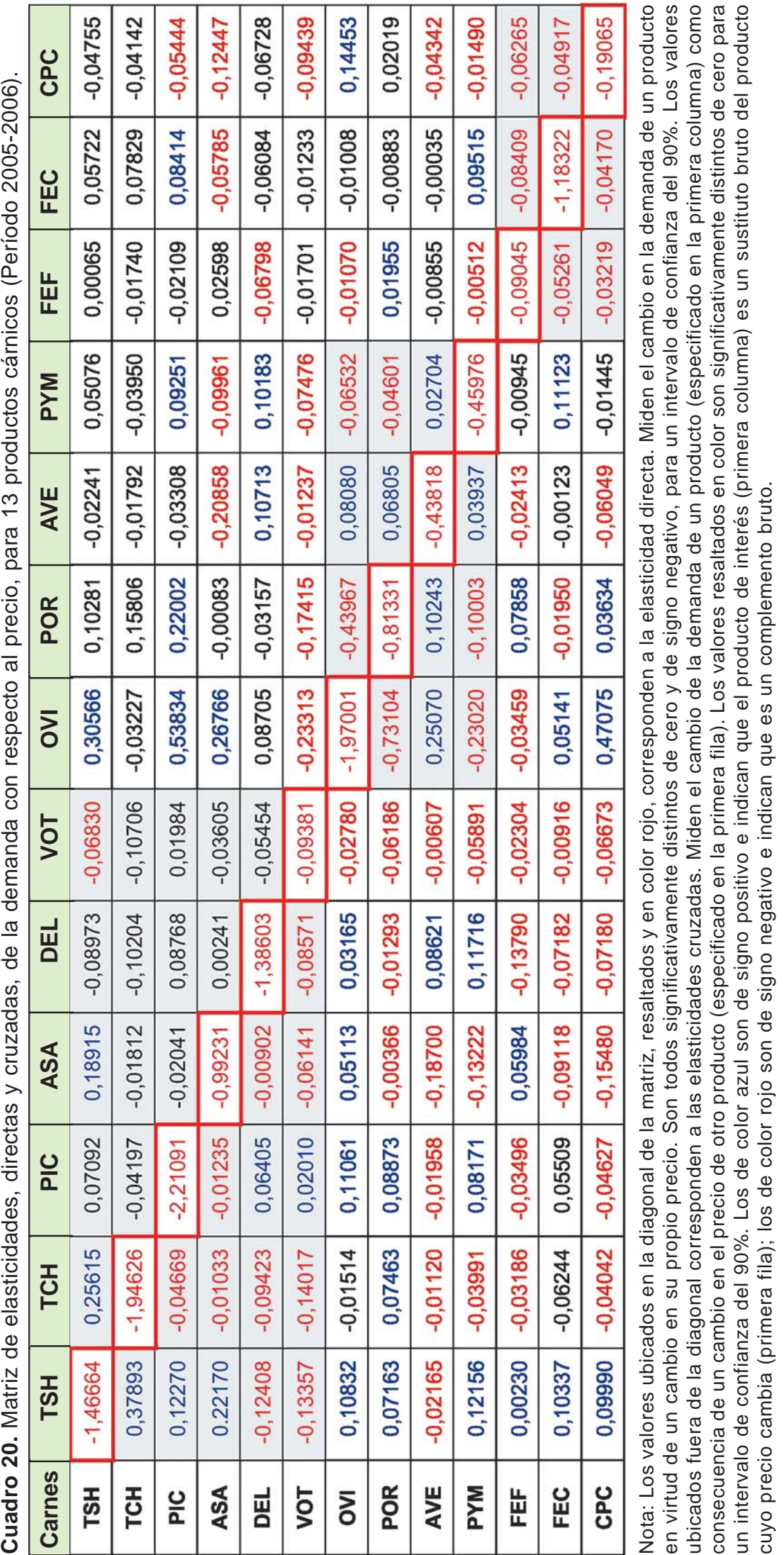


producto cuyo cambio en la demanda es consecuencia de un cambio en el producto listado en la primera fila. De acuerdo al signo que tome la correspondiente elasticidad cruzada, en el caso que su magnitud sea estadísticamente significativa, el primero es un sustituto o complemento bruto del segundo.

A los efectos de facilitar la lectura e interpretación de los resultados, los valores resaltados en color son significativamente distintos de cero para un intervalo de confianza del $90 \%$, en tanto que los presentados en negro no mostraron evidencia estadística que permita sugerirlo. Los de color azul son de signo positivo e indican que el producto de interés (primera columna) es un sustituto bruto del producto cuyo precio cambia (primera fila); los de color rojo son de signo negativo e indican que es un complemento bruto.

La primera observación general que surge del análisis de ambas matrices es que, en valor absoluto, todas las elasticidades cruzadas fueron inferiores a la unidad. En particular, todas fueron menores a 0,6 en 1994-95 mientras apenas superaron un valor de 0,7 en 2005-06. Se trata de un comportamiento esperable ya que siempre se espera que un producto muestre una respuesta más elástica frente a su propio precio que frente al precio de otros productos.

En segundo lugar, la proporción de valores significativos de elasticidad cruzada para el nivel de confianza elegido se incrementó sensiblemente, de $51,5 \%$ en $1994-95$ a $70,5 \%$ en 2005-06, lo cual puede tener cierta relación con el mayor tamaño de muestra en el segundo período.

En tercer lugar, mientras que en 1994-95 predominaron las relaciones de sustitución entre los productos, en 2005-06 fueron más frecuentes las de complementariedad. Una explicación posible puede estar relacionada con una diversificación en la dieta de los hogares en años recientes, ya no tan concentrada en un reducido número de productos cárnicos y donde la adquisición de un nuevo producto operaría en sustitución de otro. De la mano de una mayor oferta y variedad de productos cárnicos y un cambio en los hábitos de alimentación de los consumidores, podría esperarse un cambio en las relaciones de consumo entre los productos como la observada en este estudio.

Al analizar la relación entre productos de carne bovina en particular se observó que, con alguna excepción, TSH, TCH, PIC y AYD exhibieron relaciones de sustitución bruta entre sí para el período 1994-95. El único caso en que esta relación no fue significativa fue la sustitución de PIC por TCH, aunque la inversa sí lo fue. En el caso de VOT, este se comportó como sustituto bruto de TSH y TCH y como complemento neto de PIC y AYD. La inversa no se dio, es decir, no se encontró evidencia estadística de que TSH, TCH, PIC y AYD fueran sustitutos o complementos de VOT durante el período.

Para 2005-06, varias de esas relaciones cambiaron de signo. DEL pasó a ser complemento bruto de $\mathrm{TCH}$, TSH y ASA, en tanto que éste último se comportó como un complemento del TCH y la PIC. Por su parte, VOT continuó siendo sustituto de PIC pero fue complemento para TSH, TCH, ASA y DEL.

Por otro lado, mientras que AVE mostró un efecto de sustitución frente a todos los productos de carne bovina en 1994-95 (a excepción de VOT para quien siempre resultó un complemento), el mismo se transformó en complementariedad para 2005-06, a excepción de DEL, para el que continuó siendo un sustituto. Algo similar pasó con OVI, POR y PYM, que en general se comportaron como sustitutos respecto a casi todos los cortes de carne bovina, para el primer período, modificándose la relación con algunos de estos para 2005-06. La excepción estuvo referida a OVI, quien actuó como complemento de TSH, al igual que POR respecto a $\mathrm{TCH}$. Excepto para OVI en 1994-95, todas estas carnes se mostraron como complementos de VOT.

Tanto FEF como FEC operaron como sustitutos de TSH en ambos períodos, sumándose también CPC en el segundo. También lo fue PIC aunque esta relación cambió hacia complementariedad en 2005-06. En general, CPC fue complemento para casi todos los cortes de carne bovina.

Entre las carnes alternativas a la bovina, las relaciones no mostraron una consisten- 
cia clara, si bien PYM fue un complemento para OVI y POR en ambos períodos. Con respecto a AVE, resultó un complemento en el primer período pero un sustituto en el segundo.

Finalmente, en el caso de los productos mixtos, en 1994-95 se encontró un efecto de sustitución entre sí por parte de FEC y CPC. Sin embargo, en 2005-06 las relaciones entre ambos productos y entre cada uno de ellos con FEF se convirtieron en complementariedad.

\subsubsection{Efecto de las características del hogar sobre la demanda}

En el Cuadro 21 se señala el efecto de algunos rasgos distintivos de los hogares, referidos a su composición y las características del jefe o referente del mismo, sobre la demanda por cada uno de los trece productos cárnicos considerados en ambos períodos. Las flechas indican la dirección del efec- to de cada característica sobre la demanda por cada producto, para un nivel de significación de al menos $10 \%$. Las flechas que apun$\tan$ hacia arriba $(\uparrow)$ indican un efecto positivo en la demanda y las que apuntan hacia abajo $(\downarrow)$ indican un efecto negativo. Los guiones (-) indican un efecto no significativo (neutro), al mismo nivel de significación estadística.

Lo primero que puede observarse es que, al igual que ocurrió en el caso de las elasticidades, los coeficientes asociados a las características del hogar mostraron un mayor nivel de significación estadística en el segundo período (2005-06) que en el primero (1994-95). De todos modos, los resultados fueron bastante consistentes entre períodos, aunque con algunas excepciones.

En términos generales, los resultados sugieren que el tamaño del hogar, corregido por sexo y edad de los integrantes tuvo un efecto positivo sobre el consumo de carnes,

Cuadro 21. Efecto de características del hogar en la demanda de productos cárnicos (94-95 y 05-06).

\begin{tabular}{|c|c|c|c|c|c|c|c|c|c|c|c|c|c|c|c|c|}
\hline \multirow{2}{*}{ Pro } & \multicolumn{8}{|c|}{ Período 1994-1995 } & \multicolumn{8}{|c|}{ Período 2005-2006 } \\
\hline & EQH & M18 & S64 & MUJ & EJH & ED2 & ED3 & ED4 & EQH & M18 & S64 & MUJ & EJH & ED2 & ED3 & ED4 \\
\hline TSH & - & - & $\downarrow$ & - & $\uparrow$ & - & - & - & $\uparrow$ & - & $\downarrow$ & - & $\uparrow$ & - & - & $\uparrow$ \\
\hline TCH & - & - & - & $\uparrow$ & - & - & - & - & - & - & $\downarrow$ & - & $\uparrow$ & - & $\downarrow$ & - \\
\hline PIC & $\uparrow$ & - & $\downarrow$ & - & - & - & - & $\downarrow$ & $\uparrow$ & $\downarrow$ & - & $\downarrow$ & - & $\uparrow$ & $\uparrow$ & $\uparrow$ \\
\hline ASA & \multirow{2}{*}{$\uparrow$} & \multirow{2}{*}{$\downarrow$} & \multirow{2}{*}{$\downarrow$} & \multirow{2}{*}{$\downarrow$} & \multirow[b]{2}{*}{-} & \multirow{2}{*}{-} & \multirow{2}{*}{-} & \multirow{2}{*}{$\downarrow$} & $\uparrow$ & $\downarrow$ & - & - & - & - & - & $\downarrow$ \\
\hline DEL & & & & & & & & & - & - & - & - & - & - & - & $\downarrow$ \\
\hline VOT & - & - & - & - & $\uparrow$ & $\uparrow$ & $\uparrow$ & - & $\uparrow$ & $\downarrow$ & - & - & - & - & - & $\downarrow$ \\
\hline OVI & - & - & $\downarrow$ & $\downarrow$ & $\uparrow$ & $\uparrow$ & - & - & - & $\downarrow$ & - & - & - & - & - & $\downarrow$ \\
\hline POR & - & - & $\downarrow$ & - & - & $\uparrow$ & - & - & - & - & - & $\downarrow$ & - & - & $\downarrow$ & $\downarrow$ \\
\hline AVE & $\uparrow$ & - & $\downarrow$ & - & $\uparrow$ & $\uparrow$ & - & - & $\uparrow$ & - & $\downarrow$ & $\downarrow$ & $\uparrow$ & $\uparrow$ & - & - \\
\hline PYM & $\downarrow$ & $\uparrow$ & $\downarrow$ & - & $\uparrow$ & $\downarrow$ & - & - & $\uparrow$ & - & $\downarrow$ & $\downarrow$ & $\uparrow$ & - & $\uparrow$ & $\uparrow$ \\
\hline FEF & - & - & $\uparrow$ & $\downarrow$ & - & $\uparrow$ & - & - & $\uparrow$ & $\downarrow$ & - & $\downarrow$ & - & - & - & - \\
\hline FEC & - & - & - & - & - & - & - & - & - & $\downarrow$ & $\uparrow$ & - & $\uparrow$ & - & - & - \\
\hline CPC & - & - & $\uparrow$ & $\downarrow$ & - & - & - & - & $\uparrow$ & - & $\downarrow$ & - & - & $\uparrow$ & - & - \\
\hline
\end{tabular}

Nota: Las flechas indican la dirección del efecto de la característica sobre la demanda del producto cárnico para un nivel de significación de al menos $10 \%$. Las flechas que apuntan hacia arriba $(\uparrow)$ indican un efecto positivo en la demanda y las que apuntan hacia abajo $(\downarrow)$ indican un efecto negativo. Los guiones (-) indican un efecto no significativo (neutro), al mismo nivel de significación estadística.

Características del Hogar: EQH, tamaño del hogar (Equivalente Adulto); M18, Cantidad de menores de 18 años en el hogar; P64, Cantidad de mayores de 64 años en el hogar; MUJ, Mujer a cargo del hogar; EJH, Edad del jefe de hogar; ED2, Jefe de hogar con educación hasta Secundaria completa; ED3, Jefe de hogar con educación hasta Educación Técnica u Otra; ED4, Jefe de hogar con educación hasta Universidad o Superior. 
esto es, a mayor tamaño de hogar, expresado como «equivalente adulto» (EQH), mayor demanda por carnes. Este resultado fue más evidente en 2005-06, donde el efecto resultó significativo y de signo positivo para los siguientes productos: TSH, PIC, ASA, VOT, AVE, PYM, FEF y CPC. En 1994-95, el efecto positivo resultó significativo para PIC, AYD y AVE, siendo negativo para PYM. Los únicos productos para los cuales el tamaño de hogar registró ningún efecto en los dos períodos fueron $\mathrm{TCH}, \mathrm{OVI}$, POR y FEC.

La composición etaria del hogar, tanto en términos de la cantidad de integrantes menores de 18 años (M18) como de mayores de 64 años (S64), mostró un efecto preponderantemente negativo sobre el consumo de carnes. A medida que aumenta la cantidad de menores de edad o de miembros mayores, la demanda de carnes disminuye. En el caso de M18, el efecto no fue claro para 1994-95, siendo negativo para AYD y positivo para PYM. Sin embargo, para 2005-06 fue negativo en todos los casos donde el efecto resultó estadísticamente significativo: PIC, ASA, VOT, OVI, FEF y FEC. No se encontraron efectos significativos para $\mathrm{TSH}, \mathrm{TCH}, \mathrm{POR}, \mathrm{AVE}$ y CPC, en ninguno de los dos períodos.

En el caso de S64, el efecto resultó negativo para TSH, PIC, AYD, OVI, POR, AVE, y PYM y positivo para FEF y CPC, para el primer período. Para el segundo, el efecto negativo se repitió para TSH, AVE y PYM y pasó también a ser negativo para TCH y CPC. Para el caso de FEC, el efecto resultó positivo. En ninguno de los dos períodos se encontraron efectos para VOT y FEC.

Con referencia al sexo del jefe de hogar, los resultados obtenidos mostraron que los hogares a cuyo frente se encontraba una mujer (MUJ) tendieron a consumir menos productos cárnicos que aquellos cuyo referente era un hombre. En 1994-95, este efecto resultó estadísticamente significativo para AYD, OVI, FEF y CPC; para TCH, no obstante, el efecto tuvo signo positivo. En 200506, mientras tanto, todos los efectos significativos que se encontraron fueron negativos, siendo los productos PIC, POR, AVE, PYM y FEF. En ninguno de los períodos se encontró efecto alguno sobre TSH, VOT y FEC.

La edad del jefe de hogar (EJH) mostró un efecto positivo sobre la demanda de varios productos. En otras palabras, a mayor edad del referente del hogar se verificó una mayor demanda. Este fue el caso de TSH, VOT, OVI, AVE y PYM para 1994-95 y de TSH, TCH, AVE, PYM y FEC para 2005-06. No se verificó efecto significativo sobre PIC, AYD, POR, FEF y CPC.

Con respecto al nivel máximo de educación del jefe de hogar, los resultados refieren al valor por omisión, definido como hogares cuyo jefe o referente declaró haber alcanzado un nivel de formación máximo de primaria completa (ED1). A igualdad de otras características, los hogares cuyo jefe recibió un nivel de instrucción superior a primaria y alcanzó hasta un máximo de secundaria completa (ED2) mostraron una mayor demanda por VOT, OVI, POR, AVE y FEF y menor para PYM, para el período 1994-95. Para 2005-06, mostraron una mayor demanda por PIC, AVE y CPC.

Por otro lado, los hogares a cuyo frente se ubicó una persona con un nivel máximo correspondiente a educación técnica o similar (ED3) fueron los que mostraron menos diferencias en comparación a los de menor instrucción. Solamente en al caso de VOT se encontró un efecto positivo para el primer período mientras que para el segundo se verificó un efecto positivo con PIC y PYM pero negativo con $\mathrm{TCH}$ y POR.

Finalmente, para los hogares cuyo referente alcanzó o completó un nivel de educación universitaria de grado o posgrado (ED4) se verificó un efecto negativo en ambos períodos con $A Y D$, tanto en forma conjunta como por separado (ASA y DEL). Para PIC, dicho efecto fue evidente para 1994-95, mientras que para VOT, OVI y POR lo fue para 2005-06. En este último período, se verificó un efecto positivo sobre TSH, PIC y PYM. Para los restantes productos, AVE, FEF, FEC y CPC, no se encontraron efectos significativos en ninguno de los dos períodos. 


\section{CONCLUSIONES E IMPLICANCIAS}

\subsection{Consideraciones generales}

El objetivo principal de la investigación fue evaluar los patrones de consumo de diferentes cortes y tipos de carnes por parte de los hogares uruguayos, durante la última década del siglo XX y la primera del siglo XXI. Para ambos períodos se analizaron los efectos de los precios y del ingreso, principales determinantes de la demanda a nivel de consumidores, mediante las correspondientes elasticidades. También se estudiaron los efectos de diferentes características socioeconómicas de los hogares (localización, ingreso, tamaño y composición etaria) y de los jefes de hogar (edad, sexo y nivel educativo) sobre la demanda de carnes.

La investigación consideró un total de trece productos cárnicos. Seis de estos fueron de carne bovina: cortes de trasero sin hueso, cortes de trasero con hueso, carne pica$\mathrm{da}$, asado, cortes del delantero y otros productos. Los siguientes cuatro correspondieron a otros tipos de carne, a saber, carne ovina, carne porcina, carne de ave y pescados y mariscos. Los tres restantes fueron productos elaborados a partir de distintas carnes: fiambres y embutidos fríos, fiambres y embutidos para cocinar y comidas prontas en base a carnes.

El aporte adicional de este trabajo de investigación está dado por la aplicación de un paquete metodológico que permite realizar análisis empíricos de demanda totalmente consistentes con la teoría económica. Las funciones de demanda que surgen del modelo LinQuad, estimadas en forma simultánea en el marco de un sistema incompleto de ecuaciones censuradas a través de un procedimiento bietápico que separa la decisión de consumir de la decisión de las cantidades a consumir, satisfacen plenamente las condiciones requeridas por la teoría. En otras palabras, los patrones estimados empíricamente provienen de funciones de demanda que cumplen con las condiciones para ser racionalizadas a partir de un conjunto de pre- ferencias bien definidas, sin la necesidad de restricciones adicionales.

\subsection{Los patrones de consumo de carnes en Uruguay}

\subsubsection{Los cambios de la demanda en el contexto nacional y global}

El desarrollo de la presente investigación permitió conocer el comportamiento de los consumidores uruguayos frente al consumo de productos cárnicos, en dos momentos distintos. Muchas de las diferencias encontradas en los patrones de consumo entre un período y otro guardan una fuerte relación con los cambios en los hábitos de consumo observados a nivel mundial.

La disminución en el consumo de carnes en general pero por sobre todo de las carnes rojas es un fenómeno que se ha venido observando desde las últimas tres décadas del siglo pasado. A nivel global, ello ha sido acompañado de un incremento en la participación de otros tipos de carne, fundamentalmente de la carne aviar, la carne porcina y la carne de pescado y los frutos del mar.

En Uruguay, estos fenómenos comenzaron a darse más tardíamente que en otras partes del mundo. Y no parece casualidad que estos cambios en el comportamiento del consumo de los uruguayos se produjeran precisamente entre los dos períodos considerados, esto es, en el lapso de 10 años que cubren el último quinquenio del siglo pasado y el primero del presente.

Al igual que en Argentina, el consumo de carne bovina ha estado por siempre tan inserto en la cultura de la población que, aunque la disminución de consumo entre los dos períodos estudiados fue evidente, igualmente siguió y continúa siendo un componente básico de la dieta de los uruguayos. No en vano, ambos países han contado históricamente con la mayor cantidad de cabezas de ganado bovino por habitante, de todo el planeta. Lo que para el resto del mundo fue siempre la proteína más cara, para ambos países rioplatenses se trató de un alimento básico y al alcance de prácticamente cualquier mesa. 
La desregulación operada en el sector, a principios de los noventa, junto a los cambios operados a nivel del comercio internacional y la sensible mejora del estatus sanitario abrió definitivamente las puertas del mundo a la carne uruguaya. El cambio en el perfil de negocios de la cadena cárnica bovina del país, en lo referente a la relación exportación/abasto, ya había comenzado a cambiar algunos años antes, pasando de una relación 30:70 en los sesenta, a 40:60 en los setenta y prácticamente 55:45 en los ochenta.

Sin embargo, esta tendencia se profundizó en la última década del siglo XX y terminó por invertirse totalmente hasta alcanzar una relación 70:30, luego del interregno ocasionado por el rebrote de aftosa y la crisis financiera que azotó al país a comienzos del nuevo siglo. Pero tal vez el efecto más notable de este cambio de perfil, el que impulso a los frigoríficos exportadores a adaptarse a las exigencias del mercado internacional fue el traslado de estas nuevas modalidades hacia el mercado interno.

El cierre temporal de los mercados internacionales debido al rebrote de aftosa en abril de 2001 obligó a volcar excedentes de exportación hacia el abasto interno. Los consumidores locales pudieron acceder a cortes normalmente destinados al mercado internacional, de alta calidad y con nuevas formas de presentación (cortes sin hueso, al vacío). Sin desmedro de la gran confianza que el consumidor uruguayo ha tenido sobre la carne bovina desde siempre, independientemente de su origen, éste fue acostumbrándose a ponerse exigente en la elección del producto.

La ampliación de los formatos de venta de carnes a partir de la profundización observada en el avance de las grandes superficies durante esos años, contribuyó en forma importante a estos cambios. El supermercado combinó la atención personalizada propia de la carnicería tradicional con la presentación en góndolas, con productos porcionados y presentados en bandejas y al vacío. La incorporación de la rotisería, ofreciendo la posibilidad de adquirir productos ya preparados y prontos para servir, fue otro factor que apuntó en el mismo sentido. Como contrapartida, la propia carnicería tradicional debió adoptar, en muchos casos, algunas de las características del autoservicio.

Una de las características del «nuevo consumidor» fue la drástica disminución en la compra de cortes de carne bovina con hueso, en especial de trasero. No obstante, la demanda mostró una importante sensibilidad frente a los cambios en su precio (elasticidad directa) incrementándose las posibilidades de sustitución entre productos, tanto dentro mismo de la carne bovina como de otras carnes.

La competencia sufrida por la carne bovina a manos de otras carnes sustitutas quedó de manifiesto en este estudio, con algunas variaciones. En el caso de las carnes rojas, los principales competidores han sido la carne de pollo y, aunque en menor medida, también cada vez más por la carne de pescado. El incremento de la participación de estas dos carnes se advirtió claramente en este trabajo.

El fenómeno del supermercadismo acompañó las nuevas tendencias del mundo moderno. Apuntó a la comercialización de una mayor variedad de productos, todos destinados a la simplificación de las tareas domesticas y a la disminución del tiempo dedicado a la compra de alimentos y a su preparación. A nivel global, la cadena avícola fue sin dudas la que mejor aprovechó estos cambios, de la mano de una gran mejora en la cadena de producción, distribución y mercadeo, con lo cual contribuyó a disminuir sensiblemente los precios al consumidor.

En Uruguay, esto se observó claramente en los diez años que median entre ambos períodos estudiados. La proliferación de establecimientos de venta exclusiva de productos de carne aviar durante este período ha sido otra característica notoria. Como consecuencia de todo lo anterior y apoyado en una muy fuerte estrategia de marketing, el consumo de esta carne mostró un gran crecimiento.

A diferencia con lo que ocurre en otras partes del mundo, donde observa un importante nivel de consumo, la carne porcina no mostró señales de desarrollo en el país en 
ninguno de los dos períodos considerados. La evidencia obtenida mostró que la demanda de cortes frescos continuó siendo marginal en comparación con las otras carnes. En ambos períodos, el consumo de productos porcinos estuvo limitado en gran medida a los fiambres, embutidos y chacinados de todo tipo, tanto para consumo en frío como para cocinar.

Debe señalarse, no obstante, que existen claros indicios de la ocurrencia de un cambio en los patrones de consumo de cerdo en Uruguay, a partir de la segunda mitad de la década pasada, lo cual no quedó registrado en este estudio por darse fuera del período considerado. Sería dable a esperar que esto pueda verificarse en la próxima encuesta de gastos e ingresos de hogares, la cual debería llevarse a cabo alrededor de 2015.

Renglón aparte merece el tema de la carne ovina. Esta ha sido una de las que ha enfrentado mayores dificultades, de entre las carnes alternativas. Es la de menor producción y cultura de consumo a nivel mundial, con excepción de algunas regiones. A nivel global, no logró adaptarse cabalmente a los cambios en la cadena de valor alimentaria, como lo hizo la carne aviar, la porcina e inclusive la bovina.

En Uruguay, a pesar de los ingentes esfuerzos públicos y privados por promover el consumo de carne ovina, los mismos no han tenido resultados satisfactorios. La evidencia obtenida sugiere que la moderada presencia que mostraba en el consumo de los hogares uruguayos durante los noventa cayó sensiblemente durante la década siguiente. Factores como el precio, así como un menor rendimiento relativo frente a la carne bovina, le han impedido convertirse en una alternativa relevante en la dieta de los consumidores.

La carne ovina es considerada un producto de alta calidad, con una buena demanda y altos precios pagados en determinados nichos de mercado a nivel internacional. Sin embargo, la persistencia de algunos problemas «externos» como la imposibilidad de exportar productos con hueso hacia algunos mercados de alto valor, fundamentalmente en
Europa, no ha contribuido aun a incrementar en forma importante la producción de esta carne en el país, de forma de ofrecer estos productos a niveles de precios más atractivos para el consumo doméstico a nivel de los hogares.

\subsubsection{Principales conclusiones acerca de la demanda interna de carnes}

A partir de la evidencia recogida en esta investigación y en el contexto señalado en la sección anterior, se pueden enumerar una importante serie de conclusiones:

1. Los uruguayos disminuyeron la frecuencia de consumo de productos cárnicos durante los diez años transcurridos desde mediados de la última década del siglo $X X$ y el primer quinquenio del siglo $X X I$, no obstante estos continuaron siendo el elemento preponderante en la dieta de los hogares.

2. Esta disminución se verificó para todos los tipos de carne (bovina, ovina, porcina, aviar, pescados y mariscos) así como también a nivel de productos más específicos de carne bovina y de productos mixtos, como ser los fiambres, chacinados, embutidos y comidas prontas. En 1994-95, prácticamente la totalidad de los hogares uruguayos consumía algún tipo de carne por lo menos una vez a la semana. Una década más tarde, esto era realizado por 9 de cada 10 hogares.

3. La carne bovina fue claramente el tipo de carne consumido con mayor frecuencia en los hogares, en ambos períodos. En 1994-95 era consumida semanalmente por casi $90 \%$ de los hogares mientras que en 2005-06 lo era por dos de cada tres. Aunque la caída observada en el consumo de carne bovina ocurrió en todos los tipos de productos, no fue pareja siendo afectados en distinta proporción.

4. En el primer período, los cinco productos de carne bovina se ubicaron en los ocho primeros lugares entre los trece productos considerados (asado y delantero 
bovinos fueron juntos), todos con una proporción de hogares consumidores superior a 35\%. En el segundo período solamente los cortes de trasero sin hueso, los cortes del delantero y la carne picada, lograron mantenerse entre los de mayor frecuencia de consumo, siendo esta última la única que mejoró su posicionamiento relativo, pasando del quinto al segundo lugar.

5. En los dos períodos considerados, los hogares uruguayos mostraron su preferencia por el consumo de fiambres, chacinados y embutidos de todo tipo. La preferencia por los fiambres y embutidos fríos quedó reflejada al ocupar dicho producto la segunda posición en 1994-95 y la primera en 2005-06. Los fiambres y embutidos para cocinar pasaron del sexto al cuarto lugar.

6. El crecimiento relativo más espectacular en los 10 años transcurridos entre un período y otro ocurrió con la carne aviar. Si bien este producto fue consumido por alrededor de un tercio de los hogares en ambos momentos, su posicionamiento relativo saltó del noveno lugar en 199495 al tercer lugar en 2005-06.

7. La caída más importante en el porcentaje de hogares se dio con la carne ovina, a pesar del aumento en la participación de hogares del interior en la muestra analizada. Tres de cada diez hogares adquirieron carne ovina en 1994-95, proporción que cayó a bastante menos de una en 2005-06.

8. Con referencia a los restantes tipos de carne, se observó una mejora en el posicionamiento de los pescados y mariscos, pasando del lugar once al siete, en tanto que el consumo de carne porcina se mantuvo siempre en el último lugar de las preferencias, a juzgar por la proporción de hogares consumidores y muy lejos de los restantes tipos.

9. Por otro lado, mientras el consumo de comidas prontas elaboradas en base a carnes ocupaba un lugar muy marginal en 1994-95, siendo adquirida por uno de cada diez hogares, esta proporción prácticamente se duplicó en 2005-06.
10. El nivel de ingreso de los hogares mostró un efecto positivo sobre la probabilidad de consumo de prácticamente todos los productos cárnicos, a excepción de algunos productos bovinos, como carne picada, delantero y otros productos. El hecho de localizarse en Montevideo, fue un factor que mostró una incidencia negativa en la probabilidad de consumir carne ovina y bovina, a excepción de cortes sin hueso. Sin embargo, mostró efectos positivos sobre la probabilidad de consumir otros tipos de carnes y productos mixtos.

11. El tamaño del hogar resultó ser la característica más consistente en términos de exhibir un efecto positivo sobre la decisión de consumo de carnes y en particular en el caso de carne picada, asado, delantero y otros productos de carne bovina, así como para el caso de fiambres y embutidos. Algo menos consistente fue el efecto sobre la probabilidad de consumir cortes bovinos con y sin hueso, carne ovina, porcina, aviar y comidas prontas.

12. La presencia de menores de edad en los hogares verificó un efecto positivo en la decisión de consumir carne picada y comidas prontas. Menos consistente fue el efecto positivo sobre la probabilidad de consumir fiambres y embutidos para cocinar, así como cierto efecto negativo sobre la probabilidad de consumir cortes de trasero con hueso, asado y delantero y pescados y mariscos.

13. La presencia de mayores de 64 años en el hogar tuvo un efecto positivo sobre la decisión de consumir cortes bovinos de trasero sin hueso, carne de ave, pescados y mariscos. El efecto fue negativo para las comidas preparadas, carne picada y fiambres y embutidos de ambos.

14. La presencia de jefes de hogar de sexo femenino mostró un efecto negativo sobre la posibilidad de consumir asado y delantero. Aunque menos consistente entre períodos, también se observó un efecto negativo sobre la probabilidad de consumir cortes de trasero, otros cortes bovinos y carne ovina, así como un 
cierto efecto positivo sobre el consumo de comidas prontas en base a carne.

15. En ambos períodos se observó un efecto positivo sobre la probabilidad de consumo de fiambres y embutidos fríos y carnes preparadas en aquellos hogares cuyo jefe poseía un mayor nivel de educación. Dicho efecto fue negativo sobre el consumo de asado, delantero y carne ovina. Sin la misma consistencia, el efecto negativo también se registro con los cortes de trasero con hueso, otros cortes bovinos y carne aviar.

16. En términos generales, la respuesta de la demanda de carnes antes variaciones en el ingreso fue bastante baja (inelástica) aunque cabe destacar que todas las carnes se comportaron como bienes normales. Esto es, un aumento en el ingreso de los hogares se tradujo en un aumento de menor proporción en la demanda de carnes. El producto que mostró una mayor respuesta al ingreso fue la carne ovina. A modo de ejemplo, un incremento de $10 \%$ en el nivel de ingreso derivó en un aumento de la demanda de carne ovina en un porcentaje algo mayor a $5 \%$.

17. Los otros cinco productos cárnicos que mostraron una respuesta significativa ante cambios en el ingreso del hogar fueron la carne picada, el asado y delantero, los pescados y mariscos y los fiambres y embutidos, tanto fríos como para cocinar. En todos estos casos, variaciones del orden del $10 \%$ en el ingreso fueron seguidos de aumentos en la demanda de poco más del $1 \%$.

18. Todos los productos cárnicos considerados sin excepción fueron sensibles a los cambios en su propio precio. En todos los casos, incrementos en el precio de venta de un producto produjeron una caída en su demanda y viceversa. En términos de la elasticidad precio directa, se dice entonces que todos los productos cárnicos considerados se comportaron como bienes ordinarios.

19. En general, los productos de carne bovina fueron los más responsivos a las variaciones de su propio precio, hecho esperable dado su mayor nivel de desagregación. Entre estos se destaca la alta respuesta a los cambios de precio mostrada por la carne picada y por los cortes de trasero con hueso frente al precio. En ambos casos, un incremento de $10 \%$ en el precio estuvo seguido de una caída en la demanda de entre 20 y $22 \%$.

20. Tomados en forma conjunta, asado y delantero también mostraron una importante respuesta, Ilegando a 18\% la caída de demanda ante un encarecimiento del $10 \%$. Por separado, en el segundo período, la variación alcanzó a casi $14 \%$ en el delantero, similar a la verificada con los cortes de trasero sin hueso. Mientras tanto, la elasticidad precio de la demanda para el asado fue unitaria, es decir, un cambio en el precio derivó en un cambio en la demanda de asado de la misma proporción aunque de signo contrario. La respuesta de otros productos de carne bovina fue bastante inelástica, siendo que un cambio de $10 \%$ en su precio produjo un cambio en la demanda de entre 1 y $3 \%$ solamente. En este caso se trata de un producto bastante heterogéneo y con mayor nivel de agregación que los anteriores.

21. Al analizar los restantes tipos de carnes se verificó que la menor respuesta a las variaciones de precio correspondió a los pescados y mariscos, los que registraron cambios de entre 3 y $4 \%$ ante variaciones de precio del $10 \%$. Este es uno de los grupos de productos más heterogéneo, con un alto grado de sustitución interna que le permite exhibir valores absolutos relativamente reducidos.

22. También se observó una baja respuesta relativa en el caso de la carne porcina, con valores de elasticidad precio menores a la unidad. La reducción de $10 \%$ en el precio de esta carne derivó en aumentos en la demanda en el orden de 5 a $8 \%$. En tanto, la respuesta en la demanda por carne ovina fue más que proporcional al cambio en los precios, alcanzando entre 18 y $20 \%$ de reducción ante aumentos de precio del $10 \%$. 
23. Un caso a destacar fue la sensible caída registrada en la elasticidad de la carne aviar entre los dos períodos estudiados. Mientras que en 1994-95, un cambio de $10 \%$ en el precio de este producto fue seguido de un cambio de signo contrario de alrededor del 19\%, la respuesta se redujo a algo menos del $5 \%$ una década más tarde.

24. Con respecto a los productos mixtos, también se destacó una drástica caída de la elasticidad precio entre períodos, en el caso de los fiambres y embutidos fríos. De variar un $12 \%$ ante un cambio de $10 \%$ en su precio, pasó en tan solo 10 años a una respuesta muy inelástica, del orden del $1 \%$. Cabe señalar que, junto a la carne aviar, estos productos fueron los que registraron el mayor incremento relativo en la frecuencia de consumo por parte de los hogares, entre ambos períodos. La magnitud de la respuesta de los fiambres y embutidos para cocinar se mantuvo entre 10 y $12 \%$, mientras que para las comidas prontas en base a carnes los valores de respuesta variaron entre 2 y $3 \%$ entre períodos, siempre frente a una variación de $10 \%$ en su precio.

25. En valor absoluto, todas las elasticidades cruzadas fueron inferiores a la unidad. En particular, todas fueron menores a 0,6 en 1994-95 mientras apenas superaron un valor de 0,7 en 2005-06. Se trata de un comportamiento esperable ya que un producto siempre muestra una respuesta más elástica frente a su propio precio que frente al precio de otros productos.

26. Mientras que en 1994-95 predominaron las relaciones de sustitución entre los productos, en 2005-06 fueron más frecuentes las de complementariedad. Esto puede guardar relación con una mayor diversificación en la dieta de los hogares en años recientes, ya no tan concentrada en un reducido número de productos cárnicos y donde la adquisición de un nuevo producto operaría en sustitución de otro. De la mano de una mayor oferta y variedad de productos cárnicos y un cambio en los hábitos de alimentación de los consumidores, podría esperarse un cambio en las relaciones de consumo entre los productos como la observada en este estudio.

27. Al analizar la relación entre productos de carne bovina, se observó que, con alguna excepción, los cortes de trasero sin hueso, trasero con hueso, carne picada y asado y delantero exhibieron relaciones de sustitución bruta entre sí durante el primer período. Para 2005-06, varias de esas relaciones cambiaron de signo.

28. Por otro lado, mientras que la carne de ave mostró un efecto de sustitución frente a casi todos los productos de carne bovina en 1994-95, la relación se convirtió en complementariedad para 2005-06, con alguna excepción. Algo similar pasó con la carne ovina, porcina, pescados y mariscos, que en general se comportaron como sustitutos respecto a casi todos los cortes de carne bovina, para el primer período, modificándose la relación con algunos de estos para 2005-06.

29. Los fiambres y embutidos operaron como sustitutos de los cortes sin hueso en ambos períodos, sumándose las comidas preparadas en el segundo. También lo fueron de la carne picada aunque la relación cambió hacia complementariedad en 2005-06. En general, las carnes preparadas fueron un complemento para casi todos los cortes de carne bovina.

30. Entre las carnes alternativas a la bovina, las relaciones no mostraron una consistencia clara, si bien los pescados y mariscos fueron un complemento para la ovina y la porcina en ambos períodos. Con respecto a la carne de ave, resultó un complemento en el primer período pero un sustituto en el segundo.

31. En el caso de los productos mixtos, en 1994-95 se encontró un efecto de sustitución entre sí por parte de los fiambres y embutidos para cocinar y las comidas preparadas en base a carne. Sin embargo, en 2005-06 las relaciones entre ambos productos y entre cada uno de ellos 
con los fiambres y embutidos fríos se convirtieron en complementariedad.

32. En términos generales, los resultados sugieren que el tamaño del hogar, corregido por sexo y edad de los integrantes tuvo un efecto positivo sobre el consumo de carnes, esto es, a mayor tamaño, mayor demanda por carnes. Este resultado fue más evidente en el segundo período de análisis.

33. La composición etaria del hogar, tanto en términos de la cantidad de integrantes menores de 18 años como de mayores de 64, mostró un efecto preponderantemente negativo sobre el consumo de carnes. A medida que aumentó la cantidad de menores de edad o de miembros mayores, la demanda por varios de los productos cárnicos disminuyó.

34. La edad del jefe de hogar mostró un efecto positivo sobre la demanda de varios productos. En otras palabras, a mayor edad del referente del hogar se verificó una mayor demanda de productos como los cortes de trasero sin hueso, carne de ave, pescados y mariscos. Aunque no en ambos períodos, también se verificó dicho efecto sobre la demanda de cortes de trasero con hueso y otros productos de carne bovina, carne ovina y fiambre y embutidos para cocinar.

35. En términos generales, se pudo concluir que los hogares a cuyo frente se encontraba una mujer tendieron a consumir menos productos cárnicos que aquellos cuyo referente era un hombre. Por otro lado y con respecto al nivel de educación, los hogares que completaron Primaria hasta un máximo de Secundaria completa mostraron una mayor demanda por carne aviar en ambos períodos, así como por carne ovina, porcina, carne picada y otros productos de carne bovina y fiambres fríos, en comparación con los hogares cuyo referente culminó, como máximo, enseñanza Primaria.

36. Los hogares a cuyo frente se ubicó una persona con un nivel máximo correspondiente a Educación Técnica o similar fueron los que mostraron menos diferencias en comparación a los de menor instrucción. Finalmente, para los hogares cuyo referente alcanzó o completó un nivel de educación universitaria de grado o posgrado se verificó un efecto negativo en uno de los períodos estudiados con carne picada, asado y delantero, otros productos de carne bovina, carne ovina y carne porcina. Para el caso de los cortes de trasero con hueso, carne picada, pescados y mariscos, se observó un efecto positivo pero tan solo en uno de los períodos.

\subsection{Reflexiones finales e implicancias para el futuro}

Los grandes cambios ocurridos a nivel mundial en los sistemas de producción, distribución y comercialización de alimentos, particularmente las carnes, así como en los hábitos y patrones de consumo de los hogares han tenido su contrapartida en Uruguay. Con particularidades propias, las grandes tendencias surgidas a partir de los años setenta del siglo pasado se hicieron eco también entre los consumidores uruguayos.

Aunque la temporalidad de estos cambios no estuvo restringida dentro de los dos períodos considerados en esta investigación, muchos de estos cobraron gran fuerza o se hicieron evidentes en el período trascurrido entre la última década del siglo XX y primera del siglo XXI. Los ocurridos con referencia a la demanda de productos cárnicos por parte de los hogares uruguayos fueron capturados en esta investigación.

Pese a que, en términos generales, se verificó una disminución en el consumo de todas las carnes y en particular de la carne bovina, los resultados obtenidos resaltan la vigencia de un mercado interno que ha evolucionado notoriamente en términos de gustos y exigencias respecto a la calidad de los productos que consume. En ese sentido, puede resultar de interés la profundización de estudios de este tipo, a los efectos de conocer mejor las nuevas tendencias de la demanda local.

Los bajos niveles de consumo reflejados para algunos de los tipos de carnes alterna- 
tivos impidieron una mayor desagregación de los productos. Esto dificulta la comparación de las estimaciones de elasticidad entre productos cuyo nivel de especificidad es muy diferente. Tomada como un todo, la elasticidad de la carne bovina es bastante menor en magnitud al de la mayoría de las otras carnes y al de los cortes bovinos tomados en forma particular. Lo mismo ocurriría de poder comparar la elasticidad de las carnes alternativas tomadas como un todo respecto a sus productos individuales. De todos modos, los resultados obtenidos permitieron extraer conclusiones importantes para los objetivos de este trabajo.

\section{BIBLIOGRAFÍA}

AcostA, J. 2011. «Situación actual y perspectivas de la producción de proteína animal en Uruguay; nuevas formas de producción e impacto ambiental». En: Foro de las Carnes, Mesa 2, Industria \& Empleo, 2011. Instituto Nacional de Carnes. http:// www.inac.gub.uy/innovaportal/file/6093/ 1/mesa_1_-_inac.pdf

AGNEW, G.K. 1998. LinQuad: An incomplete demand system approach to demand estimation and exact welfare measures. MS Thesis. Department of Agricultural and Resource Economics, University of Arizona. Tucson, AZ.

ALBOGHDADY, M.A.; ALASHRY, M.K. 2010. «The demand for meat in Egypt». African Journal of Agricultural \& Resource Economics. 4(1): 70-81.

AMEMIYA, T. 1985. Advanced Econometrics. Cambridge, MA: Harvard University Press.

AMEMIYA, T. 1994. Introduction to Statistics and Econometrics. Cambridge, MA: Harvard University Press.

ALSTON, J.M.; FOSTER, K.A.; GREEN, R.D. 1994. «Estimating elasticities with the Linear Approximate Almost Ideal Demand System: Some Monte Carlo results». The Review of Economics and Statistics. Vol. LXXVI, No. 2:351-356.

ASCHE, F.; WESSELLS, C.R. 1997. «On price indices in the Almost Ideal Demand
System». American Journal of Agricultural Economics. 79(4):1182-1185.

BARTEN, A.P. 1964.«Consumer demand functions under conditions of almost additive preferences». Econometrica 32(1):1-38.

BARTEN, A.P. 1993. «Consumer allocation models: Choice of functional form». Empirical Economics 18:129-158.

BAUZÁ, E.A. 1952. Abasto de Carnes. Parodi \& Penino. Montevideo: $326 \mathrm{pp}$.

BIERI, J.; DE JANVRY, A. 1972. Empirical Analysis of Demand under Consumer Budgeting. Giannini Foundation Monograph, No. 30. University of California. Berkeley, CA.

BROWN, M.G.; JOHNSON, S.R. 1984. «Equivalent scales, scale economies, and food stamp allotments: Estimates from the Nationwide Food Consumption Survey, 1977-78». American Journal of Agricultural Economics. 66(3):286-293.

BUSE, A. 1994. «Evaluating the linearized Almost Ideal Demand System». American Journal of Agricultural Economics. 76(4):781-793.

BUSE, A. 1998. «Testing homogeneity in the Linearized Almost Ideal Demand System». American Journal of Agricultural Economics. 80(1):208-220.

BUSE, R.C.; SALATHE, L.E. 1978. «Adult Equivalent Scales: An alternative approach». American Journal of Agricultural Economics. 60(3):460-468.

BYRNE, P.J.; CAPPS, O. Jr.; SAHA, A. 1996. «Analysis of food-away-from-home expenditure patterns for U.S. households, 1982-89». American Journal of Agricultural Economics. 78(3):614-627.

CAPPS, O. Jr. 1989. «Utilizing scanner data to estimate retail demand functions for meat products». American Journal of Agricultural Economics. 71(3):750-759.

CAPPS, O. Jr.; HAVLICEK, J. Jr. 1987. «Concepts of consumer demand theory». In R. Raunikar y C.L. Huang, eds. Food Demand Analysis. Iowa State University Press. Ames, IA, pp. 3-32.

CAPPS, O. Jr.; NAYGA, R.M. 1990. «Effect of length of time on measured demand elasticities: The problem revisited». Canadian Journal of Agricultural Economics. 38:499-512. 
CAPPS, O. Jr.; TEDFORD, J.R., y HAVLICEK Jr., J.1985. «Household demand for convenience and nonconvenience foods». American Journal of Agricultural Economics. 67(4):862-869.

CAPURRO, D. 2000. «Tendencias en la Producción y el Consumo Mundial de Carnes». En: «Situación y Perspectivas de la Cadena Cárnica Internacional» Instituto Plan Agropecuario-Instituto Interamericano de Cooperación para la Agricultura. Montevideo: 5-9.

CAPUTTI, P. 2011. Conclusiones. Comercialización en el Mercado Interno. In Foro de las Carnes 2011. Presentación Conclusión y Cierre: Mesa Cierre. Instituto Nacional de Carnes. http:// www.inac.gub.uy/innovaportal/file/6084/1/ mesa_conculsiones_-_inac.pdf.

CAZET, J.D. 1986. «Reducir el stock hasta su extinción». Mesa redonda «Stock Regulador y Plan Ovinos». Carne. Asociación Nacional de Carniceros. Montevideo (Diciembre): 12-14.

CHALFANT, J.A. 1987. «A globally flexible, Almost Ideal Demand System». Journal of Business and Economic Statististics. 5(3):233-242.

CHALFANT, J.A.; GRAY, R.S.; WHITE, K.J. 1991. «Evaluating prior beliefs in a demand system: The case of meat demand in Canada». American Journal of Agricultural Economics. 73(2):476-490.

CHIANG, A.C. 1984. Fundamental Methods of Mathematical Economics. New York: McGraw-Hill, Inc., $3^{\text {rd }}$ edition.

CHUNG, C.F., 1994. «A cross-section demand analysis of Spanish provincial food consumption.» American Journal of Agricultural Economics. 76(3):513-521.

CHRISTENSEN, L.R.; JORGENSEN, D.W.; LAU, L.J. 1975. «Trascendental logarithmic utility functions.» American Economic Review. 65:367-383.

CIU. 1999. La Industria Frigorífica en el Uruguay. Cámara de Industrias del Uruguay. Departamento de Estudios Económicos. Montevideo. http://www.google.com.uy/ url?sa=t\&rct=j\&q=\&esrc=s\&source=web\&cd=1\&cad $=$ rja $\&$ ved $=0$ CCEQFjAA\& url=http $\% 3 A \% 2$ F\%2Fwww.ciu.com.uy\%2Finnovaporta\% 2Ftypes\%2 Ffile\%2Fdownloadfilecontent. jsp\%3Fcontentid\%3D28816\%26site\%3
D1\%26channel\%3Dinnova.net\&ei=Qf6 QUIf3HY3S9ASahoHAAw\&usg=AFQjCNE 1TM-EwAMeJJqUDGYIzIDCAd0P8g.

COMISEC, 1994a. «Análisis del sector carne bovina». Comisión Sectorial para el Mercosur. Estudios técnicos para el proyecto COMISEC/BID-UE-PNUD. Programa de Fortalecimiento de la Comisión Sectorial para el Mercosur. Convenios 702/OC-UR y ATN-4103-UR. Montevideo: $56 \mathrm{pp}$.

COMISEC. 1994b. «Análisis del sector pesquero». Comisión Sectorial para el Mercosur. Estudios técnicos para el proyecto COMISEC/BID-UE-PNUD. Programa de Fortalecimiento de la Comisión Sectorial para el Mercosur. Convenios 702/OC-UR y ATN-4103-UR. Montevideo: 54 pp.

COOPER, R.L.; MCLAREN, K.R. 1996. «A system of demand equations satisfying effectively global regularity conditions» The Review of Economics and Statistics. Vol. LXXXVIII, No. 2:359-364.

CORCORAN, K.; BERNUÉS, J.A.; BAINES, R. 2000. «Marketing Scottish Beef and the Problem of the Changing Consumer». International Food and Agribusiness Management Association (IAMA). 2000 World Food and Agribusiness Congress 2000 Agribusiness Forum. Chicago, Illinois (USA).

CORTEZ, R.; SENAUER, B. 1996. «Taste changes in the demand for food by demographic group in the United States». American Journal of Agricultural Economics. 78(2): 280-289.

COSTAS, G. 2011. El consumo de carnes en el Mercado Interno: cambios y permanencias en la dieta del uruguayo. In Foro de las Carnes 2011. Presentación Mesa 3: Consumidor Local. Instituto Nacional de Carnes. http:// www.inac.gub.uy/innovaportal/v/6079/1/ $\mathrm{i} n \mathrm{n} \quad \mathrm{o} \quad \mathrm{v} \quad \mathrm{a} . \mathrm{n} \quad \mathrm{e} \quad \mathrm{t} /$ mesa_3__consumidor_local

COSTAS, G.; HERRERA, V. 2007. Uruguay, ¿un mercado importante? Análisis del Mercado Interno, 2004-2006. Dirección de Contralor del Mercado Interno. INAC Serie Técnica 44. Montevideo: 54.

COX, T.L.; WOHLGENANT, M.K. 1986. «Prices and quality effects in cross-sectional 
demand analysis». American Journal of Agricultural Economics. 68(4):908-919.

DAVIDSON, R.; MACKINNON, J. 1993. Estimation and Inference in Econometrics. New York: Oxford University Press.

DEATON, A. 1997. The Analysis of Household Surveys: A Microeconometric Approach to Development Policy. Baltimore, MD: The Johns Hopkins University Press.

DEATON, A.; MUELLBAUER, J. 1980a. Economics and Consumer Behavior. Cambridge: Cambridge University Press.

DEATON, A.; MUELLBAUER, J. 1980b. «An Almost Ideal Demand System». The American Economic Review. 70(3):312326.

DE MATTOS, D. 2000. «Cambios en el Consumo de Carne a Nivel Mundial»- En, «Situación y Perspectivas de la Cadena Cárnica Internacional». Instituto Plan Agropecuario-Instituto Interamericano de Cooperación para la Agricultura. Montevideo: 10-16.

DELGADO, C.L.; ROSEGRANT, M.W.; STEINFELD, H.; EHUI, S.K.; COURBOIS, C. 2001. «Livestock to 2020: the next food revolution». Outlook on Agriculture. 30(1): 27-29.

DEMOUSSIS, M.; MIHALOPOULOS, V. 2001. «Adult Equivalent Scales revisited». Journal of Agricultural and Applied Economics. 33(1):135-146.

DIEWERT, W.E. 1971. «An application of the Shephard duality theorem: A generalized Leontief production function». Journal of Political Economy. 79:481-507.

DONG, D.; GOULD, B.W.; KAISER, H.M. 2004. «Food demand in Mexico; an application of the Amemiya-Tobin approach to the estimation of a censored food system». American Journal of Agricultural Economics. 86(4): 1094-1107.

DORFMAN, J.H.; KLING, C.L.; SEXTON, R.J. 1990. «Confidence intervals for elasticities and flexibilities: Reevaluating the ratios of normals case». American Journal of Agricultural Economics. 72(4):10061017.

EALES, J.S.; UNNEVEHR, L.J. 1988. «Demand for beef and chicken products: Separability and structural change».
American Journal of Agricultural Economics. 70(3):521-532.

EASTWOOD, D.B.; CRAVEN, J.A. 1981. «Food demand and savings in a complete, extended, Linear Expenditure System». American Journal of Agricultural Economics. 63(3):544-549.

ECHENIQUE, A.; CAPRA, J.M. 2006. «Diagnóstico de situación de la calidad de carne porcina para consumo fresco en el Uruguay». INIA Serie Técnica 160. Montevideo: 38 pp

EDGERTON, D.L. 1997. «Weak separability and the estimation of elasticities in multistage demand systems». American Journal of Agricultural Economics. 79(1):62-79.

EPSTEIN, L.G. 1982. «Integrability of incomplete systems of demand functions." The Review of Economic Studies. 49(3):411425.

ERREA, E. 2012a. «La producción porcina en Uruguay: evolución y perspectivas». OPYPA-MGAP.Anuario 2012, Montevideo: 79-89.

ERREA, E. 2012b. «Carne aviar: evolución y perspectivas». OPYPA-MGAP. Anuario 2012, Montevideo: 92-100.

ERREA, E. 2011a. «Evolución reciente y perspectivas de la producción porcina.» OPYPA-MGAP. Anuario 2011, Montevideo: 85-95.

ERREA, E. 2011b. «Carne aviar: situación y perspectivas.» OPYPA-MGAP. Anuario 2011, Montevideo: 97-105.

ERREA, E.; RUIZ, M.I.; SOUTO, G. 2013. Cadena Porcina. Análisis de competitividad y temas tecnológicos prioritarios. Informe de Consultoría. INIA Edición Especial. Montevideo: 92 PP

FABANI, C. 2011. «Actividad en la Industria de procesamiento de Carnes y sus repercusiones en el empleo; tendencias e implicancias». En: Foro de las Carnes, Mesa 2, Industria \& Empleo, 2011. Instituto Nacional de Carnes. http:// www.inac.gub.uy/innovaportal/file/6064/ 1/mesa_2_-_inac.pdf

FAO. 2009. El estado mundial de la agricultura y la alimentación. La ganadería, a examen. Organización de las Naciones Unidas para la Agricultura y la Alimentación (FAO). Subdivisión de 
Políticas y Apoyo en Materia de Publicación Electrónica. División de Comunicación. Roma, 2009. http:// www.fao.org/docrep/012/i0680s/ i0680s.pdf

FRASER, I.; MOOSA, I.A. 2002. «Demand estimation in the presence of stochastic trend and seasonality: the case of meat demand in the United Kingdom». American Journal of Agricultural Economics. 84(1): 83-89.

FRISCH, R. 1959. «A complete schema for computing all direct and cross-demand elasticities in a model with many sectors». Econometrica. 27(2):177-196.

GALLANT, A.R. 1981. "On the bias in flexible functional forms and an essentially unbiased form: The Fourier flexible form.» Journal of Econometrics. 15:211-245.

GEMINES CONSULTORES 2003. «EI Mercado de la carne: El Mercado Mundial». URL: http://www.gemines.cl.Última actualización: 29/01/03.

GEORGE, P.S.; KING, G.A. 1971. Consumer demand for food commodities in the United States with projections to 1980. Giannini Foundation Monograph, No. 26. University of California. Berkeley, CA.

GOLAN, A.; PERLOFF, J.M.; SHEN, E.Z. 2001. «Estimating a demand system with nonnegativity constraints: Mexican meat demand». The Review of Economics and Statistics. 83(3): 541-550.

GOULD, B.W.; COX, T.L.; PERALI, F. 1991. «Demand for food fats and oils: The role of demographic variables and Government donations». American Journal of Agricultural Economics. 73(1):212-221.

GREEN, A.J. 1964. An Aggregation in Economic Analysis: An Introductory Survey. Princeton, NJ: Princeton University Press.

GREEN, R.D.; ALSTON, J.M. 1990. «Elasticities in AIDS Models». American Journal of Agricultural Economics. 72(2):442-445.

GREEN, R.D. y ALSTON, J.M. 1991. «Elasticities in AIDS Models: A clarification and extension». American Journal of Agricultural Economics. 73(2):874-875.

GREEN, R.D.; HASSAN, Z.A.; JOHNSON, S.R. 1978. «Maximum likelihood estimation of Linear Expenditure Systems with serially correlated errors». European Economic Review. 11:207-219.

GUILKEY, D.K., HAINES, P.S. y POPKIN, B.M. 1990. «The distribution of food consumption over a year: A longitudinal analysis» American Journal of Agricultural Economics. 72(4):891-900.

HAINES, P.S.; GUILKEY, D.K.; POPKIN, B.M. 1988. «Modeling food consumption decisions as a two-step process». American Journal of Agricultural Economics. 70(3):543-552.

HALEY, M.M. 2001. «Changing Consumer Demand for Meat: The U.S. Example, 1970-2000». In «Changing Structure of Global Food Consumption and Trade». Anita Regni, editor. United States Department of Agriculture. Market and Trade Economics Division, Economic Research Service. Economics and Statistics Administration. Washington, DC. WRS-01-1:41-48.

HASSAN, Z.A.; JOHNSON, S.R. 1977. «Price elasticities from cross section and panel data: A Survey». In R. Raunikar, ed. Food Demand and Consumption Behavior. S119 Southern Regional Research Commitee and Farm Foundation. Agr. Exp. Station, The University of Georgia, pp. 140-163.

HAYES, D.J.; WAHL, T.I.; WILLIAMS, G.W. 1990. «Testing restrictions on a model of Japanese meat demand». American Journal of Agricultural Economics. 72(3):556-566.

HECKMAN, J.J. 1976. «The common structure of statistical models of truncation, sample selection, and limited dependent variables and a simple estimation for such models». Annals of Economic and Social Measurements. 5:475-592.

HECKMAN, J.J. 1979. «Sample selection bias as a specification error». Econometrica 47:153-162.

HEIEN, D.; WESSELLS, C.R. 1990. «Demand systems estimation with microdata: A censored regression approach». Journal of Business and Economic Statististics. 8(4):365-371.

HOGG, R.V.; CRAIG, A.T. 1995. Introduction to Mathematical Statistics. Upper Saddle River, NJ: Prentice Hall. 
HOGG, R.V.; TANIS, E.A. 2001. Probability and Statistical Inference. Upper Saddle River, NJ: Prentice Hall, $3^{\text {rd }}$ edition.

HOUTHAKKER, H.S. 1960. «Additive preferences». Econometrica. 28:244-257.

HOWE, H. 1977. «Cross-section application of Linear Expenditure Systems: Responses to sociodemographic effects». American Journal of Agricultural Economics. 59(1):141-148.

HOWE, H.; POLLAK, R.A.; WALES, T.J. 1979. «Theory and time series estimation of the Quadratic Expenditure System». Econometrica. 47:1231-1247.

HUANG, K.S. 1988. «An inverse demand system for U.S. composite goods». American Journal of Agricultural Economics. 70(4):902-909.

HUANG, K.S. 1996. " Nutrient elasticities in a complete food demand system». American Journal of Agricultural Economics. 78(1):21-29.

HUPKOVA, D.; BIELIK, P. 2009. «Estimating demand elasticities meat demand in Slovakia». $113^{\text {th }}$ EAAE Seminar. European Agricultural Economics Association. Chania, Crete, Greece, Sep 3-6.

ILUNDAIN, M.; LEMA, J.I.; PEYROU, J.I. 2003. «Carne Vacuna: Situación Actual y Perspectivas». OPYPA-MGAP. Anuario 2003. Montevideo: 22 pp.

ILUNDAIN, M.; LEMA, J.I.; PEYROU, J.I. 2002. «Carne Vacuna: Situación Actual y Perspectivas». OPYPA-MGAP. Anuario 2002. Montevideo: 29-48.

INAC 2012. «Consumo de Carnes. Cierre año 2011». Instituto Nacional de Carnes. Dirección de Contralor del Mercado Interno. Montevideo, Uruguay. URL: http:/ /www.inac.gub.uy/innovaportal/file/7279/ 1/cierre_ano_2011.pdf

INE. 1996. Encuesta de Gastos e Ingresos de los Hogares 1994-1995. Instituto Nacional de Estadísticas. Montevideo.

INE. 2008. Encuesta Nacional de Gastos e Ingresos de los Hogares 2005-2006. Metodología y Resultados. Instituto Nacional de Estadísticas. Montevideo. ht t p : / / www.ine.gub.uy/engih/ engih_obj.htm
IRIGOYEN, R. 1997. «Mapeo tecnológico de las cadenas agroindustriales de Uruguay». En «Mapeo tecnológico de las cadenas agroalimentarias en el Cono Sur».Programa Cooperativo para el Desarrollo Tecnológico del Cono Sur. Subprograma Agroindustria. PROCISURIICA. Montevideo: 189-239.

JOHNSTON, J.; DINARDO, J. 1997. Econometric Methods. $4^{\text {th }}$ edition. New York: McGrawHill.

KASTENS, T.L.; BRESTER, G.W. 1996. «Model selection and forecasting ability of theory-constrained food demand systems.» American Journal of Agricultural Economics. 78(2):301-312.

KENNEDY, P., 1998. A Guide to Econometrics. $4^{\text {th }}$ edition. Cambridge, MA: The MIT Press.

LAFRANCE, J.T., 1985. «Linear demand functions in theory and practice». Journal of Economic Theory. 37(1):147166.

LAFRANCE, J.T., 1986. «The structure of constant elasticity demand models». American Journal of Agricultural Economics. 68(3):543-552.

LAFRANCE, J.T., 1990. «Incomplete demand systems and semilogarithmic demand models». Australian Journal of Agricultural Economics. 34(2):118-131.

LAFRANCE, J.T.; HANEMANN, M.W. 1989. «The dual structure of incomplete demand systems». American Journal of Agricultural Economics. 71(2):262-274.

LANFRANCO, B. 1999. Food consumption patterns of the Hispanic community in the United States. Tesis MS. Department of Agricultural and Applied Economics, The University of Georgia. Athens, GA.

LANFRANCO, B. 2001. Characteristics of Hispanic households' demand for meats: A comparison with other ethnic groups utilizing an incomplete system of censored equations. Disertación PhD. Department of Agricultural and Applied Economics, The University of Georgia. Athens, GA.

LANFRANCO, B. 2003a. «El Mercado de la carne: exigencias desde el consumo». En Seminario El Campo Natural y la Empresa Ganadera. Instituto Plan Agropecuario. Salto: 91-94. 
LANFRANCO, B. 2003b. «Encuestas y entrevistas a agentes calificados de la cadena cárnica bovina». Auditoría de Calidad de la Carne Vacuna. Documento Final Fase. INIA: 79 pp.

LANFRANCO, B., GARCÍA, F. y CAPUTI, P. 2006. «Estimation of household demand: Income and price elasticity for selected food products in Uruguay». En: Cap et al. Mercosur + 2: Estimation of Supply and Demand Elasticities of Agricultural Products. Projection to 2012 of Baseline Supply Scenarios. EC Project EUMercoPol 2005-2008. Buenos Aires, Argentina: 175-186.

LANFRANCO, B.; REYES, M.L.; RISSO, J.M. 2003. Empezando a conocer el mercado doméstico: Análisis de la oferta de productos de carne bovina. INIA Serie Técnica 147. Montevideo: 52 pp.

LAU, L.J. 1978. «Testing and imposing monotonicity, convexity and quasiconvexity constraints». In M. Fuss and D. McFadden, eds. Production Economics: A Dual Approach to Theory and Applications, Vol. 1, Chapter I.3. Amsterdam: North Holland Publishing Co.

LEMA, D.; BRESCIA, V.; BERGES, M.; CASELLAS, K. 2006. «Food demand elasticities in Argentina, Paraguay, and Bolivia. Econometric estimation elasticities from household surveys». En: Cap et al. Mercosur + 2: Estimation of Supply and Demand Elasticities of Agricultural Products. Projection to 2012 of Baseline Supply Scenarios. EC Project EUMercoPol 2005-2008. Buenos Aires, Argentina: 84-146.

LEUNG, S.F.; YU, S. 1996. «On the choice between sample selection and two-part models». Journal of Econometrics, Vol. 72:197-229.

LÓPEZ-RíoS, J. 2007. El mercado de pescado en Montevideo. INFOPESCA Serie Estudios de Mercado. Montevideo: 25 pp.

MADDALA, G.S. 1983. Limited Dependent and Qualitative Variables in Econometrics. Cambridge, UK: Cambridge University Press.

MANCHESTER, A.C. 1977. «Household consumption behavior: Understanding, measurement, and applications in policy-oriented research». American
Journal of Agricultural Economics. 59(1):149-154.

MAZZA, C.A. 2007. Análisis del Mercado Interno: Consumo de Productos Pesqueros en el Departamento de Montevideo. Monografía: 106 pp.

MAZZOCCHI, M. 2006. «No news is good news: stochastic parameters versus media coverage indices in demand models after food scares». American Journal of Agricultural Economics. 88(3): 727-741.

MILLER, S.E.; CAPPS O., Jr.; WELLS, G.J. 1984. «Confidence intervals for elasticities and flexibilities from linear equations». American Journal of Agricultural Economics. 66(2):392-396.

MOHAN, A.M. 2002. «Food Industry Faces Tides of Change: Forces 2001». Packaging Digest. Anne Marie Mohan, senior editor. (January): 42-44.

MOSCHINI, G. 1995. «Units of measurement and the Stone Index in demand system estimation». American Journal of Agricultural Economics. 77(1):63-68.

MOSCHINI, G.; MEILKE, K.D. 1989. «Modeling the pattern of structural change in U.S. meat demand». American Journal of Agricultural Economics. 71(2):253-261.

MOSCHINI, G.; MORO, D. 1996. «Structural change and demand analysis: A cursory review». European Review of Agricultural Economics. 23:239-261.

MOSCHINI, G., MORO, D. y GREEN, R.D. 1994. «Maintaining and testing separability in demand systems». American Journal of Agricultural Economics. 76(1):61-73.

MOTALLEBI, M. y PENDELL, D.L. 2013. «Household demand for fats and oils: two-step estimation of a censored demand system». 2013 Joint Annual AAEA\&CAES Meeting. Agricultural and Applied Economics Association. Canadian Agricultural Economics Society. Washington, DC, Aug 4-6.

MUELLBAUER, J. 1980. «The estimation of the Price-Houthakker model of equivalence scales». Econometrica. 48(1):153-176.

MURPHY, K.M.; TOPEL, R.H. 1985. «Estimation and inference in two-step econometric models». Journal of Business and Economic Statististics. 3(4):370-379. 
NAYGA, R.M. 1995. «Determinants of U.S. household expenditures on fruit and vegetables: A note and an update» Journal of Agricultural and Applied Economics. 27(2):588-594.

NAYGA, R.M.; CAPPS Jr., O. 1994. «Test of weak separability in disaggregated meat products» American Journal of Agricultural Economics. 76(4):800-808.

NELSON, J.A. 1991. «Quality variation and quantity aggregation in consumer demand for food». American Journal of Agricultural Economics. 73(4):12041212.

OECD-FAO. 2014. Perspectivas Agrícolas 20132022. Organización de las Naciones Unidas para la Agricultura y la Alimentación (FAO). Departamento Económico y Social. Roma.

OECD-FAO. 2012. Agricultural Outlook 20122021. OECD Publishing and FAO. http:// dx.doi.org/10.1787/agr_outlook-2012en.

ORDEIX, M. 2001. «Competitividad y Coordinación en la Cadena de Carne Bovina». Instituto Nacional de Investigación Agropecuaria. Serie Actividades de Difusión. INIATacuarembó. Núm. 277 (Diciembre): $74 \mathrm{pp}$.

PAGÉS, W.H. 1986. «Stock regulador: Siempre dan pérdidas». Mesa redonda «Stock Regulador y Plan Ovinos». Carne. Asociación Nacional de Carniceros. Montevideo (Diciembre): 12-14.

PARK, J.L., HOLCOMB, R.B., RAPER K.C., CAPPS Jr. O. 1996. «A demand systems analysis of food commodities by U.S. households segmanted by income». American Journal of Agricultural Economics. 78(2): 290-300.

PASHARDES, P. 1993. «Bias in estimating the Almost Ideal Demand System with the Stone Index approximation». The Economic Journal. 103:908-915.

PERALI, F.; CHAVAS, J.P. 2000. «Estimation of censored demand equations from large cross-section data» American Journal of Agricultural Economics. 82(4):10221037.

PRATO, A.A. 1977. «Estimation of food demand and consumption relationships». In R. Raunikar, ed. Food Demand and Consumption Behavior. S-119 Southern
Regional Research Commitee and Farm Foundation. Agr. Exp. Station, The University of Georgia, pp. 94-115.

PRICE, D.W. 1970. «Unit equivalent scales for specific food commodities». American Journal of Agricultural Economics. 52(2):224-233.

PURICELLI, E. 2011. «Las carnes en el mundo». Revista Brangus, 33(63):60-64. (Disponible en Sitio Argentino de Producción Animal. http://www.produccion-animal.com.ar/)

PUDNEY, S. 1981. «An empirical method of approximating the separable structure of consumer preferences». Review of Economic Studies. 48:561-577.

RAMEZANI, C.A.; ROSE, D.; MURPHY, S. 1995. «Aggregation, flexible forms, and estimation of food consumption parameters». American Journal of Agricultural Economics, 77(3):525-532.

REALINI, C.E.; DUCKETT, S.K.; BRITO, G.W.; DALLA RIZZA, M.; DE MATTOS, D. 2003. «Effects of Pasture vs. Concentrate Feeding with or without Antioxidants on Carcass Characteristics, Fatty Acid Composition, and Quality of Uruguayan Beef». Meat Science. 66: 567-577.

RESENDE FILHO, M.A.; BRESSAN, V.G.F.; BRAGA, M,J.; BRESSAN, A.G. 2012. «Sistemas de equações de demanda por carnes no Brasil: especificação e estimação». Brazilian Journal of Rural Economy and Sociology. 50(1): 33-50.

ROHNER, C. 2010. Análisis de las variables de crecimiento de la ganadería en el Uruguay en los últimos 40 años. Tesis de Grado. Facultad de Agronomía. Universidad de la República. Montevideo.

RYAN, D.L.; WALES, T.J. 1999. «Flexible and semiflexible consumer demands with quadratic Engel curves». The Review of Economics and Statistics. Vol. LXXXI, No. 2:277-287.

SCHMIT, T.M., CHUNG, C., DONG, D., KAISER, H.M. y GOULD, B. 2000. «The effect of generic diary advertising on the household demand for milk and cheese». 2000 Annual Meeting, American Agricultural Economics Association. Tampa, FL.

SÁDER, M. 2000. «El consumo de carne en Uruguay en el período 1990-1999». OPYPA-MGAP. Anuario 2000. Montevideo: 287-294. 
SCHRIMPER, R.A. 1977. «Household consumption behavior: Discussion». American Journal of Agricultural Economics. 59(1):161-163.

SHONKWILER, J.S.; YEN, S.T. 1999. «Two-step estimation of a censored system of equations» American Journal of Agricultural Economics. 81(4):972-982.

STONE, J.R.N. 1954. The measurement of consumer's expenditure and behavior in the United Kingdom, 1920-1938. Vol. I, Cambridge. UK: Cambridge University Press.

SWOFFORD, J.L.; WHITNEY, G.A. 1987. «Nonparametric tests of utility maximization and weak separability for consumption, leisure and money». The Review of Economics and Statistics. Vol. LXIX, No. 3:458-464.

TANIGUCHI, K.; CHERN, W.S. 2000. «Income elasticity of rice demand in Japan and its implications: cross-sectional data analysis». 2000 Annual Meeting, American Agricultural Economics Association. Tampa, FL.

THEIL, H. 1965. «The information approach to demand analysis». Econometrica. 33:67-87.

THOMPSON, W. 2004. «Elasticities from an Almost ideal Demand System? Watch out for group expenditure»! American Agricultural Economics Association. 86(4): 1108-1116.

TNS GALLUP. 2005. El consumo de carne vacuna en la Argentina. Documento $\mathrm{N}^{\circ}$ 2. Convenio TNS Gallup-IPCVA. TNS Gallup Argentina. Instituto de Promoción de la Carne Vacuna. Buenos Aires, Argentina: 114 pp.

TOMEK, W.G. 1977. «Empirical analyses of the demand for food: A review». In $\mathrm{R}$. Raunikar, ed. Food Demand and Consumption Behavior. S-119 Southern Regional Research Commitee and Farm Foundation. Agr. Exp. Station, The University of Georgia, pp. 1-30.

TRONCOSO, C. 2003. «Demanda interna de alimentos de origen animal». Instituto de Economía. Serie Documentos de Trabajo. DT11/03. Abril de 2003. Montevideo: 59 pp.
VÁZQUEZ PLATERO, R.; PICERNO, A. 1994. «Comercialización del Ganado en Pie». Comisión Sectorial para el MERCOSUR. Informe de Consultoría para el Proyecto COMISEC/BID-UE-PNUD. Programa de Fortalecimiento de la Comisión Sectorial para el Mercosur. Convenios 702/OC-UR y ATN-4103-UR. Versión Preliminar para la discusión. Octubre de 1994. Montevideo: $113 \mathrm{pp}$.

VERNAZZA, R. 2003. «Preferencias y actitudes del consumidor montevideano hacia la carne vacuna». Revista Plan Agropecuario. Número 106 (Junio):2630.

VERNAZZA, R.; COSTAS, D. 2003. «La comercialización de carne vacuna en la ciudad de Montevideo: Una primera aproximación». Instituto Nacional de Carnes. Serie Técnica S/N (en imprenta). Mayo, 2003. Montevideo, Uruguay.

VERNAZZA, R. y CÉSAR, D. 2002. «Mercado Doméstico: ¿Cómo estamos y hacia dónde vamos»? Del Campo al Plato. Segundo Congreso de Producción y Comercialización de Carne. INIA-INACLATU. Noviembre 2002. Montevideo.

WADSWORTH, J. 1997. Análisis de Sistemas de Producción Animal-Tomo 2: las Herramientas Básicas. Organización de las Naciones Unidas para la Agricultura y la Alimentación (FAO). Departamento de Agricultura y Protección del Consumo. Estudio FAO Producción y Sanidad Animal 140/2. Disponible en: http:// www.fao.org/docrep/w7452s/ W7452S00.htm

WOHLGENANT, M.K. 1984. «Conceptual and functional form issues in estimating demand elasticities for food». American Journal of Agricultural Economics. 66(2):211-215.

YEN, S.T.; KAN, K. 2000. «Household demand for fats and oils: Two-step estimation of a censored demand system». 2000 Annual Meeting, American Agricultural Economics Association. Tampa, FL.

YEN, S.T.; LIN, B.H. 2006. «A sample selection approach to censored demand systems». American Journal of Agricultural Economics. 88(3):742-749. 
Impreso en Editorial Hemisferio Sur S.R.L.

Buenos Aires 335

Montevideo - Uruguay

Depósito Legal 364-795 /14 